\title{
Ultrasonically-Enhanced Dense-Medium Cycloning for Fine Coal and Coal Refuse Impoundment Materials
}

Final Report

Reporting Period Start Date: February 18, 1999

Reporting Period End Date: May 31, 2001

DOE Patent Clearance Granted

Mark Dvorscak

Intellectual Property Law Division

U.S. Dept. of Energy, Chicago

Nov. 2, 2001

Principal Authors:

Dr. Mark S. Klima

Dr. Barbara J. Arnold

August 2001

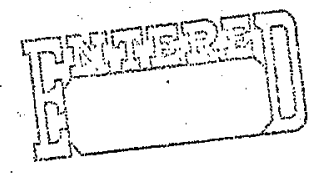

DOE Project Number DE-AC26-99FT40151

Submitting Organizations:

The Pennsylvania State University

Department of Energy and Geo-Environmental Engineering

110 Hosler Building

University Park, PA 16802

PrepTech, Inc.

532 Route 66

Apollo, PA 15613 
From: $\quad$ Carl Maronde

To: $\quad$ Ricciuti, Ja'vet

Date: $\quad$ 10/2/01 7:50AM

Subject: $\quad$ Re: Award: DE-AC26-99FT40151r01, Technical Progress Report Period Ending:

$5 / 31 / 2001$

Below are my responses and attached is the letter I sent to PSU confirming approval of the final report.

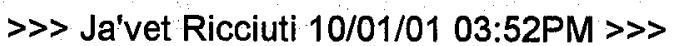

Subject: Review of Technical/Topical Report on

Contract/Grant/Cooperative Agreement No. DE-AC26-99FT40151

with PENNSYLVANIA STATE UNIVERSITY Period Ending 5/31/2001

Carl Maronde,

The attached technical/topical report has been submitted by the contractor/recipient and requires your review and approval. Review should be completed within 30 calendar days of the date of this e-mail.

Please provide the contractor/recipient with approval or notification of changes required prior to approval, and obtain and approve these changes. A copy of your correspondence concerning the report should be provided to the Contract Specialist.

After reviewing the report, please provide an e-mail approval.

Please advise if Public Distribution of this report would be beneficial. _ _

General Energy Policy

X_Clean Coal Technology (must also include on of the following).

- X_ Coal - Fuels

Coal - Industrial Processes

- Coal - Environmental Processes

- Electricity - General

- Electricity - Coal Combustion

- Electricity - Gasification

- Electricity - Fuel Cells

- Electricity - Turbines

- Electricity - Regulatory

_ Oil/Gas - Regulatory

_ Oil/Gas - General

- Oil/Gas - Supply Technologies (must also include at least one of the following)

- Oil/Gas - Drilling/Completion, Stimulation

- Oil/Gas - Diagnostics/lmaging

- Oil/Gas - Reservoir Life Extension

- Oil/Gas - Gas Storage

- Oil/Gas - Processing

- Oil/Gas - Environmental

- Oil/Gas - Modeling/Analysis 


\title{
Ultrasonically-Enhanced Dense-Medium Cycloning for Fine Coal and Coal Refuse Impoundment Materials
}

\author{
Final Report
}

Reporting Period Start Date: February 18, 1999

Reporting Period End Date: May 31, 2001

Principal Authors:

Dr. Mark S. Klima

Dr. Barbara J. Arnold

August 2001

DOE Project Number DE-AC26-99.FT40151

Submitting Organizations:

The Pennsylvania State University

Department of Energy and Geo-Environmental Engineering

110 Hosler Building

University Park, PA 16802

PrepTech, Inc.

532 Route 66

Apollo, PA 15613

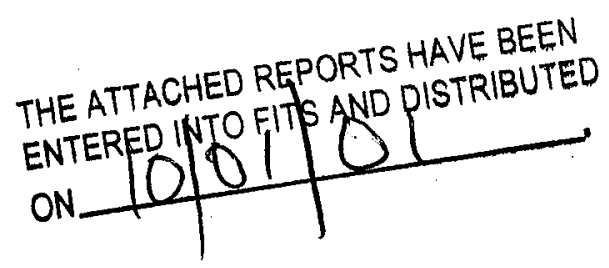




\section{Disclaimer}

This report was prepared as an account of work sponsored by an agency of the United States Government. Neither the United States Government nor any agency thereof, nor any of their employees, makes any warranty, express or implied, or assumes any legal liability or responsibility for the accuracy, completeness, or usefulness of any information, apparatus, product, or process disclosed, or represents that its use would not infringe privately owned rights. Reference herein to any specific commercial product, process, or service by trade name, trademark, manufacture, or otherwise does not necessarily constitute or imply its endorsement, recommendation, or favoring by the United States Government or any agency thereof. The views and opinions of authors expressed herein do not necessarily state or reflect those of the United States Government or any agency thereof. 


\begin{abstract}
The Pennsylvania State University, its project team (Typlex, Inc., DAGER, Inc., and PrepTech, Inc.), and advisory committee members have demonstrated the application of ultrasonic energy during dense-medium cycloning and subsequent recovery of fine coal and coal refuse impoundment materials. The results will help to extend the range of conventional densemedium cycloning to sizes now typically cleaned in relatively inefficient water-only cyclone and spiral concentrator circuits. This technology also provides a potential approach to produce ultraclean material as would be used for feedstocks for premium carbon products.

This report describes Phase I of the project; which involved laboratory testing of densemedium cycloning and subsequent medium recovery, with and without ultrasonic treatment, along with fundamental dispersion testing. Dense-medium cycloning was conducted with a 76.2-mm (3-in.) diameter cyclone under various conditions including magnetite grade, medium relative density, inlet pressure, cyclone geometry, and feed coal. Dense-medium recovery testing was carried out with a $305-\mathrm{mm}$ (12-in.) diameter x 152-mm (6-in.) wide wet-drum magnetic separator using the cyclone clean coal and refuse products as the feed material. Fundamental testing of dispersion/reagglomeration phenomena was conducted with coal/clay mixtures.

In almost all cases, the dense-medium cyclone was capable of achieving separations down to approximately $0.037 \mathrm{~mm}$. Ultrasonic treatment had a slight effect on reducing the ash content of the clean coal. It was also found that ultrasonic treatment improved the purity of the magnetic fraction during wet-drum magnetic separation. The treatment was particularly beneficial for the cyclone overflow material. The fundamental testing indicated that agitation after ultrasonic treatment is necessary to disperse fine particles and to prevent reagglomeration.
\end{abstract}




\section{TABLE OF CONTENTS}

Page

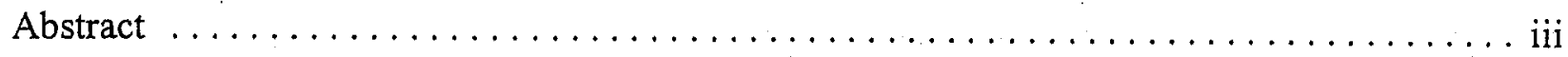

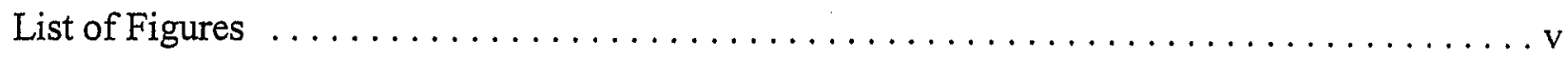

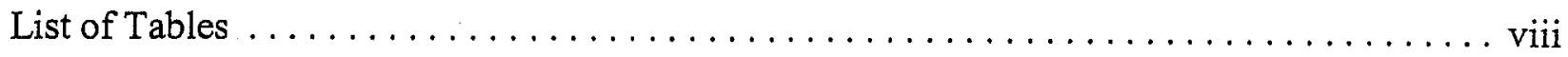

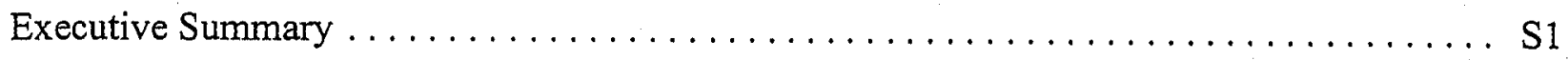

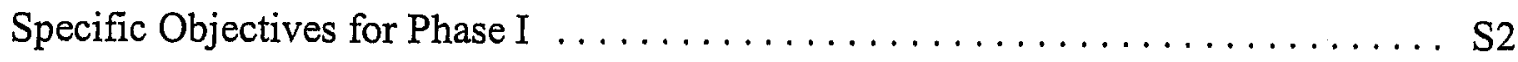

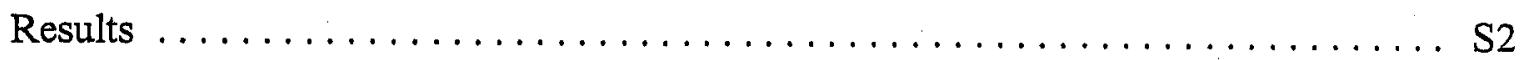

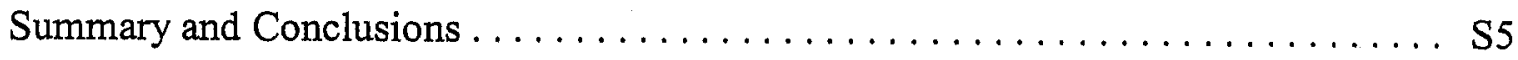

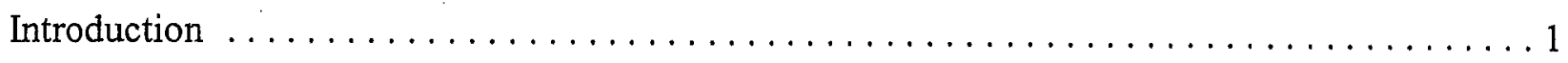

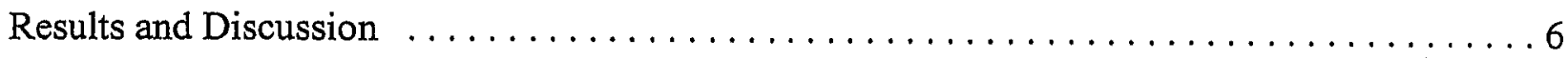

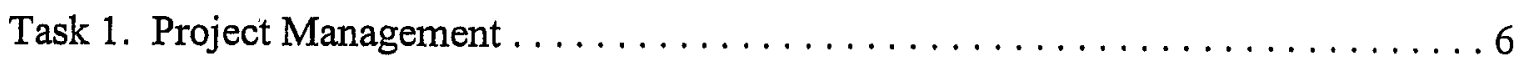

Task 2. Sample Procurement and Characterization $\ldots \ldots \ldots \ldots \ldots \ldots \ldots 7$

Task 3. Fundamental Dispersion Testing $\ldots \ldots \ldots \ldots \ldots \ldots \ldots \ldots \ldots \ldots \ldots \ldots \ldots \ldots \ldots \ldots$

Task 4. Dense-Medium Cyclone Testing $\ldots \ldots \ldots \ldots \ldots \ldots \ldots \ldots \ldots \ldots \ldots \ldots \ldots \ldots \ldots \ldots \ldots$

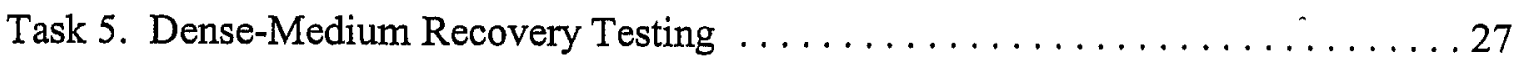

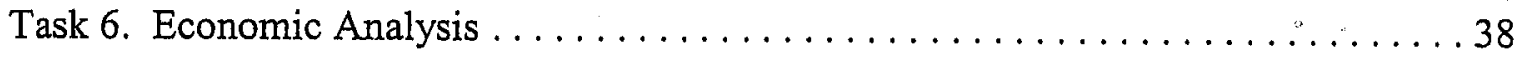

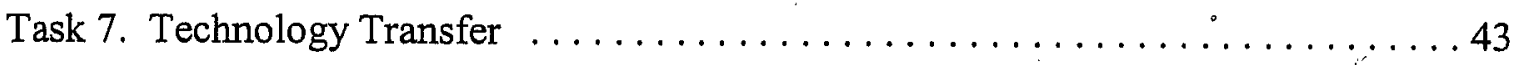

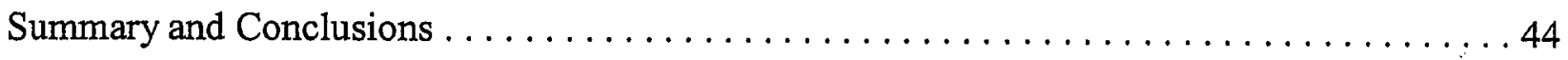

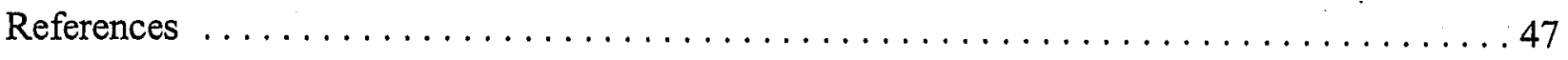

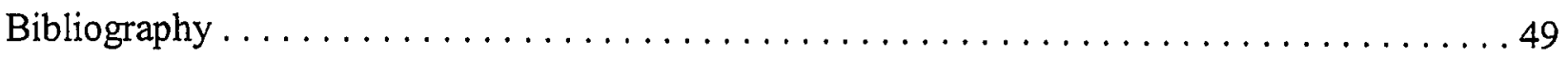




\section{LIST OF FIGURES}

Figure

S-1 Actual partition values and fitted curves for coal 2 at 1.45 medium relative density: (a) without ultrasonics; (b) with ultrasonics

S-2 Simulated grade-yield curves for dense-medium and spiral separations:

(a) clean coal yield vs. ash content; (b) clean coal yield vs. sulfur content . . . . . . S S

1 Size distributions and ash and sulfur contents: (a) Yellow Run plant feed;

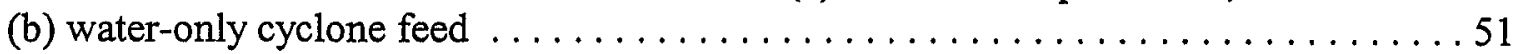

2 Washability analysis for $30 \times 200$ mesh size fraction of Yellow Run plant feed . . . . 52

3 Washability analysis for $30 \times 50$ mesh size fraction of Yellow Run plant feed .....53

4 Washability analysis for 50x100 mesh size fraction of Yellow Run plant feed . . . . 54

5 Washability analysis for $100 \times 200$ mesh size fraction of Yellow Run plant feed . . . . 55

6 Size distributions for all three magnetite samples. $\ldots \ldots \ldots \ldots \ldots \ldots \ldots \ldots$

$7 \quad$ Ultrasonic dispersion/reagglomeration test setup $\ldots \ldots \ldots \ldots \ldots \ldots \ldots \ldots \ldots$

8 Effect of agitation and ultrasonic treatment on coal and coal/clay cakes $\ldots \ldots \ldots 58$

9 Effect of ultrasonic amplitude on coal/clay dispersion $\ldots \ldots \ldots \ldots \ldots \ldots$

10 Effect of solution $\mathrm{pH}$ on the dispersion behavior of coal/clay cakes $\ldots \ldots \ldots \ldots$

11 Effect of added salt $\left(\mathrm{CaCl}_{2}\right)$ on coal/clay dispersion by stirring and ultrasonic

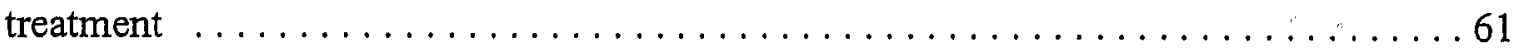

12 Ultrasonic dispersion and reagglomeration testing of coal/fine refuse mixture

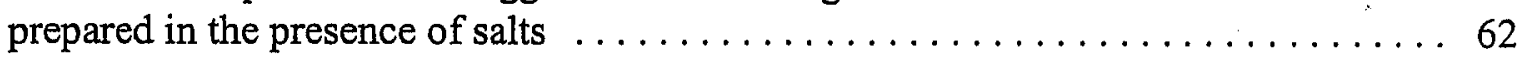

13 Krebs 3 -in. cyclone circuit with ultrasonic unit $\ldots \ldots \ldots \ldots \ldots \ldots \ldots$

14 Water flow rates through the 3 -in. Krebs cyclone $\ldots \ldots \ldots \ldots \ldots \ldots \ldots$

15 Cyclone results for coal 1 at 1.35 medium relative density for different test conditions: (a) clean coal yield; (b) ash content 


\section{LIST OF FIGURES (cont.)}

Figure

$\underline{\text { Page }}$

16 Cyclone results for coal 1 at 1.45 medium relative density for different test conditions: (a) clean coal yield; (b) ash content

17 Cyclone results for coal 1 at 1.55 medium relative density for different test conditions: (a) clean coal yield; (b) ash content $\ldots \ldots \ldots \ldots \ldots \ldots 67$

18 (a) Clean coal yield; (b) clean coal ash versus medium relative density

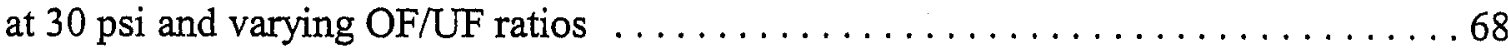

19 Actual partition values and fitted curves for coal 2 at 1.45 medium relative density: (a) without ultrasonics; (b) with ultrasonics . . . . . . . . . . . . . 69

20 Eriez wet-drum magnetic separator $\ldots \ldots \ldots \ldots \ldots \ldots \ldots \ldots \ldots \ldots \ldots \ldots$

21 Zenith ultrasonic batch unit $\ldots \ldots \ldots \ldots \ldots \ldots \ldots \ldots \ldots \ldots \ldots \ldots \ldots \ldots$

22 Baseline wet-drum magnetic separator test circuit $\ldots \ldots \ldots \ldots \ldots \ldots \ldots \ldots \ldots$

23 Wet-drum magnetic separator test circuit showing in-line ultrasonic unit $\ldots \ldots \ldots 73$

24 Average magnetic recovery for baseline testing of simulated coal and

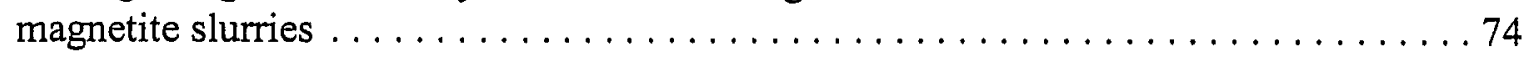

25 Average magnetic purity for baseline testing of simulated coal and

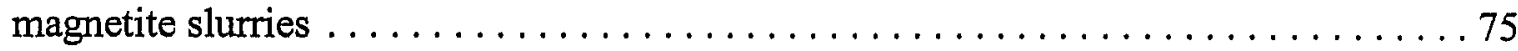

26 Magnetic purity as a function of $\mathrm{M} / \mathrm{C}$ ratio and solids concentration for the feed characteristics tests (closed symbols = no ultrasonic treatment;

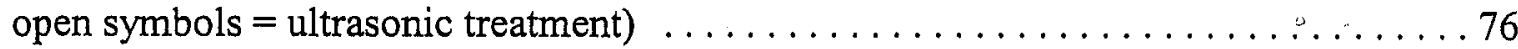

27 Average magnetic recovery for the cyclone underflow using coal $1 \ldots \ldots \ldots \ldots 77$

28 Average magnetic purity for the cyclone underflow using coal $1 \ldots \ldots \ldots \ldots \ldots 78$

29 Average magnetic recovery for the cyclone overflow using coal $1 \ldots \ldots \ldots \ldots \ldots$

30 Average magnetic purity for the cyclone overflow using coal $1 \ldots \ldots \ldots \ldots$

31 Average magnetic recovery for the cyclone underflow using coal $2 \ldots \ldots \ldots . \ldots 81$

32 Average magnetic purity for the cyclone underflow using coal $2 \ldots \ldots \ldots \ldots$ 


\section{LIST OF FIGURES (cont.)}

Figure

Page

33 Average magnetic recovery for the cyclone overflow using coal $2 \ldots \ldots \ldots \ldots . \ldots 3$

34 Average magnetic purity for the cyclone overflow using coal $2 \ldots \ldots \ldots \ldots \ldots 4$

35 Estimated versus actual magnetic purity considering first and

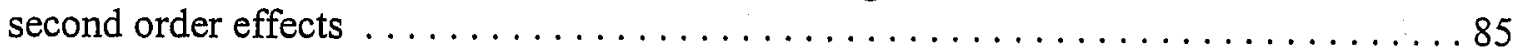

36 Estimated versus actual magnetic recovery considering first and

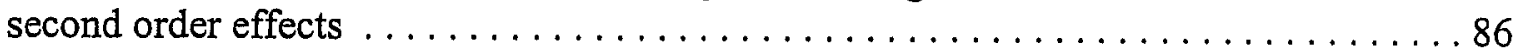

37 Simulated grade-yield curves for dense-medium and spiral separations:

(a) clean coal yield vs. ash content; (b) clean coal yield vs. sulfur content . . . . . . 87

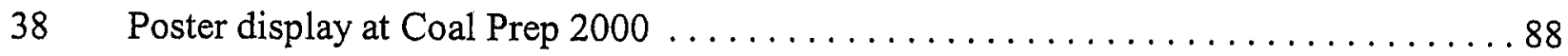




\section{LIST OF TABLES}

Table

Page

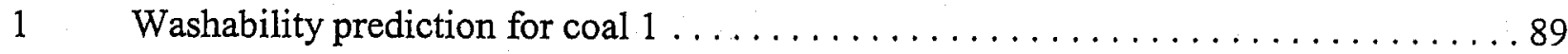

2 Size selectivity results and water splits for coal $2 \ldots \ldots \ldots \ldots \ldots$

3 E-grade magnetite splits, with and without ultrasonic treatment $\ldots \ldots \ldots \ldots 1$

$4 \quad$ B-grade magnetite splits, with and without ultrasonic treatment $\ldots \ldots \ldots \ldots 2$

5 Summary of dense medium-cyclone test conditions and results

(medium R.D. $=1.35$, medium-to-coal ratio $=5: 1$, OF diameter $=0.5$ in.) $\ldots \ldots .93$

6 Summary of dense-medium cyclone test conditions and results

(medium R.D. $=1.45$, medium-to-coal ratio $=4: 1$, OF diameter $=0.5$ in. $) \ldots \ldots 94$

7 Summary of dense-medium cyclone test conditions and results

(medium R.D. $=1.55$, medium-to-coal ratio $=5: 1$, OF diameter $=0.5$ in. $) \ldots \ldots 95$

8 Size distributions and ash contents of the +400 mesh material at

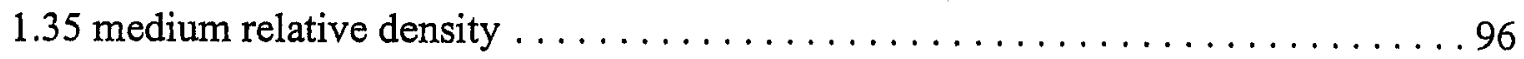

9 Size distributions and ash contents of the +400 mesh material at

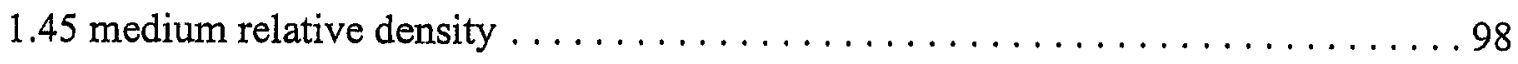

10 Size distributions and ash contents of the +400 mesh material at

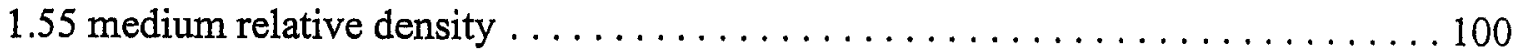

11 Example of actual versus theoretical yield for coal 1

(medium R.D. $=1.45 ;$ pressure $=30$ psi; $\mathrm{OF} / \mathrm{UF}=1.33 ;$ ultrasonics off $) \ldots \ldots \ldots 102$

12 Comparison of size and ash distributions for coal 1 feed samples $\ldots \ldots \ldots \ldots 2$

13 Summary of baseline test results for the wet-drum magnetic separator

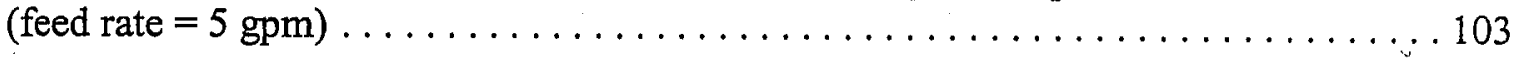

14 Summary of test results for the wet-drum magnetic separator

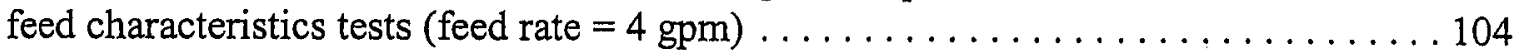

15 Comparison of size distributions of the magnetic material in the

wet-drum magnetic separator product streams (feed rate $=4 \mathrm{gpm}), \ldots \ldots \ldots \ldots$ 


\section{LIST OF TABLES (cont.)}

Table

$\underline{\text { Page }}$

16 Summary of cyclone product test results for the wet-drum magnetic

separator for coal 1 (feed rate $=4 \mathrm{gpm}$; solids concentration $=15 \%) \ldots \ldots \ldots 106$

17 Summary of cyclone product test results for the wet-drum magnetic

separator for coal 2 (feed rate $=4 \mathrm{gpm}$; solids concentration $=15 \%) \ldots \ldots \ldots 107$

18 Size and ash analyses for coal 1 and coal 2 after separation at

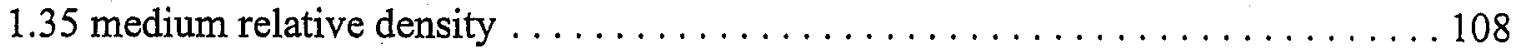




\section{EXECUTIVE SUMMARY}

The Pennsylvania State University, its project team (Typlex, Inc., DAGER, Inc., and PrepTech, Inc.), and advisory committee members have demonstrated the application of ultrasonic energy during dense-medium cycloning and subsequent recovery of fine coal and coal refuse impoundment materials. The results will help to extend the range of conventional densemedium cycloning to sizes now typically cleaned in relatively inefficient water-only cyclone and spiral concentrator circuits. Potential benefits of this application are:

- Improved grade/recovery relationship over water-only circuits for fine coal down to about $0.075 \mathrm{~mm}$ (200 mesh).

- Ability to produce low-ash material for possible use as feedstocks for high-value carbon products.

- Greater control at the cleaning plant because separating densities are easily controlled and changed in dense-medium circuits. This will allow greater flexibility in processing feeds that fluctuate in size and quality -- such as impounded materials.

- Improved purity of the recovered medium for fine coal applications.

- Environmental benefits including reduced impoundment requirements and remediation of existing ponds.

Phase I was a laboratory investigation that was conducted in the Mineral Processing laboratory at The Pennsylvania State University and included studies of dispersion fundamentals, dense-medium cycloning and dense-medium recovery. 


\section{Specific Objectives for Phase I}

The objectives for the Phase I laboratory investigation included the following:

- Evaluating the performance of ultrasonically-enhanced dense-medium cycloning for fine coal and coal refuse from impoundments

- Studying the effects magnetite grade, coal quality, and ultrasonic treatment during densemedium cycloning and recovery

- Understanding the mechanisms involved in applying ultrasonics to improve the performance of dense-medium cycloning so that appropriate scale-up factors can be developed and so that the technology can be readily transferred to other coals and coal refuse impoundment materials that have not been specifically investigated by the study

- Evaluating the effect of ultrasonics on downstream media recovery

- Estimating the economic viability of applying ultrasonics to dense-medium cycloning

- Keeping the coal industry informed of project developments through publishing and presenting technical papers and displaying project results at industry exhibits

\section{Results}

For this project, two different coal samples were obtained from the Yellow Run cleaning plant located in Stoystown, Somerset county, Pennsylvania. These samples were separated in the dense-medium cyclone circuit at several medium relative densities, without and with ultrasonic treatment. Additional tests were carried out under various conditions including cyclone geometry, inlet pressure, and medium relative density. As expected, the relative density differential (underflow relative density minus the overflow relative density) varied with test conditions. The differentials were less than 0.4 for the E-grade magnetite but were much greater 
for the B-grade magnetite, indicating a very unstable medium. For both grades of magnetite, ultrasonic treatment had minimal effect on the differentials.

For coal 1 -- a fines fraction screened from raw material collected at the refuse impoundment -- the cyclone was capable of cleaning down to approximately $0.037 \mathrm{~mm}$ (400 mesh), even without desliming. Because of the high efficiency of the cyclone, ultrasonic treatment was generally not needed. Exposure to ultrasonics had a minimal effect on the quality of the clean coal. Coal 1 contained approximately 40 percent of -200 -mesh material.

For coal 2, Figure S-1 shows the partition (fractional recovery) curves for the +100 $(0.15 \mathrm{~mm}), 100 \times 200$, and $200 \times 400$ mesh size fractions at 1.45 medium relative density, before and after exposure to ultrasonics. As expected, in both cases, the relative density of separation (dp) increased with decreasing particle size. The corresponding probable errors also increased but were still quite low, with a value of 0.21 even for the $200 \times 400$-mesh fraction. Interestingly, both the dp and Ep values increased after ultrasonic treatment. Because the feed for these tests was not deslimed and contained over $63 \%$ of -400 -mesh material, it is likely that the ultrasonics had "scrubbed" the clays from the coal surface. This would lead to an increase in the apparent viscosity of the medium, resulting in a worsening of the separation after treatment. As such, desliming after ultrasonic treatment should result in improved size classification, because additional "liberated" slimes would be removed. This has implications in the selection of circuitry and the location of the ultrasound unit. For example, if clays are liberated using ultrasound, it may be best to apply ultrasonics prior to a desliming step in advance of densemedium cycloning.

The dense-medium recovery testing evaluated the effects of ultrasonic treatment on magnetite recovery. The clean-coal and refuse products from the dense-medium cyclone tests 
were processed in a laboratory wet-drum magnetic separator, before and after exposure to ultrasonics. It was found that ultrasonic treatment improved the purity of the recovered magnetic material and to a lesser extent, magnetite recovery. The improvement in purity was particularly prevalent with the cyclone overflow products. Moreover, it was found that the benefits of ultrasonic treatment continued for several minutes after exposure.

The fundamental dispersion/reagglomeration testing indicated that mixing after exposure to ultrasonics is needed to prevent reattachment of fine particles. Furthermore, the environment under which the dispersion occurs impacts the effectiveness of the treatment and subsequent reagglomeration. Factors such as $\mathrm{pH}$ and the presence of dissolved salts must be considered during treatment.

Using very simplified and conservative examples, the economic evaluation investigated the application of ultrasound in existing fine coal circuitry to improve yield. Assuming a fine coal yield increase of a modest one percent, the investigators determined that the application of ultrasound alone could pay for itself in a reasonable time frame (approximately 4 months) at a large (1000 tph) coal cleaning plant. PrepTech investigators have laboratory evidence of increases in froth flotation yield that are greater than this modest amount.

In addition, application of both fine-coal dense-medium cycloning and ultrasound at the Yellow Run facility was evaluated. In this case, even with a substantial increase in fine coal yield of 11 percent (compared with the plant's existing water-based technology), the installation of both the fine dense-medium cyclone circuit and ultrasound required a 1.6 year payback. Figure S-2 shows the comparison between a dense-medium cyclone and spiral concentrator as simulated for coal 1 . This payback may or may not be justified by the owner depending on economic conditions. 
In order to promote technology transfer, two meetings were held with members of the industrial advisory board to discuss project progress and results. The advisory board was comprised of representatives from a coal preparation plant construction company (Farnham \& Pfile Construction Co.), a cyclone manufacturer (Krebs Engineering), a magnetics manufacturer (Eriez Magnetics), and a magnetite supplier (Penn Mag). These meetings provided valuable feedback to the project participants as well as providing a mechanism for technology transfer to the industry. This project led to the publication of two Master's theses. In addition, a poster display of the technology was presented at the 2000 Coal Preparation Exhibition in Lexington, Kentucky, and a paper was presented at the 2001 Meeting of the Society of Mining, Metallurgy, and Exploration in Denver, Colorado.

\section{Summary and Conclusions}

Dense-medium cycloning was conducted with a 76.2-mm (3-in.) diameter cyclone under various conditions, including magnetite grade, medium relative density, inlet pressure, cyclone geometry, and feed coal. Dense-medium recovery testing was carried out with a 305 -mm (12-in.) diameter x 152-mm (6-in.) wide wet-drum magnetic separator using the cyclone clean-coal and refuse products as the feed material. Fundamental testing of dispersion/reagglomeration phenomena was conducted with coal/clay mixtures.

The dense-medium cyclone was capable of achieving separations down to approximately 400 mesh. For example, the ash content of the +400 mesh material from coal 1 was reduced from 37 to 6 percent. For coal 2, however, both the dp and Ep values increased after ultrasonic treatment. Because the feed for these tests was not deslimed and contained over 63 percent -400 -mesh material, it is likely that the ultrasonics had "scrubbed" the clays from the coal 
surface. This likely led to an increase in the apparent viscosity of the medium, resulting in a worsening of the separation after treatment. As such, desliming after ultrasonic treatment should result in improved size classification, because additional "liberated" slimes would be removed. This has implications in the selection of circuitry and the location of the ultrasound unit. For example, if these clays are liberated to this extent using ultrasound, it may be best to apply ultrasonics prior to a desliming step in advance of dense-medium cycloning.

It was also found that ultrasonic treatment prior to wet-drum magnetic separation improved the purity of the magnetic fraction and to a lesser extent, recovery. The treatment was particularly beneficial for the cyclone overflow material. The fundamental testing indicated that agitation after ultrasonic treatment is necessary to disperse fine particles and to prevent reagglomeration. The application of ultrasound in conjunction with fine dense-medium cycloning can be economical under certain circumstances.

The application of ultrasound must be investigated further in a complete circuit that also evaluates the effect of ultrasound on desliming prior to dense-medium cycloning. The potential improvements in desliming are hypothesized by noting the difference in performance between the two coals. Coal 1 , with a smaller amount of ultrafine material present, gave good performance results down to 400 mesh and showed improvements in clean coal ash at the same yield. However, coal 2, with a substantially higher proportion of ultrafine material present, showed poorer performance in the presence of ultrasound. This is related to the "scrubbing" of clay from the surface of the coal, resulting in a higher medium viscosity and poorer separation of the slimes. If a desliming cyclone was applied first to this material, then the fine clays should be readily removed prior to dense-medium cycloning. This should allow also the application of a magnetic separator to the products from the dense-medium cyclone. 

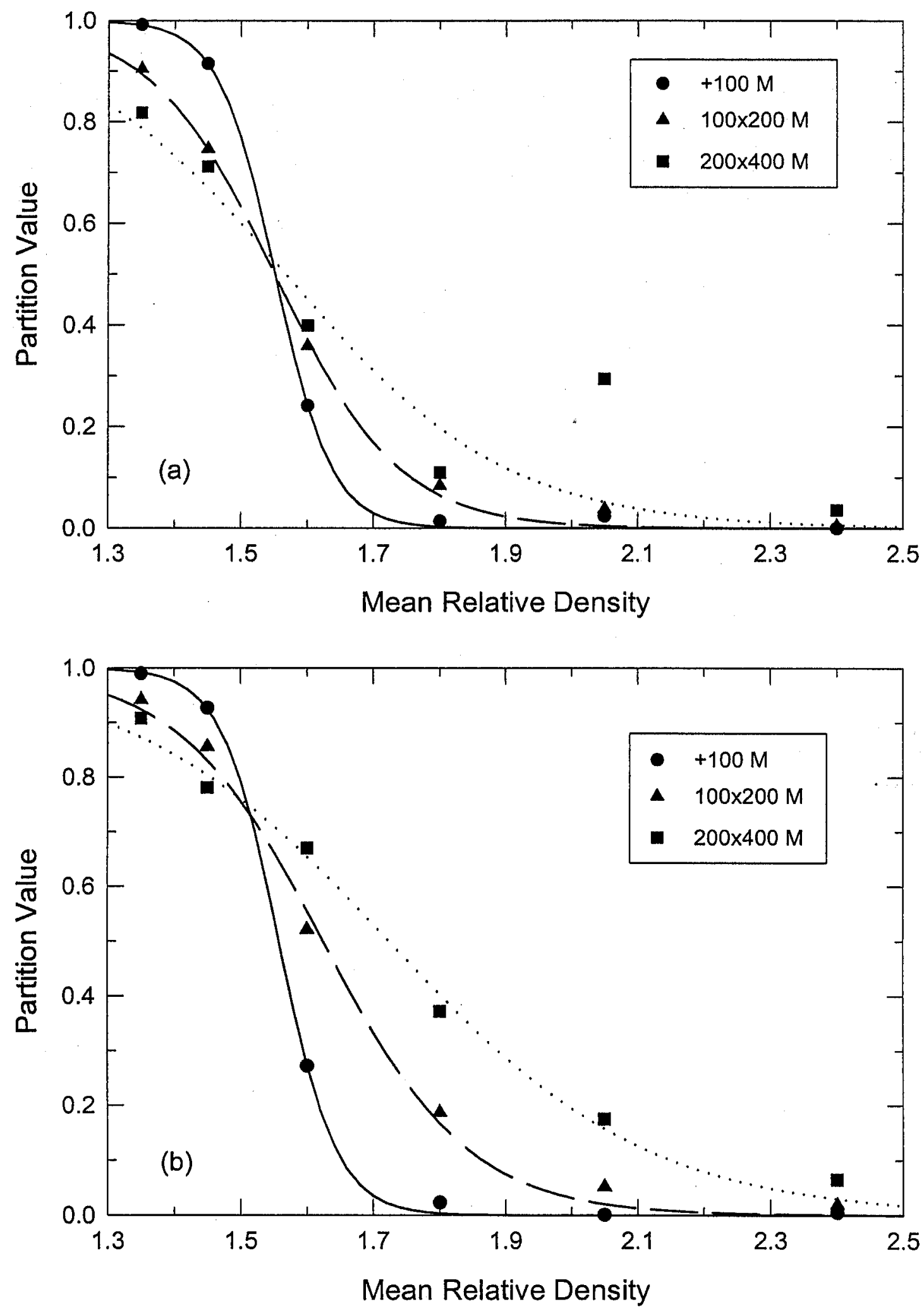

Figure S-1. Actual partition values and fitted curves for coal 2 at 1.45 medium relative density: (a) without ultrasonics; (b) with ultrasonics. 

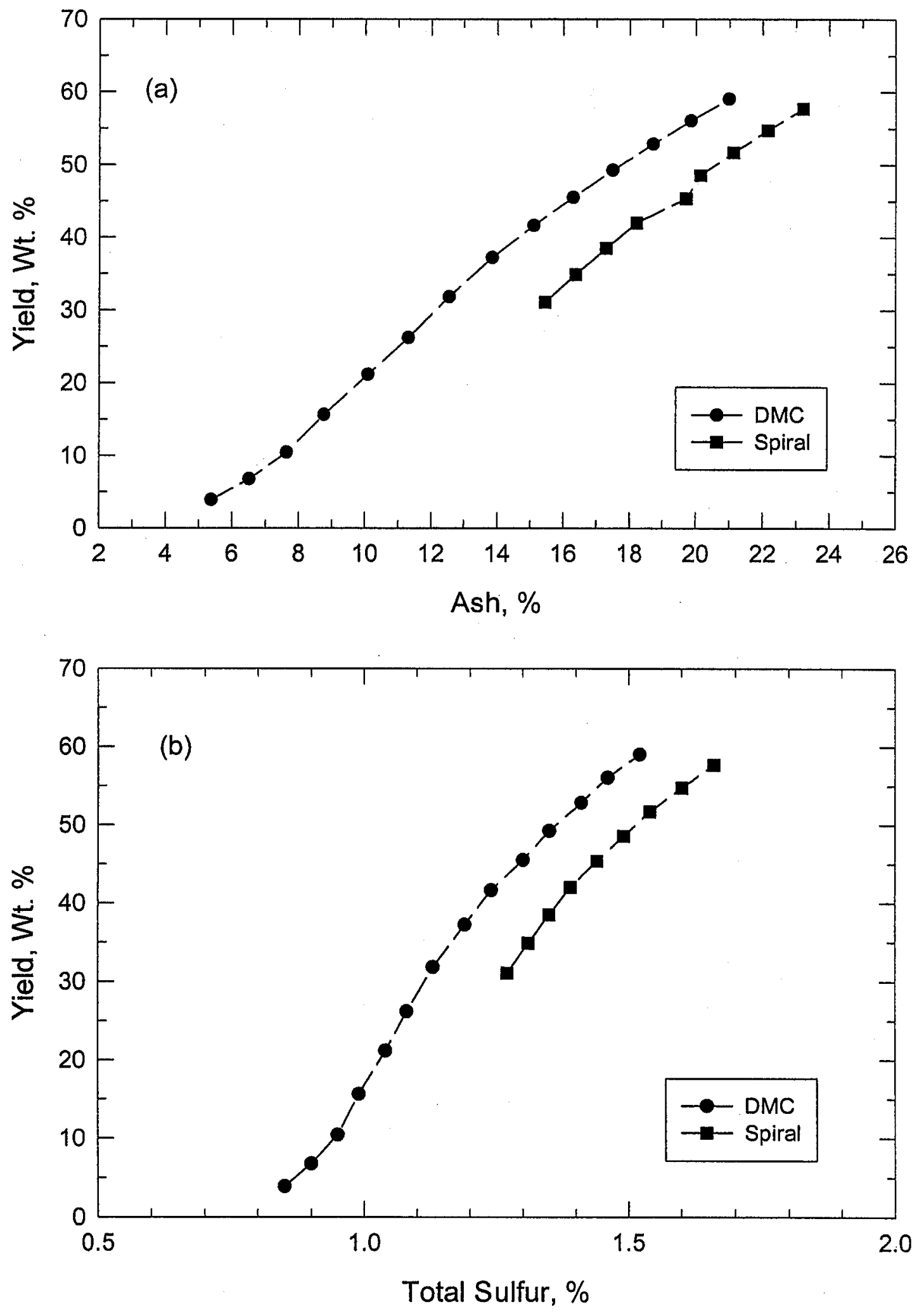

Figure S-2. Simulated grade-yield curves for dense-medium and spiral separations: (a) clean coal yield vs. ash content; (b) clean coal yield vs. sulfur content. 


\section{INTRODUCTION}

Coal is the major source of energy for power generation, and about 800 million tons of coal are being burned every year in the United States [DOE/EIA, 1997]. Another 300 or so million tons are used in coke production, are exported, or are utilized directly by the industrial sector. Of the total coal production in the United States, approximately $50 \%$ is subjected to mechanical cleaning, which represents over 500 million tons of material that must be cleaned. Consequently, any improvement in carbon recovery would have a major impact on the total tons of cleaned material that are produced from the same feed tonnage.

For coarse and intermediate sizes, down to approximately $1 \mathrm{~mm}$ in diameter, cleaning technologies are very efficient with carbon recoveries often exceeding $95 \%$. However, as the particle size decreases, the cleaning efficiency decreases dramatically when utilizing conventional gravity concentration (density-based) processes such as water-only cyclones and spiral concentrators. In particular, the cleaning efficiency in the size range from about 1 to $0.15 \mathrm{~mm}$ is quite poor. Although water-only cyclones and spirals are only moderately efficient in this size range, they are used almost exclusively to treat this size fraction. Hence, a large portion of carbon is ultimately lost to the refuse and high-ash, high-sulfur material is invariably misplaced to the product stream, resulting in dilution of the product.

Water-based processes are also not readily adjustable when attempting to change the separating density to meet a new product specification or to account for changes in the feed stream. Moreover, these devices are not capable of making low relative density separations (below about 1.5), which is often required to produce premium carbon products.

These limitations can be overcome in part by using available technology, for example, dense-medium cyclones to clean the $1 \times 0.15 \mathrm{~mm}$ size fraction in place of water-based devices. 
However, other barriers such as the efficiency of existing dense-medium recovery circuits must be addressed before dense-medium cycloning can be considered as a viable option. Hence any technology improvement that increases carbon recovery and/or reduces production costs for this size fraction would be very beneficial to the overall economics of the cleaning plant.

In addition to raw coal, another 2-3 billion tons of fine coal are located in impoundment areas within the United States. Much of this material is of high quality, but the technology is often lacking for cleaning the $1 \times 0.15-\mathrm{mm}$ size fraction efficiently. Even dense-medium cycloning suffers when treating impounded material because of the high clay content. To address this concern, advanced dense-medium cycloning or the "Micro-Mag" technology using micronized magnetite and high pressures was developed to clean these finer sizes [Klima et al., 1990; Kindig, 1992]. However, using micronized magnetite and high operating pressures increase the operating costs significantly over the traditional technologies used to clean the fine coal. In addition, recovery of the ultrafine magnetite, particularly when contaminated with fines from waste ponds, is very difficult and expensive, often requiring very elaborate cleaning circuits. The objective would then be to improve carbon recoveries, while maintaining or reducing processing costs. This can be accomplished by enhancing the performance of current dense-medium cycloning circuits including improving dense-medium recovery through the use of ultrasonic technology.

If conventional dense-medium cycloning can be extended to finer sizes without significantly greater operating costs, then it may begin to replace water-only cyclones and spirals to clean the $1 \times 0.15-\mathrm{mm}$ fraction. Froth flotation can then be utilized to clean the ultrafine fractions $(-0.15 \mathrm{~mm})$, or these fractions can be discarded if they are very high in ash content. Many of the difficulties encountered in the use of dense-medium cyclones for fine coal 
cleaning can be attributed to inadequate dispersion (i.e., aggregation) of the coal and mineral (especially clay) particles. Similar aggregation phenomena may contribute to both media loss and media contamination in the recovery circuit.

Treating the feed to a fine dense-medium cyclone circuit via ultrasonics "scrubs" fine clay particles from the surface of coal and allows the coal and clay minerals to act as separate particles in the cyclone, resulting in improved performance. Currently, ultrasonic technology is being applied commercially to improve fine coal dewatering and thickening, and it is the "scrubbing" mechanism that is assumed to be promoting performance improvements.

In addition to improved performance, using dense-medium cycloning at finer sizes will allow greater overall control within a cleaning plant; the dense-medium cyclone separating density is easily changed on-line by changing media density. To effect changes in separating density in a water-only cyclone, changes must be made to cyclone geometry. Changes in spiral concentrator separating density are made by either changing the position of the clean coal or middlings splitters or by changing the percent solids in the feed to the spiral. In addition, the separation efficiency of water-only cyclones and spirals is much lower compared to densemedium cyclones. Water-only cyclones and spirals are also not able to separate at low relative densities (e.g., below 1.5), a prerequisite when producing ultra-clean coal.

From a separation standpoint, the general consensus has been that dense-medium cyclone separations are feasible, at least for fine raw coal. Separation efficiencies as measured by the probable error vary as a function of particle size. For example, probable errors on the order of 0.06 were achieved for the $1 \times 0.5-\mathrm{mm}$ size fraction but increased to 0.13 for the $0.25 \times 0.1-\mathrm{mm}$ size fraction using conventional 250-mm diameter dense-medium cyclones [Mengelers and Dogge, 1979]. The overall probable error for the composite $1 \times 0.1-\mathrm{mm}$ material was on the order 
of 0.1 compared to typical values of $0.02-0.03$ when processing coarse size fractions (e.g., $19 \times 1 \mathrm{~mm}$ ) in dense-medium cyclones. However, recovery of the media when processing the finer size fractions has been difficult. Add to it an increased clay content such as that associated with coal from refuse impoundments, and the magnetite recovery process may become formidable.

Systems exposed to ultrasonic energy are known to experience locally over-heated spots and local shear forces caused by drastic pressure changes. For instance, local temperatures on the order of $5000^{\circ} \mathrm{C}\left(9032^{\circ} \mathrm{F}\right)$ and pressures as high as $500 \mathrm{Atm}(7348 \mathrm{psi})$ are quite common. Simultaneous heating and cooling rates could reach one billion degrees Kelvin per second. These conditions often bring about the formation and collapse of microbubbles that may scrub ultrafine coal or mineral slimes from coarser particles, remove surface oxidation, or cause other changes that can improve the performance of coal cleaning and dewatering processes. Increased clean-coal recovery, improved clean-coal quality, and the reduction in dewatering chemical costs all improve the economics of a coal producing operation.

The use of ultrasonics to improve the performance of coal cleaning and dewatering processes has been investigated by a number of researchers over the past two decades [Angle et al., 1988; Buttermore et al., 1990; Dawson et al., 1991; Slomka and Buttermore, 1991]. Indeed, DAGER, Inc. of Berlin, Pennsylvania, owns the rights to a patent for the application of ultrasonics for improving these processes [Vujnovic, 1995]. DAGER has applied ultrasonics with success at a commercial coal refuse recovery plant for fine coal froth flotation and dewatering and has evaluated the use of ultrasonics at laboratory-scale to improve the froth flotation recovery of fine coal. However, some investigations have failed to demonstrate that ultrasonics improve coal cleaning and dewatering process performance, while still other 
investigations have shown that performance improvement is coal-dependent. The acceptance of and use of this technology has been limited by these discrepancies and the lack of understanding of the underlying mechanisms.

The Pennsylvania State University, its project team (Typlex, Inc., DAGER, Inc., and PrepTech, Inc.), and advisory committee members have demonstrated the application of ultrasonic energy during dense-medium cycloning and subsequent recovery of fine coal and coal refuse impoundment materials. The results will help to extend the range of conventional densemedium cycloning to sizes now typically cleaned in relatively inefficient water-only cyclone and spiral concentrator circuits.

The Phase I laboratory investigation of this project evaluated the application of ultrasonic energy to the feed to a dense-medium cyclone to improve the performance -- yield and/or cleancoal quality -- of the device for cleaning fine coal and coal wastes from refuse impoundments. It also evaluated the effect on downstream media (i.e., magnetite) recovery. Fundamental testing was also carried out to examine dispersion/reagglomeration phenomena. Based on the test results, an economic evaluation was then made on the separation process. 


\section{RESULTS AND DISCUSSION}

The results from this project are organized by task to facilitate the discussion.

\section{Task 1. Project Management}

The objective of the project management task was to provide a coordinated planning, scheduling, budgeting, and reporting effort.

\section{Project Reporting}

After award of the contract, the following plans were prepared and submitted to the DOE: Management Plan, Milestone/Schedule Plan, Labor Plan, and Cost Plan. In addition to these plans, quarterly reports were submitted to the DOE throughout the course of the research project as per the reporting requirements. This final report contains results from the Phase I study with an interpretation of the results.

During the first month of the project, a Hazardous Substance Plan was prepared and submitted, detailing the anticipated environmental effects of the study. This included the identification of the hazardous chemicals, which were utilized during the project. The nature of the wastes generated throughout the course of the study are given in the Hazardous Substance Report.

\section{Technical Advisory Committee Meetings}

A technical advisory committee consisting of representatives from the project team, a coal cleaning plant construction company (Farnham \& Pfile Construction Co.), a magnetite supplier (Penn Mag), a magnetite recovery equipment manufacturer (Eriez Magnetics), and a 
cyclone manufacturer (Krebs Engineering) provided technical review and advice during the course of the project. Two meetings were held at Penn State during the course of the project: July 14, 1999 and March 10, 2000.

\section{Task 2. Sample Procurement and Characterization}

This task involved the characterization of the coal and magnetite samples, which were used over the course of the project. Two coal refuse samples and three magnetite samples were characterized and used in various parts of the project.

\section{Coal Characterization}

One coal sample (coal 1) was acquired from the refuse impoundments at the Yellow Run site located in Stoystown, Somerset county, Pennsylvania. A second sample (coal 2) was collected as desliming screen underflow $(-0.5 \mathrm{~mm})$ being fed to the water-only cyclone circuit in the Yellow Run processing plant. This material was from a different refuse pile than coal 1. These materials were quite different as evidenced by the results of the sample characterization. As such, they represent some of the extremes in quality and size distribution that may be found in refuse impoundments.

The initial coal sample (coal 1) was collected with a front end loader and consisted of six 208-L (55-gal) drums of material. After drying, the drums were combined and screened at $38.1 \mathrm{~mm}(1-1 / 2$-in.) and $0.6 \mathrm{~mm}$ (30 U.S. mesh). The $-0.6-\mathrm{mm}$ fraction was screened further at $0.3,0.15$, and $0.075 \mathrm{~mm}(50,100$, and $200 \mathrm{mesh})$. Ash and sulfur analyses were performed on each size fraction. The size, ash, and sulfur distributions are given in Figure 1. It can be seen that coal 1 contained a significant portion of -200 -mesh material $(\sim 40 \%)$ and that the ash 
contents ranged from about 37 percent to 47 percent. The sulfur contents ranged from 2.8 to 3.4 percent.

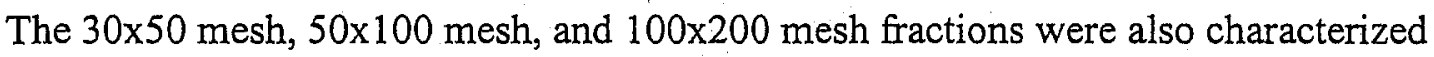
using washability analysis. The results of this testing are given in Figures 2-5. Figure 2 gives the combined washability analysis for the $30 \times 200$ mesh fraction. Figures 3-5 give the individual washability analyses for the $30 \times 50$ mesh, $50 \times 100$ mesh, and $100 \times 200$ mesh fractions.

Using these washability analyses, the theoretical yield of the +200 mesh material at a given ash level can be predicted. This was done in Table 1, which also shows the relative density of the separation required to achieve these separations. From Table 1, the theoretical yield to produce a 10-percent-ash clean-coal product is 25 percent. The separating relative density is 1.47. A 15-percent-ash product can be produced at a theoretical yield of 43 percent at a relative density of 1.70. When processing this feedstock, the Yellow Run processing plant produced, typically, a 12-percent-ash product at a medium relative density of 1.50-1.55 in its dense-medium cyclone circuit processing 1-1/2-in. x 30-mesh coal. From the washability results presented here, the finer sizes should be separated at similar relative densities to produce similar ash levels.

The second coal sample (coal 2) was a slurry sample, which was collected in the Yellow Run processing plant as desliming screen underflow (water-only cyclone feed). Six 208-L (55-gal) drums of this slurry were obtained, along with a 57-L (15-gal) head sample, which was used to characterize the size, ash, and sulfur distributions. In order to increase the solids concentration of the plant samples, the solids in each 208-L (55-gal) drum were allowed to settle, and then the supernatant was decanted. This was repeated several times during the course of the sampling. The size, ash, and sulfur distributions are included in Figure 1. As can be seen, this 
sample was considerably finer than the first sample and was higher in ash content. However, the sulfur contents for all size fractions were approximately 1 percent or less.

\section{Magnetite Characterization}

Two samples of E-grade magnetite and one sample of B-grade magnetite were obtained from Penn Mag in Adrian, Pennsylvania for use in this study. For each sample, the magnetite was dry screened at $0.84 \mathrm{~mm}$ (20 mesh) to remove any tramp oversize material. The undersize material was then redistributed among several drums for use in the testing.

The size distributions of the magnetite samples were determined by using a combination of screening and analysis with a Microtrac X-100 particle size analyzer. Wet screening of representative samples was performed at $38 \mu \mathrm{m}$ on a 400 mesh sieve. After the +400 -mesh material was dried, it was dry screened using a Ro-Tap sieve shaker. The -400 -mesh fractions from the wet and dry screening operations were combined and analyzed using the Microtrac. For each grade of magnetite, four samples of the -400 -mesh material were analyzed. Results from the sieve analysis were adjusted to correspond to the Microtrac sizes. Complete size distributions for the three magnetite samples can be found in Figure 6.

Davis tube analyses were performed on each magnetite sample to determine product purity (magnetics content). The first E-grade magnetite had an average purity of $94.7 \%$ magnetics, while analysis of the second E-grade magnetite gave a slightly higher purity of $96.4 \%$ magnetics. The purity of the B-grade magnetite was similar at $96.5 \%$ magnetics.

Density measurements were performed with a helium stereopycnometer. The E-grade magnetite samples had densities of 4.95 and $5.05 \mathrm{~g} / \mathrm{cc}$, while the B-grade magnetite had a density of $4.99 \mathrm{~g} / \mathrm{cc}$. For comparison purposes, pure magnetite has a density of $5.2 \mathrm{~g} / \mathrm{cc}$. 


\section{Task 3. Fundamental Dispersion Testing}

This task evaluated the role of ultrasonic treatment in the specific context of dispersion/deagglomeration of the various components of the fine coal slurries and how they are affected by various physical and chemical variables.

\section{Background}

Aggregation of fine particles can be a critical, limiting factor in the performance of densemedium cyclones treating fine coal and coal refuse impoundment materials. Adhesion of fine clays and other minerals to coal-particle surfaces can be especially detrimental. Various kinds of forces can promote adhesion and aggregation. These include electrostatic attractions between charged particles in water, van der Waals forces and chemical bonds resulting from crystallization of dissolved salts, etc., at particle-particle contact points. The latter may play an important role in opposing dispersion, while electrostatic and van der Waals forces can be expected to favor reagglomeration of dispersed particles.

Review of the literature on the principles and mechanisms of fine-particle dispersion by ultrasonic treatment reveals that the process depends primarily on micro-cavitation to disrupt particle-particle bonds. More specifically, it appears to be the collapse of large cavitation bubbles that provides the strong pressure impulses responsible for aggregate break-up.

Dispersion of fine particles is a breakage process akin to grinding of solids. In slurry systems, it is invariably accompanied by simultaneous reaggregation of the particles due to agitation, thermal effects and even the action of the ultrasound waves. The overall state produced represents a balance between these competing effects. Application of ultrasonics generally favors aggregate breakup because of the large, highly localized forces generated. 
Agitation in the absence of ultrasonic waves can also promote aggregate breakage due to shear. However, reagglomeration, resulting from particle-particle collisions becomes more significant under these conditions. An important objective of the investigations carried out in this task has been to evaluate dispersion/reagglomeration phenomena in aggregated fine particles based on models for ultrasonic dispersion, together with those for ortho- and perikinetic aggregation. The ultimate goal is to use the findings of these studies to establish realistic criteria for the design and operation of full-scale dispersion systems.

\section{Experimental Procedures}

A bench-scale laboratory test procedure has been developed for evaluating the extent and kinetics of fine-particle detachment and re-deposition. Dispersion/reagglomeration tests have been carried out on various mixtures of coal, magnetite and fine clays.

Sample Preparation. Aggregated mixtures were prepared by a slurry-drying procedure.

Pretreatment of the coarse component (usually coal) was carried out to minimize fines production due to degradation of friable coarse particles. A 100-g sample of $0.6 \times 0.105-\mathrm{mm}$ (30x140-mesh) material (prepared by dry screening) was placed in a baffled $1000-\mathrm{mL}$ beaker. Distilled water was added up to the $800-\mathrm{mL}$ mark on the beaker. The mixture was stirred for two minutes at $1000 \mathrm{rpm}$. A 20 -second burst of ultrasonics was applied using an ultrasonic probe. The mixture was removed and wet screened at 140 mesh to remove any fine material. Additional samples were treated until sufficient +140 -mesh material was produced. The +140 -mesh material was dried at approximately $110^{\circ} \mathrm{F}$ and saved for testing.

Samples of the fine component (usually coal 2 fines) were wet screened at 140 mesh. 
The -140-mesh material was filtered and dried, and then samples were wet screened at $0.025 \mathrm{~mm}$ (500 mesh). The -500 -mesh material was dried at $110^{\circ} \mathrm{F}$. After drying, any large agglomerates were broken using a mortar and pestle prior to use of the material for cake preparation.

Aggregated material for dispersion testing was prepared in the form of dried cakes.

Samples of the coarse (30x140-mesh) and fine (-500-mesh) components were mixed by hand in a $600-\mathrm{mL}$ beaker. A total of approximately $90 \mathrm{~g}$ of water was added slowly to the mixture. Care was taken to ensure that the solids were thoroughly mixed during water addition. The mixture was placed in an oven at $210^{\circ} \mathrm{F}$ to dry (generally overnight). For those tests when chemical additives such as $\mathrm{NaOH}$ and $\mathrm{FeCl}_{3}$ were used, the solutions were added at the desired concentration during the wet mixing stage, while keeping the total volume of liquid the same for each cake.

Dispersion Tests. The dried/agglomerated solids were removed from the $600-\mathrm{mL}$ beaker and transferred to the $1000-\mathrm{mL}$ baffled beaker. Any remaining solids were removed with distilled water. Additional distilled water was added up to the $800-\mathrm{mL}$ mark. The mixture was stirred for two minutes at $1000 \mathrm{rpm}$ and then allowed to settle for four minutes. The mixture was then wet screened at 200 mesh to remove the non-agglomerated fines. Both fractions were filtered, dried, and weighed.

The +200 -mesh material, which included adhering fines, was placed back into the 1000-mL baffled beaker. Distilled water was added to bring the volume to $800 \mathrm{~mL}$. A pH reading was then taken. The mixture was again stirred for two minutes at $1000 \mathrm{rpm}$ and allowed to settle for four minutes. A $20-\mathrm{mL}$ sample of the supernatant was withdrawn and analyzed using a turbidimeter. A pH reading was also taken. The sample was returned to the baffled beaker and 
the mixture was stirred for an additional two minutes. After 1 minute and 50 seconds of stirring, a one-second burst of ultrasonics was applied using the probe. Figure 7 shows the test setup. The sampling and measurement procedures were repeated as noted above. Additional readings were taken for total mixing times of $6,8,10$, and 12 minutes. For each two-minute interval, a one-second burst of ultrasonincs was applied after 1 minute and 50 seconds of stiming. In each case, the mixture was allowed to settle for four minutes prior to taking the $\mathrm{pH}$ and turbidity measurements. Duplicate samples were taken for QA/QC. In cases when the 20-mL sample was too concentrated to obtain a turbidity reading, it was diluted with distilled water. Diluted samples were not returned to the solution so as to avoid volume changes.

Reagglomeration Tests. Both short-term and long-term reagglomeration tests were carried out. The short-term tests consisted of a continuation of the dispersion tests with the ultrasonic application omitted. After the twelve minutes of ultrasonic dispersion testing was completed, agitation of the slurry at $1000 \mathrm{rpm}$ was continued and further samples were withdrawn at two-minute intervals. Turbidity and $\mathrm{pH}$ measurements were made on each sample. This procedure was continued for an additional twelve minutes. After all required samples had been taken, the remaining mixture was transferred into a larger beaker, covered, and saved for longterm reagglomeration testing.

The long-term tests were carried out using mixtures that had been standing for at least one week. The mixture was transferred into the $1000-\mathrm{mL}$ baffled beaker, using small amounts of distilled water as necessary to remove any solids. The mixture was stirred for two minutes at $1000 \mathrm{rpm}$ and allowed to settle for four minutes before taking a turbidity sample and $\mathrm{pH}$ reading. This was continued at two-minute intervals until twelve minutes of overall stirring time were 
completed. For each turbidity reading, a 20-mL sample was withdrawn. The sample was diluted with distilled water as necessary. Undiluted samples were returned to the mixing tank.

Duplicate samples were not taken when dilution was required to avoid removing large quantities of slurry.

\section{Test Results}

Dispersion Tests. Taggart seam coal was used as the coarse component for most of the coal/clay studies. This particular coal was selected because of its low ash content $(\sim 3 \%)$, thereby isolating the mineral matter effects to the fine component. Coal 2 refuse $(-30$ mesh) from the Yellow Run cleaning plant was used to prepare the fine (clay) component. Some typical results from the dispersion tests are shown in Figure 8. The data shown are from three separate tests. The first set is from a baseline test in which a sample of the Taggart coal, with no adhering clay, was subjected to the standard ultrasonic treatment. The small increase in turbidity represents a slight degradation of the coal. The second set shows the effect of agitation alone, i.e., with no ultrasonic treatment. In this case there was some detachment of the fine clay particles. The last of the three tests shows the effects of ultrasonics followed by a period of agitation alone. The turbidity can be seen to increase substantially due to the period of exposure to ultrasonics followed by a further increase with agitation only. It appears that some additional agitation is necessary, following the ultrasonic treatment, to allow for actual dispersion of the fine particles. Similar results were obtained in many other tests. The implication is that ultrasonic treatment is effective in disrupting particle-particle bonds, but that additional agitation is necessary to prevent the particles from becoming reattached.

The amplitude of the ultrasonic waves can obviously be expected to affect the dispersion 
process. Preliminary testing revealed that amplitudes greater than $30 \%$ of the maximum output of the probe were sufficient to cause significant degradation of the coal. Figure 9 shows the results of dispersion tests conducted at amplitudes of 0,10 and $20 \%$. It can be seen that there is little additional benefit in increasing the amplitude to more than the $20 \%$ level without risking degradation of the coal. Hence, subsequent testing was carried out at the $20 \%$ level.

The effects of $\mathrm{pH}$ during cake preparation and during ultrasonic dispersion have also been investigated. Some results are shown in Figure 10. Redispersion, both with ultrasonics and with further agitation, is least under acid $(\mathrm{pH} 2)$ conditions. The natural $\mathrm{pH}(\sim 6)$ and $\mathrm{pH} 10$ conditions give similar redispersion during ultrasonic application but, for the natural $\mathrm{pH}$ condition, there is substantially more fines detachment during the subsequent period of agitation only as indicated by the high turbidity values. A possible explanation for this observation is that binding of the fines to the coal particles is weakest at the natural $\mathrm{pH}$, but that agitation and shear are necessary to prevent reagglomeration. Those fine particles that are detached by ultrasonic treatment at pH 10 are more likely to be re-deposited on the coal surfaces.

The deposition of mineral matter in coal seams may occur in the presence of inorganic salts that may influence the coal/mineral binding. The addition of salts during cake preparation was investigated to evaluate such effects. The results for cakes prepared in the presence of calcium ions are presented in Figure 11. It is clear that the added salt significantly enhances coal/clay binding. Similar effects were observed with ferric salts.

Reagglomeration Tests. Long-term re-deposition of fine clays may be important in applications related to the processing of refuse impoundment materials. Some experiments were carried out on slurries that had been used in ultrasonic dispersion tests and then stored for an extended 
period (at least one week). These aged slurries were then agitated at $1000 \mathrm{rpm}$ in the baffled beaker and turbidity measurements were taken at two-minute intervals. Some examples of the results obtained for slurries produced from cakes prepared under different conditions can be seen in Figure 12. It appears that, in general, slurries that were readily dispersed in the original ultrasonic testing $\left(0.1 \mathrm{M} \mathrm{Ca}^{+2}\right.$ or $\left.\mathrm{Fe}^{+3}\right)$ were easily redispersed after long-term storage, giving supernatant turbidities equal to or even higher than before. For slurries that were more difficult to disperse by the ultrasonic treatment, the strong particle-particle bonds appear to be reestablished during storage, leading to substantially reduced turbidities.

\section{Task 4. Dense-Medium Cyclone Testing}

The bulk of the testing in this task centered on the application of the ultrasonic device to dense-medium cycloning of fine coal. Tests were also conducted using water only and densemedium only systems to establish baseline operating conditions for the circuit. In addition, size classification testing was conducted, with and without ultrasonic treatment [Turek, 2000].

\section{Test Circuit}

The cyclone test circuit consisted of a variable-speed centrifugal pump, 379-L (100-gal) steel sump, variable-speed mixer, pressure gauge, and ultrasonic test unit. A 76.2-mm (3-in.) diameter Krebs urethane cyclone (Model U3-10 $)$ was used for all tests. The cyclone was supplied with various overflow (vortex finder) and underflow (apex) orifices, which were changed as required during the testing. The ultrasonic unit was a flow-through design, which was placed in the feed line to the cyclone (Figure 13). The test loop was designed in a closed circuit such that the slurry could be pumped through the cyclone or recirculated into the sump. 


\section{Test Procedures}

Water Only Tests. Cyclone testing using only water was done with the test circuit to establish flow rates and to ensure proper performance of the unit. Various configurations of vortex finder diameter, apex diameter, and inlet pressure were tested to establish initial operating conditions. The cyclone was operated at $69,138,207,276$, and $345 \mathrm{kPa}(10,20,30,40$, and $50 \mathrm{psi})$ with combinations of $12.7-\mathrm{mm}(0.5-\mathrm{in}$.$) and 19.1-\mathrm{mm}(0.75$-in.) vortex finders and $6.35,9.53$, and 12.7-mm $(0.25,0.375$, and 0.5 -in.) apexes. For each test, the overflow and underflow cyclone streams were collected simultaneously into a calibrated drum, and the collection time was measured. Knowing the total water volume and collection time, the cyclone flow rate (in gallons-per-minute) was then determined.

Coal Only Tests. Cyclone testing with coal 2 was done to examine the classification of the coal and to analyze the effects of ultrasonic treatment on a slurry containing coal and water only (no dense medium). Initially, a weighed amount of water was added to the sump. After the pump and mixer were started, the water was recirculated through the bypass line. The coal slurry was added to increase the solids concentration to $5 \%$ by volume.

After several minutes of circulation (to ensure adequate mixing), feed samples were taken from the bypass line. Subsequent feed samples were taken prior to each test and after the slurry was treated with ultrasonics for 5 minutes. Product samples were taken without and with ultrasonic treatment at 138,207 , and $276 \mathrm{kPa}(20,30$, and $40 \mathrm{psi})$, using the $12.7-\mathrm{mm}(0.5$-in.) apex and 12.7-mm (0.5-in.) vortex finder. For each sample, the ultrasonic unit was turned on for ten seconds before the samples were taken and then turned off until the next set of samples was taken. This amount of time was used to ensure that the treated material would pass through the 
cyclone. The cycling of the ultrasonic unit was done to minimize treatment of the recirculated slurry. A separate set of samples was also taken at $276 \mathrm{kPa}$ ( $40 \mathrm{psi}$ ) after applying the ultrasonics for 5 minutes. Product samples were taken from the overflow and underflow streams in preweighed $1000-\mathrm{mL}$ beakers. The samples were saved for size analysis.

For each set of tests, a representative sample of the overflow stream was obtained by mixing the slurry using a mechanical stirrer and siphoning a sample into a vacuum flask. This sample was wet screened at 400 mesh. The -400 -mesh material was mixed, and an eye dropper of material was taken for Microtrac analysis. The remainder of the overflow sample was wet screened at 400 mesh. The +400-mesh material was dried and screened in a Ro-Tap sieve shaker at $20,30,40,50,70,100,140,200,270$, and 400 U.S. mesh. The -400 -mesh material was dried and weighed. The underflow sample was also wet screened at 400 mesh. A representative sample of the -400-mesh material was obtained for Microtrac analysis, and the remainder of the sample was dried and weighed. The +400 -mesh material was dried and screened at the same sizes as the overflow material. The feed samples were also analyzed using the same procedures. The resulting size distribution data were then used to determine the size selectivity values.

Dense-Medium Only Tests. Cyclone testing using the magnetite and water dense medium was carried out to determine the medium splits for different cyclone geometries and operating conditions. Both E-grade and B-grade magnetite were tested at 1.35, 1.45, and 1.55 medium relative densities. The cyclone was operated at 138,207 , and $276 \mathrm{kPa}(20,30$, and $40 \mathrm{psi})$ with combinations of the 12.7 and $19.1-\mathrm{mm}(0.5$ and 0.75 -in.) vortex finders and $6.35,9.53$, and 12.7-mm $(0.25,0.375$, and 0.5 -in. $)$ apexes. 
The appropriate weights of magnetite and water were added to the sump to obtain the desired medium relative density. Samples of the feed stream were taken while the circuit was in bypass to ensure the accuracy of the sump calculations for the desired medium relative density. For each test condition, simultaneous samples were taken from the overflow and underflow streams in 1000- $\mathrm{mL}$ beakers, without and with ultrasonic treatment. The beakers were weighed, dried, and weighed again to determine slurry densities and medium splits. The differentials were calculated from the difference in relative densities between the underflow and overflow streams.

Dense-Medium/Coal Testing. Tests were performed using both coal samples. For all tests, E-grade magnetite was used. The B-grade magnetite was not used because of the large density differentials that were obtained under nearly all conditions of the dense-medium only testing.

Coal 1 -- The -30-mesh coal refuse from the Yellow Run cleaning plant was used in the first set of tests. A $12.7-\mathrm{mm}(0.5$-in. $)$ vortex finder was used for all conditions. The appropriate weights of magnetite and water were added to the sump to give the desired medium relative density. Sufficient coal was then added to produce the desired medium-to-coal ratio. The slurry was circulated through the bypass line for several minutes to ensure adequate mixing. Feed samples were taken from the bypass line at the beginning and end of each test series.

The slurry was then diverted to the cyclone. The pump speed was increased to obtain the desired cyclone pressure. Simultaneous samples were taken from the underflow (UF) and overflow (OF) streams with the ultrasonic unit off. This approach was repeated for combinations of the following test conditions: cyclone inlet pressure $=138,207,276 \mathrm{kPa}(20,30,40 \mathrm{psi})$; UF diameter $=12.7,9.53 \mathrm{~mm}(0.5,0.375 \mathrm{in}$.$) ; medium relative density =1.35,1.45,1.55$; and 
medium-to-coal (by weight) $=4: 1,5: 1$. The sampling procedure was repeated at the same conditions, but after exposing the slurry to ultrasonic treatment. Ultrasonic energy was applied in the same manner as in previous tests to minimize exposure to the remaining slurry in the sump.

All samples were weighed, dried, and weighed again to determine the solids concentrations. The material was reslurried and passed through a Frantz magnetic filter to remove the magnetite. The non-magnetic fraction was wet screened at 400 mesh. The -400-mesh material was allowed to settle, decanted, dried, and weighed. The +400 -mesh fraction was dried and weighed. The +400-mesh material was dry screened in a Ro-Tap sieve shaker at $50,100,200$, and 400 mesh. The size fractions were then analyzed for ash and sulfur content.

The clean-coal yield for the +400 -mesh size fraction was calculated via ash balance by

$$
Y_{C}=\frac{A_{F}-A_{R}}{A_{P}-A_{R}}
$$

where, $A_{F}, A_{R}$, and $A_{P}$ are the ash contents of the feed, refuse, and clean-coal samples, respectively, for the +400 -mesh material.

Coal 2 -- The test procedure for the second coal sample was similar to that for the first coal. However, in this case, the coal refuse was added as a slurry rather than as a dried solid. Prior to use in the test circuit, the slurry was thoroughly mixed and samples were taken to determine the solids concentration for sump calculations. The amount of water added to obtain the desired relative density was reduced accordingly. E-grade magnetite was again used for all tests. Simultaneous samples were taken with the ultrasonic unit off and on for the following test conditions: cyclone inlet pressure $=276 \mathrm{kPa}(40 \mathrm{psi}) ; \mathrm{UF}$ diameter $=12.7 \mathrm{~mm}(0.5 \mathrm{in}$.$) ; medium$ 
relative density $=1.35,1.45,1.55 ;$ and medium-to-coal (by weight) $=5: 1$

The UF and OF samples were taken by diverting both streams into tubes directed into 19-L (5-gal) buckets. The slurry samples were weighed and then passed through an Eriez wetdrum magnetic separator (described under Task 5) to remove the magnetite. The non-magnetic material was wet screened at 400 mesh. The +400 -mesh material was dried and weighed. The -400 -mesh material was allowed to settle, decanted, dried, and weighed. The +400 -mesh coal was dry screened to obtain samples in $+100,100 \times 200$, and $200 \times 400$-mesh size fractions.

Float/sink separations were then performed on each size fraction. Representative samples of the desired weights were obtained by riffling or cone-and-quartering. The sample weights were selected to obtain a solids concentration of approximately $5 \%$ at each relative density. Mixtures of organic liquids having relative densities of $1.4,1.5,1.7,1.9$, and 2.2 were used.

Prior to passing the cyclone products through the wet drum, head samples of each stream were taken. This material was passed through the Frantz magnetic filter to remove the magnetite. The non-magnetic material was wet screened at 400 mesh, dried, and dry screened at 30, 50, 100, 200 , and 400 mesh to obtain the product size distribution. Ash analyses were performed on each of these size fractions.

\section{Test Results}

Water Only Tests. The results for the cyclone tests using only water are shown in Figure 14. As expected, for all cyclone geometries, increasing pressure increased cyclone capacity at a given inlet pressure. When using the $12.7-\mathrm{mm}(0.5$-in.) vortex finder, increasing the apex diameter produced a significant increase in cyclone capacity. However, when using the 19.1-mm (0.75-in.) vortex finder, changing the apex diameter had minimal effect on cyclone capacity. 
Coal Only Tests. The results from sieving and Microtrac size analyses were combined to obtain size distributions for the cyclone feed, overflow, and underflow samples. The reconstituted feed values, $\mathrm{p}_{\mathrm{i}}^{\prime}$, for each size interval $i$, were calculated by

$$
p_{i}^{\prime}=\frac{t_{i} C+q_{i}}{1+C}
$$

where $t_{i}$ and $\mathrm{q}_{i}$ are the weight fractions of coarse and fine material in size interval $i$. The circulation ratio, $\mathrm{C}$, was calculated using the least absolute sum method

$$
C=\frac{\sum_{i=1}^{n-1}\left|p_{i}-q_{i}\right|}{\sum_{i=1}^{n-1}\left|t_{i}-p_{i}\right|}
$$

where $\mathrm{p}_{\mathrm{i}}$ represents the actual weight fraction of feed material in size interval $i$, and $n$ is the total number of size intervals. The size selectivity values, $s_{i}$, were then calculated by

$$
s_{i}=\frac{t_{i} C}{p_{i}^{\prime}(1+C)}
$$

It was necessary to correct the size selectivity values for apparent bypass by

$$
c_{i}=\frac{s_{i}-a}{1-a-b}
$$

where $a$ represents material that apparently bypassed the separation and reported to the underflow, while $b$ represents material that apparently bypassed the separation and reported to 
the overflow. The b-bypass was zero in all cases. The corrected size selectivity (classification) values were fitted to the log-logistic function given by

$$
c_{i}=\frac{1}{1+\left(x_{i} / d_{50}\right)^{2.1972 / \ln S I}}
$$

where $\mathrm{x}_{\mathrm{j}}$ is the upper particle size for size interval $i$, and $\mathrm{d}_{50}$ is the equiprobable size, i.e., the size at which $c_{i}=0.5$. The sharpness index, SI, is defined as $d_{25} / d_{75}$ and represents a measure of the deviation of the curve from an ideal separation. Finally, the yield to the underflow stream was calculated by

$$
Y_{\mathrm{T}}=\frac{\mathrm{C}}{1+\mathrm{C}}
$$

Table 2 summarizes the $d_{50}$, SI, apparent bypass, and coarse yield at the various operating conditions, with and without ultrasonic treatment. As can be seen in Table 2, the cyclone was able to obtain $d_{50}$ values that ranged from 10-14 $\mu \mathrm{m}$. As expected, the values decreased with increasing pressure. Ultrasonic treatment had minimal effect on the cut size. Overall the classification efficiency was rather poor as indicated by sharpness indexes of less than 0.3 (where 1. represents ideal and 0.4-0.6 is typical). Ultrasonic treatment tended to decrease the sharpness index slightly. The a-bypass was approximately $50 \%$ in all cases.

Dense-Medium Only Tests. Dense-medium only cyclone tests were performed using E-grade and B-grade magnetite. The relative density differentials were calculated at each condition and are given in Tables 3 and 4 . As expected, the medium splits varied with cyclone geometry and 
operating conditions. For the E-grade magnetite, the differentials ranged from 0.33 to 0.61 . For the B-grade magnetite, the differentials were much higher at the same conditions, ranging from 0.67 to 1.49 . Because differentials greater than 0.4 are an indication of a very unstable medium, no further testing was done with the B-grade magnetite. Tables 3 and 4 also show that ultrasonic treatment had little or no effect on the differentials for both grades of magnetite.

Dense-Medium/Coal Tests. Dense-medium cyclone tests were carried out using both coal samples at $1.35,1.45$, and 1.55 medium relative densities. The operating conditions at each medium relative density, along with the resulting sulfur and ash contents, and the calculated yields are given in Tables 5-7 for coal 1. Replicates of certain conditions at each density were taken and are included in the tables.

Figures 15-17 illustrate the effects of pressure drop and OF/UF ratios on clean coal yield and ash content of the product and refuse streams at 1.35, 1.45, and 1.55 relative medium densities, respectively. The results are given with and without ultrasonic treatment. As can be seen, there is a minimal change in product yield and ash content over the range of tested pressure drops. As expected, increasing the OF/UF ratio (by using a smaller UF opening) allowed more material to be carried to the overflow stream, resulting in an increased clean-coal yield, but with a corresponding increase in ash content. The results also indicate that ultrasonic treatment had only a slight effect on cyclone separation.

For example, the effect of changing medium relative density on clean coal yield and clean coal ash, before and after ultrasonic treatment, is shown in Figure 18. The points in these graphs represent the products taken at $207 \mathrm{kPa}(30 \mathrm{psi})$ and two OF/UF ratios, 1:1 and 1.33:1. As expected, the clean-coal ash content increased with an increase in medium relative density and 
overflow-to-underflow ratio, because more of the ash-forming material went to the overflow stream. Ultrasonic treatment appeared to have a small effect on the ash content of the clean coal. Figure 18 shows that the samples taken after ultrasonic treatment had a slightly lower ash content at the same yield than those without ultrasonic treatment, especially at the 1.35 and 1.45 medium relative densities. However, these results all fall within the expected range of ash contents based on the reproducibility testing. The lower effect at 1.55 medium relative density may be due to the dampening effects at the higher solids concentration.

The size distributions and the ash contents of the individual size fractions are given in Tables 8-10. These results again demonstrated that the cyclone is capable of achieving very good separations down to 200 mesh, with cleaning occurring down to as fine as 400 mesh.

The yields that were achieved with coal 1 were much larger than the theoretical yield . predicted from the washability analysis (refer to Figures 2-5). Table 11 compares the actual yield that was achieved at a certain clean-coal ash to the theoretical yield that was predicted for the same ash content. The actual yields are over twice that predicted from the analysis of the asreceived coal. It is clearly impossible to achieve a yield greater than that predicted by the washability analysis of the feed. Table 12 offers an explanation these discrepancies. Sample 1 represents the feed sample taken immediately prior to testing the various cyclone operating conditions. At that point, the feed had been circulated in the sump for 30-40 minutes prior to starting product sampling. Sample 2 represents the feed sample taken immediately after the cyclone tests were completed. At that point, the feed had been either passed through the cyclone or circulated through the sump while changes were made to cyclone geometry. Approximately one hour elapsed between taking sample 1 and sample 2 . 
Table 12 shows that the size distribution of the as-received material was much coarser than the other samples. The amount of -400-mesh material in the feed doubled, with some liberation occurring. This may be attributed to grinding of the coal during circulation in the test circuit. It can also be seen that the size distributions of samples 1 and 2 were similar, indicating that the majority of the grinding occurred in the first 30 minutes of circulation.

Because the piping and the pump impeller openings in the test circuit were relatively small, more grinding may have occurred in the test circuit than would be expected in a processing plant. However, the grinding and liberation of mineral matter from the coal due to slurry travel through the plant could actually enhance plant performance through increased yields. At the same time, the increase in fines could lead to other problems associated with plant stability. Size degradation could be especially problematic when processing refuse material, because refuse material usually contains large amounts of flat, shaley particles. These particles are more prone to size degradation because of their angular nature.

Figure 19 shows the partition (fractional recovery) curves for the $+100,100 \times 200$, and $200 \times 400$-mesh size fractions for coal 2 at 1.45 medium relative density, before and after exposure to ultrasonics. As expected, in both cases, the relative density of separation (dp) increased with decreasing particle size. The corresponding probable errors also increased but were still very low, with a value of 0.21 for the $200 \times 400$-mesh fraction. Interestingly, both the $\mathrm{dp}$ and Ep values increased after ultrasonic treatment. Because the feed for these tests was not deslimed and contained over $63 \%-400$-mesh material, it is likely that the ultrasonics had "scrubbed" the clays from the coal surface. This would lead to an increase in the apparent viscosity of the medium, resulting in a worsening of the separation after treatment. As such, desliming after ultrasonic treatment should result in improved size classification, because 
additional "liberated" slimes would be removed. However, no additional testing was conducted in this area.

\section{Task 5. Dense-Medium Recovery Testing}

The testing in this task was carried out using a wet-drum magnetic separator (WDMS) to recover the magnetite from the dense-medium cyclone products. However, initial testing using coal/magnetite mixtures was conducted to establish the baseline operating conditions for the subsequent dense-medium recovery tests.

\section{Test Circuit}

The wet-drum magnetic separator test circuit consisted of a variable-speed progressive cavity pump, 57-L (15-gal) stainless steel sump, variable-speed mixer, flow meter, and ultrasonic test unit. A 304.8-mm (12-in.) diameter x 152.4-mm (6-in.) wide Eriez wet-drum magnetic separator (Model L-8) was used for all tests (Figure 20). A stand was fabricated for the WDMS, and a discharge ball valve was added to the unit to control the flow of non-magnetic material. A Zenith (Model T130-2) 5-L (1.3-gal) ultrasonic bath was used to treat the slurry prior to separation. The bath was equipped with a discharge valve, which allowed the slurry to exit through the bottom of the device (Figure 21). The test loop was designed in closed circuit such that several circulation options could be employed. In one case, the slurry could be recirculated into the sump or directed to the WDMS. Another option allowed circulation through the ultrasonic unit and back into the sump or into the WDMS. 


\section{Test Procedures}

Dense-medium recovery testing occurred in three parts. The first set of tests was performed to establish baseline operating conditions involving dense-medium only tests and coal/dense-medium tests, both without ultrasonic treatment. The second set of tests was performed to evaluate the effects of feed characteristics on the performance of the WDMS using simulated dense-medium cyclone products, with and without ultrasonic treatment. The third set of tests involved dense-medium recovery of the actual cyclone products, with and without ultrasonic treatment.

Baseline Tests. Baseline testing was performed to develop the test procedures and determine the optimum test conditions for the WDMS. Several series of tests were conducted using only magnetite, and several series were conducted using dense-medium and coal. The test coal was prepared by crushing the $1 \frac{1}{2} " \times 30$-mesh material from coal 1 . The material was stage crushed using a jaw crusher, a roll crusher, and a hammermill. After each stage of crushing, the material was screened at 20 mesh with a Kason vibrating screen. All -20-mesh material was combined and used for WDMS testing.

Magnetite only tests were performed at 10 and $15 \%$ feed solids by weight. Tests that used coal and magnetite were performed under the following conditions: E-grade magnetite; -20-mesh coal; slurry feed rate $=18.9 \mathrm{Lpm}(5 \mathrm{gpm}) ;$ magnetite-to-coal ratio $(\mathrm{M} / \mathrm{C})=0.33,1.63$ (by weight); feed solids concentration $=10,15,20 \%$ solids (by weight). In all cases, the WDMS was operated with a co-current rotation at a magnet setting of 77 volts. $\mathrm{M} / \mathrm{C}$ ratios were selected to simulate the $\mathrm{M} / \mathrm{C}$ ratio obtained from cyclone overflow and underflow streams in previous cyclone tests. For a fixed solids concentration, the $\mathrm{M} / \mathrm{C}$ ratio was obtained by changing the 
proportion of coal and magnetite added. Sufficient solids were used to create approximately $22.7 \mathrm{~L}$ ( 6 gal) of slurry, which allowed for two 20 to 30 second passes through the WDMS. Figure 22 shows the test circuit for the baseline tests.

Feed Characteristics Testing. Tests were conducted to determine the effects of feed characteristics on the performance of the WDMS using simulated dense-medium cyclone products. The simulated cyclone products were created in the same manner as the slurries used for the baseline testing by combining E-grade magnetite and crushed coal in the proportions needed to achieve the desired $\mathrm{M} / \mathrm{C}$ ratio. The tests were conducted at solids concentrations of 10 , 15 and $20 \%$ (by weight) for magnetite-to-coal (M/C) ratios of $0.33,1.0$, and 6.0. An additional test was conducted at a solids concentration of $30 \%$ and $\mathrm{M} / \mathrm{C}$ ratio of 6.0 . For all tests, the slurry was fed to the WDMS at a volumetric feed rate of $15.1 \mathrm{Lpm}(4 \mathrm{gpm})$.

Each solids concentration and $\mathrm{M} / \mathrm{C}$ ratio was tested with and without ultrasonic treatment. The ultrasonic energy was applied by passing the slurry through the ultrasonic bath prior to feeding the WDMS. Figure 23 shows this test circuit, including the ultrasonic unit. The products from the WDMS were collected and analyzed for magnetic content.

Dense-Medium Recovery Tests. Testing of the actual dense-medium cyclone products was conducted using the baseline results as a guide. Because of the high solids concentrations of the cyclone products, dilution to $\sim 15 \%$ solids (by weight) was required prior to passing the material through the WDMS. First, the entire cyclone product slurry sample of approximately $19 \mathrm{~L}$ (5 gal) was placed into the sump along with dilution water. The slurry was allowed to circulate for approximately five minutes after which several gallons of the slurry were collected. Slurry 
remaining in the sump was drained and saved. The collected slurry was put back into the sump and mixed with enough water to bring the slurry to a solids concentration of $15 \%$. This diluted slurry was used to feed the WDMS at a rate of $15.1 \mathrm{Lpm}$ (4 gpm).

After dilution, each feed sample was tested under three different conditions. Tests one and two were conducted without and with ultrasonic treatment of the feed. In both cases, the feed slurry was passed through the ultrasonic bath and then to the WDMS. A feed rate of 15.1 Lpm ( $4 \mathrm{gpm})$ gave a retention time of about 2 seconds in the ultrasonic unit. For the third test, the slurry remaining in the sump was treated with ultrasonics and then fed back into the sump. After all the slurry was treated, it was circulated through the sump for approximately 2 minutes more and then was fed to the WDMS with no further treatment. For all tests, the entire WDMS overflow (magnetics) and underflow (non-magnetics) streams were collected.

Dense-medium cyclone products that were treated with ultrasonics prior to entering the dense-medium cyclone were also tested in the WDMS. Samples of the 1.55 medium relative density dense-medium cyclone products (overflow and underflow) were used as feed for the WDMS. These samples were treated with ultrasonics prior to being fed to the cyclone. As was done with the other cyclone products, these samples were also diluted to $15 \%$ solids by weight. The diluted slurry was fed to the WDMS at a feed rate of $15.1 \mathrm{Lpm}$ (4 gpm).

Both of the cyclone products were tested under two different conditions. First, the slurry was fed through the ultrasonic unit (with the unit off) and then to the WDMS. For the second condition, the slurry was passed through the ultrasonic unit (with the unit on) prior to feeding the WDMS. Samples of the WDMS products were collected and analyzed as in the previous cyclone product testing. 


\section{Sample Analysis}

The WDMS products were weighed, dried, and weighed again to determine solids concentrations and the product yields. Representative samples of the dried products were obtained and then analyzed for percentage of magnetics using a Davis tube magnetic separator. These tests were run in duplicate for each product sample. With the results from the Davis tube and the product yields, the recovery of magnetic material was calculated for each test by

$$
\mathrm{R}_{\mathrm{M}}=\frac{\mathrm{Oo}}{\mathrm{Oo}+\mathrm{Uu}}
$$

where $\mathrm{O}$ and $\mathrm{U}$ are the mass flow rates of the overflow (magnetic) and underflow (non-magnetic) streams; o and $u$ are the grades (\% magnetics) of the overflow and underflow streams as determined by the Davis tube.

For selected tests, representative samples from the WDMS underflow streams were obtained for subsequent size and ash analyses. The samples were wet screened at 400 mesh. The +400-mesh material was dried and dry screened in a Ro-Tap sieve shaker at 30,50,100,200, and

400 mesh. Representative samples of the combined wet/dry screened -400-mesh nonmagnetic material were wet screened at 500 mesh. An ash analysis was then performed on each size fraction.

Also, for several tests, samples of magnetic material from the overflow and underflow streams were obtained after separation in the Davis tube. The size distribution of each sample was then determined using the Microtrac particle size analyzer. 


\section{Test Results}

Baseline Tests. Results from the baseline testing can be found in Table 13. Tests 1 and 2 were performed with magnetite only for solids concentrations of 10 and $15 \%$ solids by weight. The purities (\% magnetics) of the magnetite concentrates (WDMS overflow) for these tests were greater than that of the feed magnetite, which had a purity of $96.4 \%$. This indicates that the wet drum had rejected additional nonmagnetic material. Magnetite recoveries for these tests were generally greater than $99 \%$ in nearly all cases.

Tests 3 through 8 were performed with coal-magnetite slurries. For these tests, the recovery of magnetic material was over $99 \%$ in all cases. The purity of the magnetite concentrate in these tests ranged from 93 to $96 \%$. Recoveries and purities for the coal-magnetite slurry tests can be seen in Figures 24 and 25. As can be seen, the highest recoveries and purities were obtained at $15 \%$ solids.

In order to validate the reproducibility of the test procedures, three separate tests were conducted using the coal-magnetite system at a $\mathrm{M} / \mathrm{C}$ ratio of $0.33: 1$. For these tests, the magnetite recoveries were $99.8,99.4$, and $99.6 \%$, which gave a mean of $99.6 \%$ and a standard deviation of $0.2 \%$. The corresponding magnetics contents were $96.6,96.6$, and $96.3 \%$, which gave a mean of $96.5 \%$ and a standard deviation of $0.2 \%$. These results indicate that the test procedures were very reproducible.

Feed Characteristics Tests. For a fixed solids concentration, it was found that the purity of the magnetic concentrate was a minimum for a $M / C$ ratio of one, and a maximum at a $M / C$ ratio of 6 (Figure 26). Treating the slurry with ultrasonics improved the purity of the concentrate for tests with $\mathrm{M} / \mathrm{C}$ ratios of 1.0 or greater for all solids concentration. An increase in the purity was also 
seen in the tests performed with a solids concentration of $20 \%$ at a $\mathrm{M} / \mathrm{C}$ ratio of 0.33 . However, at $10 \%$ solids, there was a slight decrease in purity for the $0.33 \mathrm{M} / \mathrm{C}$ test after treating the slurry with ultrasonics.

The purity of the WDMS concentrate decreased as the solids concentration of the feed slurry increased. For example, for a $\mathrm{M} / \mathrm{C}$ ratio of 6.0 , the purity of the magnetic concentrate decreased from $97.3 \%$ to $96.8 \%$ to $95.0 \%$ to $93.4 \%$ as the solids concentration increased from 10 to $30 \%$, by weight, prior to ultrasonic treatment (Table 14).

In all cases, the recovery of the magnetic material was again above $99 \%$. No specific trends were noted in the recoveries, which varied from 99.3 to $99.8 \%$. The purities and recoveries of the magnetic concentrates for all tests from this series are given in Table 14.

Magnetic Material Size Analyses -- Size analyses of the magnetic fractions for tests at solids concentrations of $10,15,20$, and $30 \%$ at a $\mathrm{M} / \mathrm{C}$ ratio of 6.0 were also performed. After separation in the Davis tube, size distributions of the magnetic fractions from the WDMS overflow and underflow streams were determined using the Microtrac. Initially, only the ultrasonic probe was used to disperse the samples prior to size analysis. For example, consider the results for a feed solids concentration of $20 \%$ as shown in Table 15 . It can be seen that the magnetic material in both the WDMS overflow and underflow streams was coarser than the feed magnetite. Based on these results, it was determined that the magnetic flocs were not being dispersed properly using only ultrasonic energy.

The size analyses were repeated using a demagnetizing coil to demagnetize the samples prior to dispersing it with the ultrasonic probe. As can be seen in Table 15, the size distributions of the magnetic material for both the overflow and underflow streams were now similar to the 
feed magnetite. This indicated that the WDMS was not preferentially losing ultrafine magnetite (e.g., $-5 \mu \mathrm{m}$ ) and that the lost material was comparable in size to that of the feed material. The results also indicate that ultrasonic treatment prior to feeding the WDMS did not change the size distributions of the magnetic material in either product stream. This demonstrates that ultrasonic treatment can increase product purity without preferentially losing ultrafine magnetite.

Dense-Medium Recovery Tests. Dense-medium recovery tests were carried out using the cyclone products for both coal samples.

Coal 1 -- The results for the WDMS tests (tests 19-24) using products from the cyclone separations of coal 1 are given in Table 16. It can be seen that ultrasonic treatment primarily affected the purity of the WDMS overflow material. Treating the slurry immediately before feeding it to the WDMS increased the product purity by $2-5 \%$ compared to no treatment. The effect on magnetic recovery was less clear. After ultrasonic treatment, magnetic recovery increased slightly in two cases and decreased slightly in another. When the slurry was allowed to mix after ultrasonic treatment, the effects were still apparent but reduced. This demonstrates that the effects of ultrasonic treatment remain with the slurry several minutes after treatment.

Figures 27 and 28 show the recoveries and purities for tests using coal 1 collected from the cyclone underflow. Because of the high $\mathrm{M} / \mathrm{C}$ ratio of this stream, magnetite recovery was $99.8 \%$ or higher in all tests. The recovered magnetic fraction had a purity ( $\%$ magnetics) of approximately $97 \%$ or higher in all instances.

The WDMS results for the cyclone overflow material are given in Figures 29 and 30. Magnetite recovery increased in all but one case after being treated with ultrasonics. Recoveries 
ranged from 96 to $99 \%$ for these tests. The purity (\% magnetics) increased every time after being treated with ultrasonics, ranging from 83 to almost $90 \%$.

Coal 2 -- Tests 25 through 30 were performed on material collected from cyclone testing performed with coal 2. Results from these tests can be found in Table 17. Figures 31 and 32 show the recovery and purity obtained from the tests performed with the cyclone underflow products. Magnetite recovery was $99.9 \%$ in all tests. The purity of the magnetic fraction ranged from 93 to almost $98 \%$.

The recovery and purity of the magnetite concentrate when the cyclone overflow material was used for the WDMS feed can be seen in Figures 33 and 34. When the cyclone overflow was used to feed the WDMS, magnetic recoveries varied from 97 to $99 \%$. The purity of the magnetic fraction varied from 87 to almost $91 \%$. Ultrasonic treatment had little effect on this coal except for slight improvements in the separation of the 1.35 medium relative density material.

Treating the slurry prior to entering the cyclone appears to benefit the purity of the magnetite recovered from the cyclone underflow stream. The purity of the magnetite concentrate when not treated prior to feeding the WDMS was $97.7 \%$ compared to $97.4 \%$ when the slurry was not treated at the cyclone. When the slurry was treated with ultrasonics at the cyclone and prior to the WDMS, the purity of the concentrate was $97.7 \%$. The corresponding test condition for slurry not treated at the cyclone had a purity of $97.1 \%$. Recovery of the magnetite was not affected by the application of ultrasonics at the cyclone. The recovery of magnetite was above $99.8 \%$ in all cases.

The cyclone overflow stream was affected in a different manner when treating the slurry at the cyclone. Purities of the samples from the cyclone overflow decreased when treated at the 
cyclone with ultrasonics. With no further treatment of ultrasonics at the WDMS, the purity of the magnetic concentrate decreased from $90.8 \%$ to $89.6 \%$. Treating the slurry with ultrasonics before feeding the WDMS gave a higher purity $(90.0 \%)$ as opposed to not treating the slurry again. This value was similar to the $90.1 \%$ purity that was obtained when treating the slurry prior to the WDMS, which did not receive treatment at the cyclone. There was an increase in the recovery of magnetics when treating the slurry before entering the cyclone. Table 17 also shows the purities and recoveries for tests conducted with slurry that was treated with ultrasonics at the cyclone.

Non-Magnetic Product Size/Ash Analyses -- Selected WDMS underflow (non-magnetic) streams were analyzed further to determine the size and ash distributions. Cyclone overflow and underflow products for both coals were analyzed, and the results can be found in Table 18. For coal 1, the clean coal had a composite ash content of $27.0 \%$. However, after screening the WDMS underflow at 500 mesh, as would be done in a desliming operation, the clean coal ash content ( +500 mesh) was reduced to $6.9 \%$. The ash content of the refuse material (cyclone underflow) had an ash content of $56.2 \%$. For coal 2 , the overall ash content was $36.4 \%$. After screening at 500 mesh, the composite ash content was again reduced to $6.9 \%$. The ash content of the refuse material was $63.3 \%$. These results demonstrate the effectiveness of dense-medium cycloning for cleaning down to 500 mesh.

Regression Analysis. Using the data obtained from the WDMS tests for both coal 1 and coal 2, multiple regressions were performed to develop equations for the purity of the magnetic concentrate and magnetic recovery as a function of operating conditions [Franko, 2001]. 
Stepwise regressions were also performed using Minitab ${ }^{\circledast}$ to evaluate both first order and second order effects, including variable interactions. Variables were added based on an F-test performed at a significance level of 0.05 .

Considering only single order effects, the purity of the WDMS concentrate, $P$

(\% magnetics), can be estimated by

$$
\begin{aligned}
P= & 117.762+3.359 \mathrm{M}-37.671 \mathrm{~S}-0.492 \mathrm{X}_{50}-1.687 \mathrm{Y}_{5.5} \\
& -1.447 \mathrm{~V}+0.766 \mathrm{U}+5.776 \mathrm{C}
\end{aligned}
$$

where $\mathrm{M}$ is the weight fraction of the magnetic material in the feed; $\mathrm{S}$ is the weight fraction of feed solids; $X_{50}$ is the $50 \%$ passing size (in $\mu \mathrm{m}$ ) of the feed magnetite; $Y_{5.5}$ is the percent of magnetite passing $5.5 \mu \mathrm{m} ; \mathrm{V}$ is the volumetric feed rate in GPM; U is an indicator of ultrasonic treatment $(\mathrm{U}=0$ for no treatment, $\mathrm{U}=1$ when treated); and $\mathrm{C}$ identifies if the coal was not crushed $(\mathrm{C}=0)$ or crushed $(\mathrm{C}=1)$ prior to feeding the WDMS. The uncrushed material contained more natural fine material (of higher ash content) than the crushed material, which was obtained by crushing the +30 -mesh material from coal 1 . However, it was not possible to isolate the effects of these variables beyond what was done for this analysis.

The magnetic recovery can be estimated by

$$
\begin{aligned}
R_{M}= & 95.065+0.373 \mathrm{M}+1.599 \mathrm{~S}+0.028 \mathrm{X}_{50}-0.357 \mathrm{Y}_{5.5} \\
& +1.173 \mathrm{~V}+0.147 \mathrm{U}+1.356 \mathrm{C}
\end{aligned}
$$

The $r^{2}$ value for the estimated concentrate purity was 0.824 , and $r^{2}=0.893$ for the estimated magnetic recovery. 
Using stepwise regression and considering second order effects also, the purity of the magnetic concentrate can be estimated by

$$
\mathrm{P}=104.53+0.378 \mathrm{Y}_{5.5} \mathrm{~V}+1.36 \mathrm{VC}-2.53 \mathrm{SX}_{50}+0.186 \mathrm{MX}_{50}
$$

Likewise, the recovery of magnetic material can be estimated by

$$
\mathrm{R}_{\mathrm{M}}=95.07+0.0517 \mathrm{X}_{50} \mathrm{~V}+0.086 \mathrm{VC}-0.0652 \mathrm{Y}_{5.5}^{2}+0.63 \mathrm{Y}_{5.5}
$$

Figure 35 shows a good fit of the estimated and actual purities $\left(r^{2}=0.863\right)$, while Figure 36 shows that the estimated recoveries closely match the actual values $\left(r^{2}=0.925\right)$.

\section{Task 6. Economic Analysis}

The purpose of this evaluation was to determine the economic benefits of applying the combined ultrasound/fine coal dense-medium cycloning and recovery technology as a replacement for water-based fine coal cleaning circuitry in conventional coal cleaning plants and in pond fine recovery applications and to discuss the application of the ultrasound/fine-coal dense medium cycloning and recovery technology in the preparation of low-ash coal as feedstocks for premium carbon products.

We approached this economic analysis with the understanding that treatment with ultrasound provided the following results:

1. Enhanced the detachment of fine clay particles.

2. Improved dense-medium cyclone yield in certain size fractions.

3. Permitted dense-medium cycloning down to 400 mesh.

4. Improved magnetite grade and recovery. 
Application of Ultrasound/Fine Dense-Medium Cycloning for Fine Coal Recovery and Pond Recovery Plants

Applying dense-medium cycloning to fine coal recovery can improve yields of clean coal dramatically compared to yields from water-based separations in water-only cyclones or spirals achieving the same clean coal ash contents. This can be evaluated using the washability data from coal 1 with simulations of dense-medium cycloning and spiral concentration. The results of such a simulation are given in Figure 37. The washability used in each simulation was that for the $30 \times 200$ mesh fractions, a deslimed feed. The lowest ash achievable for the spiral concentrator was about 15.5 percent, operating at its lowest separating relative density of 1.5 . The resulting yield was about 31 percent. The yield of clean coal at 15.5 percent ash from the dense-medium cyclone is expected to be about 43 percent or 12 percentage points higher. The dense-medium cyclone is also capable of operating at lower relative densities. In this case, with the Yellow Run refuse, the lowest ash of 5.4 percent was achieved at a separating relative density of 1.25. The yield, of course, was extremely low at about 4 percent. Such dramatic increases in yield may not be accomplished with a raw coal feedstock; though for some raw coals, the capability of producing ultra-low ash coal would exist at these lower separating densities as discussed below. Similar benefits are shown for reducing clean-coal sulfur content.

Additional increases in yield appear to be one potential benefit of the use of ultrasound in conjunction with fine dense-medium cycloning. To further evaluate these benefits we can look at two examples: 1) fine raw coal yield increase, and 2) treating refuse at Yellow Run. For the raw coal case, we simply look at an increase in fine coal yield of one percent to evaluate the potential for the use of ultrasound alone (that is, not including the benefit for switching to fine densemedium cycloning as well). While not evaluated here, the ultrasound technology may hold the 
potential for increasing yield in water-based technology. There is evidence (PrepTech in-house laboratory testwork) that it can greatly improve froth flotation yield in some cases.

Raw Fine Coal Yield Increase. In U.S. bituminous coal cleaning plants, up to about 20 percent of the coal can be considered as "fines", coal less than one millimeter. This varies based on the grindability of the particular coal being cleaned. Using this estimate, up to $80,000,000$ tons of coal fines require treatment annually, assuming that about $400,000,000$ tons of coal are cleaned each year in the United States. A one percent improvement in yield means that 800,000 additional tons can be recovered each year for sale at a total value of $\$ 20,000,000$, assuming a selling price of $\$ 25.00$. Disposal costs are also avoided.

For a cleaning plant processing 1000 tons per hour, a one percent increase in yield for the fine coal (approximately 20 percent of the feed) equates to an overall 0.2 percent plant yield increase. This equates to an additional 2 tons per hour of clean coal or an additional $\$ 50 /$ hour of revenue. Over the course of a 24 -hour operating day, this extra revenue equals $\$ 1,200$; and over the course of a 5-day operating week, this equates to $\$ 6,000$. If the ultrasound installation required $\$ 100,000$ in capital, it would pay for itself in about 16.7 weeks. Remember this does not include any increase in yield expected by switching from water-based technology to fine dense-medium cycloning. Capital and operating costs for dense medium are also not included. Operating costs for the ultrasound technology include electricity use, which is minimal. [Note: At this point, the technology owners may wish to lease the equipment for a tolling fee, which would be equated to a portion of the increased revenue.] 
Treating Refuse at Yellow Run. Most slurry ponds contain predominately -1-mm material, and the most common method of recovery utilizes some combination of water-only cyclones, classifying cyclones, spirals, and froth flotation. Slimes present a major problem in these facilities, and the use of ultrasound to detach clay particles may significantly improve clean coal quality.

For the Yellow Run application, the improvement in yield by switching to dense-medium cycloning can be up to 11 percentage points, assuming that a 15.5 percent ash content in this fraction is acceptable. Knowing that the -30 -mesh material is 16 percent of the feed to the plant and the plant feed capacity is $150 \mathrm{tph}$, the increase in fine coal yield equates to approximately 2 tph of additional clean coal. At $\$ 25 /$ ton, this gives an additional $\$ 50 /$ hour of revenue. For a 5-day/wk, 24-hour/day operation, this gives additional revenue of $\$ 6,000 /$ week. In this case, we must consider the capital cost for the fine dense-medium cyclone installation in addition to the ultrasound application. The new circuit would consist of desliming cyclones, dense-medium cycloning treating the desliming cyclone underflow, and magnetic separator(s) separating the clean coal and refuse products from the recovered magnetite streams.

The capital outlay would include purchase of dense-medium cyclones and a magnetic separator (finer magnetite will likely need to be used in this circuit and the tailings will be the recovered clean coal and fine coal) and piping changes in the facility. Desliming cyclones are already included in the plant and would be used in this new circuit prior to the dense-medium cyclones. If we assume that this new circuit could be installed for $\$ 500,000$, in the simplest case, it would require about 1.6 years to pay for this installation. The owner would need to determine if this was acceptable using a more sophisticated analysis.

However, the real application of the ultrasound in combination with the fine coal dense- 
medium cyclone technology may lie in its ability to be operated efficiently at much lower separating relative densities than the water-based technologies commonly used to upgrade these fine particles. This will be discussed below.

\section{Economic Analysis for Premium Carbon Applications}

The major use for ultrasound and fine coal dense medium circuitry in coal processing may be in the production of low-ash coal (less than 1 or $2 \%$ ) as a feedstock for premium carbon applications. Other major applications would be for the recovery of precious elements, minerals, and gems, where small improvements in grade and recovery mean large improvements in the economics.

Investigators are evaluating the need to produce ultra-low-ash coal to be used as a feedstock for the production of premium carbon products. For several premium carbon applications, low ash content (less than 1 to $2 \%$ ) is critical. Over the next several years the demand for a low-cost feedstock will dramatically increase. In other work by the authors, it was found that the greatest potential is in the continued increase for activated carbon $(250,000$ tpy market), for carbon fibers (15,000 tpy market), for anodes for aluminum smelting ( 7 million tpy market), and for carbon black applications (8 million tpy market). It was shown that fine coal will have the greatest application in these areas. In applications using coal tar pitch (anodes and carbon black), fine coal can be readily converted into this fraction. Targeting fine-coal streams from cleaning plants makes the most sense, thereby avoiding crushing and grinding costs.

Dense-medium cycloning offers the only solution for producing low density separations, and therefore low-ash clean coal products, for the $1 \times 0.1-\mathrm{mm}$ size fraction. Column froth flotation holds some promise for producing ultra-low-ash coal for finer sizes. 
The ultra-low-ash coal may be produced utilizing the ultrasound/dense medium technology in the following manner:

1. The feedstock can be a -16-mesh, a -30-mesh or a -100-mesh clean coal produced by conventional methods or a -16-mesh, a -30-mesh or a -100-mesh raw coal.

2. The feedstock would be deslimed at 200 or 400 mesh in a classifying cyclone. (Applying ultrasound at this step could be even more critical to the operation of the circuit than applying it directly before the dense-medium cyclone.)

3. The +400-mesh material would be processed in a dense-medium cyclone at low separating densities to produce an ultra-low-ash product.

4. The clean coal and refuse streams would be treated in magnetic separators to separate the coal and refuse from the recovered magnetite stream.

This type of technology could be added to various coal processing facilities in the United States where the feedstock is capable of producing ultra-low-ash coal.

\section{Task 7. Technology Transfer}

Technology transfer activities have occurred throughout the project. Two Industrial Advisory Board meetings were held at Penn State during Phase I. An update on the project was also presented at a meeting of EPRI's Upgraded Coal Interest Group, which was held at the National Energy Technology Laboratory in Pittsburgh in January 2000. A poster display (see Figure 38) was presented at the PrepTech, Inc. booth at CoalPrep 2000. From this project, two Master's theses were published [Turek, 2000; Franko, 2001]. Likewise, wet-drum magnetic separator results was presented at the SME Annual Meeting in Denver in February 2001 [Franko and Klima, 2001]. 


\section{SUMMARY AND CONCLUSIONS}

The Pennsylvania State University, its project team (Typlex, Inc., DAGER, Inc., and

PrepTech, Inc.), and advisory committee members have demonstrated the application of

ultrasonic energy during dense-medium cycloning and subsequent recovery of fine coal and coal refuse impoundment materials. The results will help to extend the range of conventional densemedium cycloning to sizes now typically cleaned in relatively inefficient water-only cyclone and spiral concentrator circuits.

Phase I was a laboratory investigation that was conducted in the Mineral Processing laboratory at The Pennsylvania State University. This study involved laboratory testing of densemedium cycloning and subsequent medium recovery, with and without ultrasonic treatment, along with fundamental dispersion testing.

Dense-medium cycloning was conducted with a 76.2-mm (3-in.) diameter cyclone under various conditions, including magnetite grade, medium relative density, inlet pressure, cyclone geometry, and feed coal. Dense-medium recovery testing was carried out with a 305-mm (12-in.) diameter x 152-mm (6-in.) wide wet-drum magnetic separator using the cyclone clean coal and refuse products as the feed material. Fundamental testing of dispersion/reagglomeration phenomena was conducted with coal/clay mixtures.

The dense-medium cyclone was capable of achieving separations down to approximately 400 mesh. For example, the ash content of the +400 -mesh material was reduced from over $37 \%$ to about $6 \%$ for coal 1 . For coal 2 , both the dp and Ep values increased after ultrasonic treatment. Because the feed for these tests was not deslimed and contained over $63 \%$ of -400 mesh, it is likely that the ultrasonics had "scrubbed" the clays from the coal surface. This likely led to an increase in the apparent viscosity of the medium, resulting in a worsening of the 
separation after treatment. As such, desliming after ultrasonic treatment should result in improved size classification, because additional "liberated" slimes would be removed. This has implications in the selection of circuitry and the location of the ultrasound unit. For example, if these clays are liberated to this extent using ultrasound, it may be best to apply ultrasonics prior to a desliming step in advance of dense-medium cycloning. Desliming may also lead to an improvement in the dense-medium recovery operation.

It was also found that ultrasonic treatment improved the purity of the magnetic fraction during wet-drum magnetic separation. The treatment was particularly beneficial for the cyclone overflow material. The fundamental testing indicated that agitation after ultrasonic treatment is necessary to disperse fine particles and to prevent reagglomeration. The application of ultrasound in conjunction with fine dense-medium cycloning may be economical under certain circumstances.

The results from this study have led to the following observations and conclusions:

1. Dense-medium cycloning can improve the grade/recovery relationship for fine coal down to 200 mesh and perhaps as fine as 400 mesh.

2. Greater control can be achieved at the cleaning plant, because separating densities are easily controlled and changed in dense-medium circuits. This will allow greater flexibility in processing feeds that fluctuate in size and quality -- such as impounded materials.

3. Improvements in magnetite purity for fine coal applications are possible.

4. Environmental benefits can be realized including reduced impoundment requirements and remediation of existing ponds.

5. The most appropriate circuitry for the fine-dense medium cyclone/ultrasound 
application may consist of applying the ultrasound to the fine coal feed to a desliming cyclone. The desliming cyclone underflow would be processed in dense-medium cyclones. The products from the dense-medium cyclones would then be separated from the magnetite to produce the coal and refuse streams. This would take advantage of any residual effects of the ultrasound on downstream processes. This would result in a fine dense-medium cyclone circuit much simpler than those proposed to date. This would also be a more economical circuit. 


\section{REFERENCES}

Angle, C. W., Donini, J.C., and Hamza, H.A., 1988, "The Effect of Ultrasonication on the Surface Properties, Ionic Composition and Electrophoretic Mobility of an Aqueous Coal Suspension," Colloids Surf., 30, 373.

Buttermore, W. H., Slomka, B. J., and Dawson, M. R., 1990, "The Sonic Enhancement of

Physical Coal Cleaning," Sixth Annual Coal Preparation, Utilization, and Environmental Control Contractor's Conference, August 6-9, U.S. Department of Energy.

Dawson, M.R., Buttermore, W.H., and Slomka, B. J., 1991, "The Effect of Sonic Energy on the Beneficiation of a High-Sulfur Coal," Processing and Utilization of High Sulfur Coals IV,

Eds. P.R. Dugan, D.R. Quigley, and Y.A. Attia, Elsevier Science Publishers B.V., Amsterdam, 185-193.

DOE/EIA, 1997, "Coal Industry Annual 1996," DOE/EIA-0584(96), 256 pp.

Franko, J., 2001, Performance of a Wet-Drum Magnetic Separator for Media Recovery from

Dense-Medium Cycloning of Fine Refuse Coal Aided by Ultrasonic Treatment, M.S.

Thesis, The Pennsylvania State University, 132 pp.

Franko, J., and Klima, M.S., 2001, “Application of Ultrasonics to Enhance Wet-Drum Magnetic Separator Performance," SME Annual Meeting, Denver, Preprint.01-36.

Kindig, J.K., 1992, "Self-Scrubbing Coal - An Integrated Approach to Clean Air," Coal Prep '92 Conference, 110-123.

Klima, M.S., Killmeyer, R.P., and Hucko, R.E., 1990, "Development of a Micronized-Magnetite Cycloning Process," 11th Int. Coal Preparation Congress, Tokyo, 145-149.

Mengelers, J., and Dogge, C., 1979, “A New Technique for the Treatment of 1-0 mm Fine Coal by Means of Dense Media Cyclones," 8th Int. Coal Preparation Cong., USSR, 105-111. 
Slomka, B.J., and Buttermore, W. H., 1991, "Sonically Enhanced Beneficiation of Illinois No. 6 Coal," Fuel Processing Technology, 29, 133-142.

Turek, M.L., 2000, The Effects of Ultrasonic Treatment on Dense-Medium Cycloning of Fine Coal Refuse, M.S. Thesis, The Pennsylvania State University, 159 pp.

Vujnovic, J.B., 1995, "Apparatus and Method for the Beneficiation of Ore and Coal with the Aid of Ultrasound," U.S. Patent No. 5,577,669. 


\section{BIBLIOGRAPHY}

Arnold, B.J., and Aplan, F.F., 1986a, "The Effect of Clay Slimes on Coal Flotation, Part I: The Nature of the Clay," International Journal of Mineral Processing, 17, 225-242.

Arnold, B.J., and Aplan, F.F., 1986b, "The Effect of Clay Slimes on Coal Flotation, Part II: The Role of Water Quality," International Journal of Mineral Processing, 17, 243-260.

Baumgartner, F.E., 1978, "Washing Raw Coal to Zero with Heavy Media Cyclones," Mining Congress Journal, October, 45-50.

Buttermore, W. H., and Slomka, B. J., 1991, "The Effect of Sonic Treatment on the Floatability of Oxidized Coal," International Journal of Mineral Processing, 32, 251-257.

Chedgy, D.G., Watters, L.A., and Higgins, S.T., 1986, "Heavy Media Cyclone Separations at Ultralow Specific Gravity," 10th Int. Coal Preparation Congress, Edmonton, 60-79.

Chung, H.S. and Hogg, R., 1985, "Stability Criteria for Fine-Particle Dispersions," Colloids and Surfaces, 15, 119-135.

Deurbrouck, A.W., 1974, "Washing Fine-Size Coal in a Dense-Medium Cyclone," USBM RI 7982, $6 \mathrm{pp}$.

Fourie, P.J., Van Der Walt, P.J., and Falcon, L.M. 1980, "The Beneficiation of Fine Coal by Dense-Medium Cyclone," J SAIMM, 80, 357-361.

Hogg, R., Healey, T.W., and Fuerstenau, D.W., 1966, "Mutual Coagulation of Colloidal Dispersions," Trans. Faraday Soc., 62, 1638-1651.

Hogg, R., 1992, "Agglomeration Models for Process Design and Control," Powder Techology, 69, 69-76.

Kempnich, R.J., van Barneveld, S., and Lusan, A., 1993, "Dense-Medium Cyclones on Fine Coal - The Australian Experience," $6^{\text {th }}$ Australian Coal Preparation Conf., Mackay, 272-288. 
King, R.P., and Juckes, A.H., 1984, "Cleaning of Fine Coals by Dense-Medium Hydrocyclone," Powder Technology, 40, 147-160.

Klima, M.S., and Cho, H., 1995, "Use of a Batch Hindered-Settling Model to Explain Variable Interactions in Dense-Medium Cyclone Separations", Coal Preparation, 15, 129-148.

Klima, M.S., and Killmeyer, R.P., 1992, "Baseline Performance Evaluation of MicronizedMagnetite Recovery Using Conventional Wet-Drum and High-Gradient Magnetic Separators," U.S. Dept. of Energy Topical Report DOE/PETC/TR-92/10, 39 pp.

Klima, M.S., and Killmeyer, R.P., 1996, "An Evaluation of a Laboratory Wet-Drum Magnetic Separator for Micronized-Magnetite Recovery," Coal Preparation, 16, 203-215.

Parfitt, G.D., 1973, Dispersion of Powders in Liquids, $2^{\text {nd }}$ Ed., Wiley, New York.

Skolnik, E., 1980, "Heavy Medium Cleaning of -28 Mesh Coal," Mining Engineering, 32, $1235-1237$. 

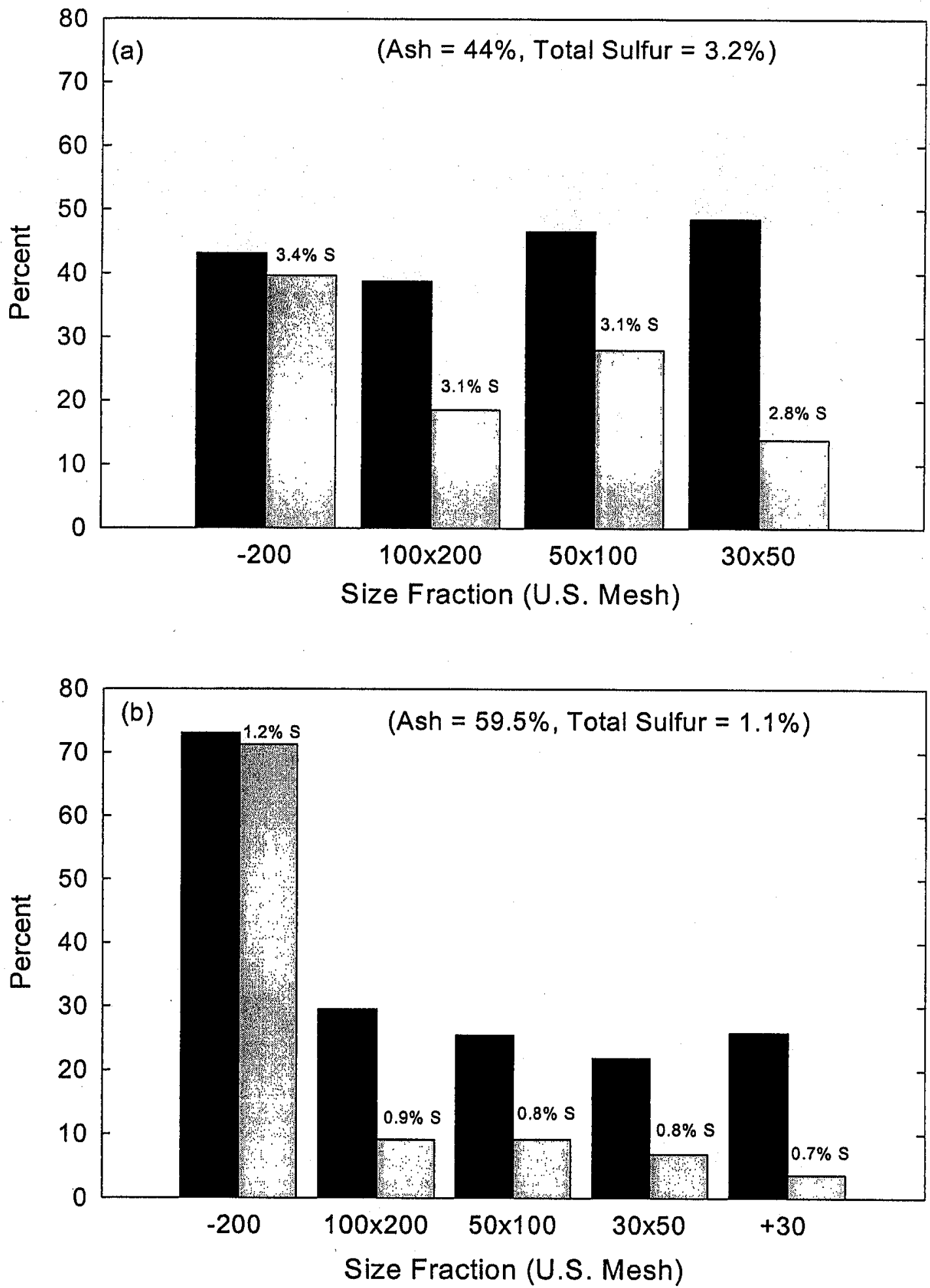

Ash Percent

Weight Percent

Figure 1. Size distributions and ash and sulfur contents: (a) Yellow Run plant feed; (b) water-only cyclone feed. 

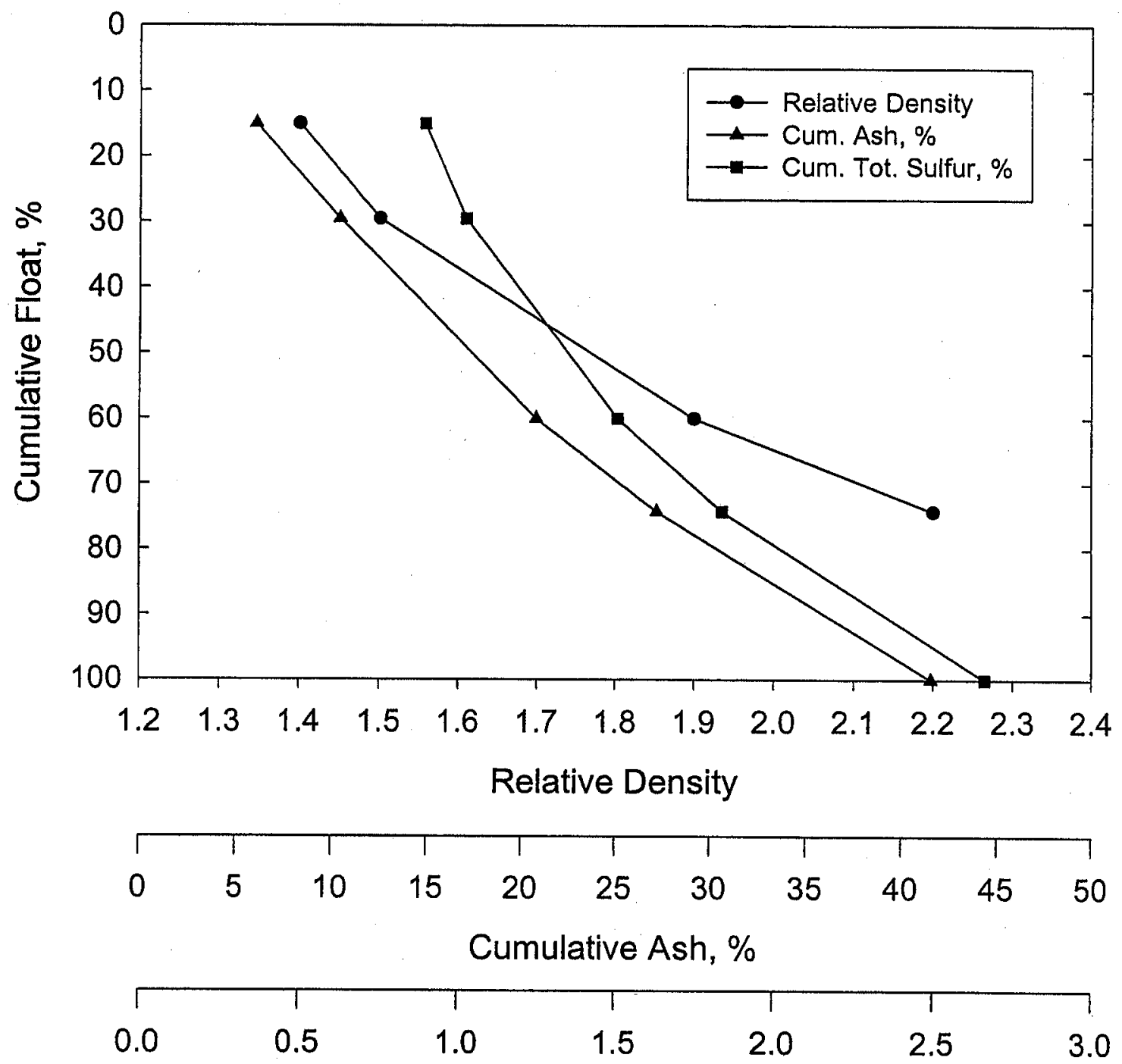

Cumulative Total Sulfur, \%

Figure 2. Washability analysis for 30x200 mesh size fraction of Yellow Run plant feed. 


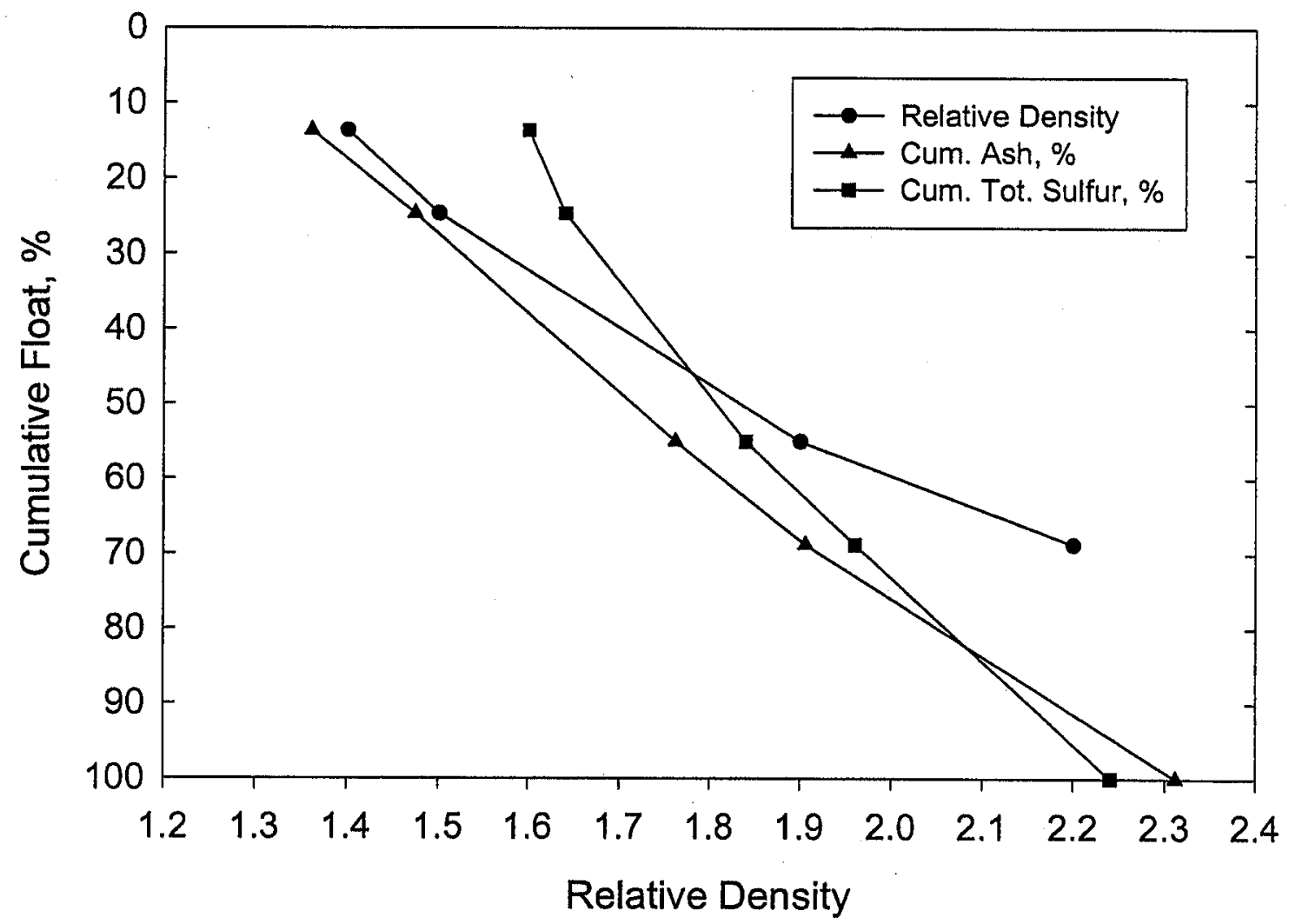

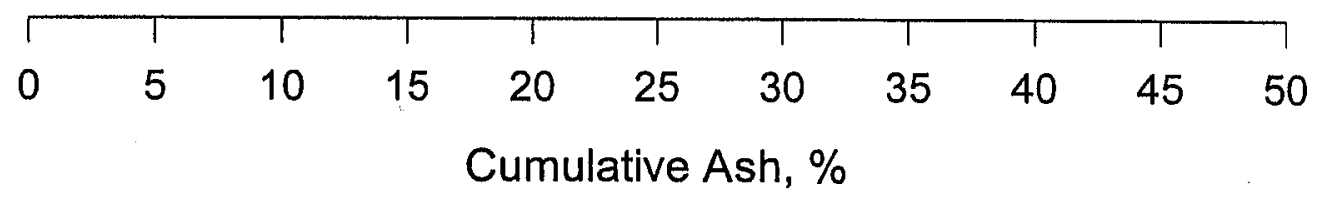

\begin{tabular}{llllllll}
\hline 0.0 & 0.5 & 1.0 & 1.5 & 2.0 & 2.5 & 3.0 \\
& & Cumulative & Total Sulfur, $\%$ & &
\end{tabular}

Figure 3. Washability analysis for $30 \times 50$ mesh size fraction of Yellow run plant feed. 


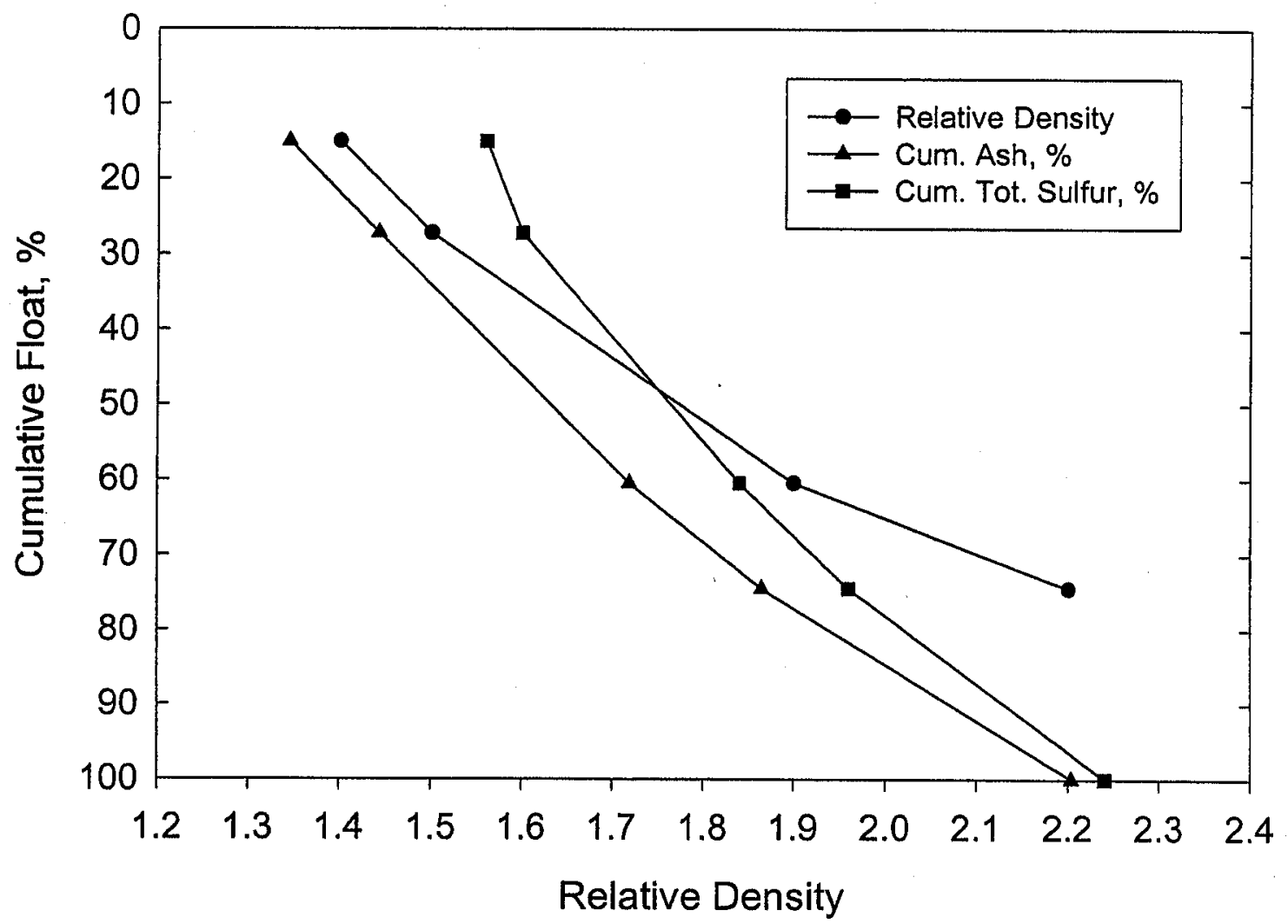

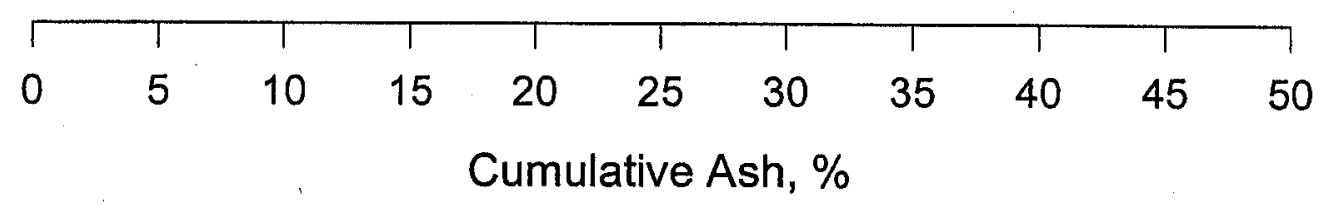

\begin{tabular}{llllllll}
\hline 0.0 & 0.5 & 1.0 & 1.5 & 2.0 & 2.5 & 3.0 \\
& & & Cumulative & Total Sulfur, $\%$ & &
\end{tabular}

Figure 4. Washability analysis for $50 \times 100$ mesh size fraction of Yellow run plant feed. 


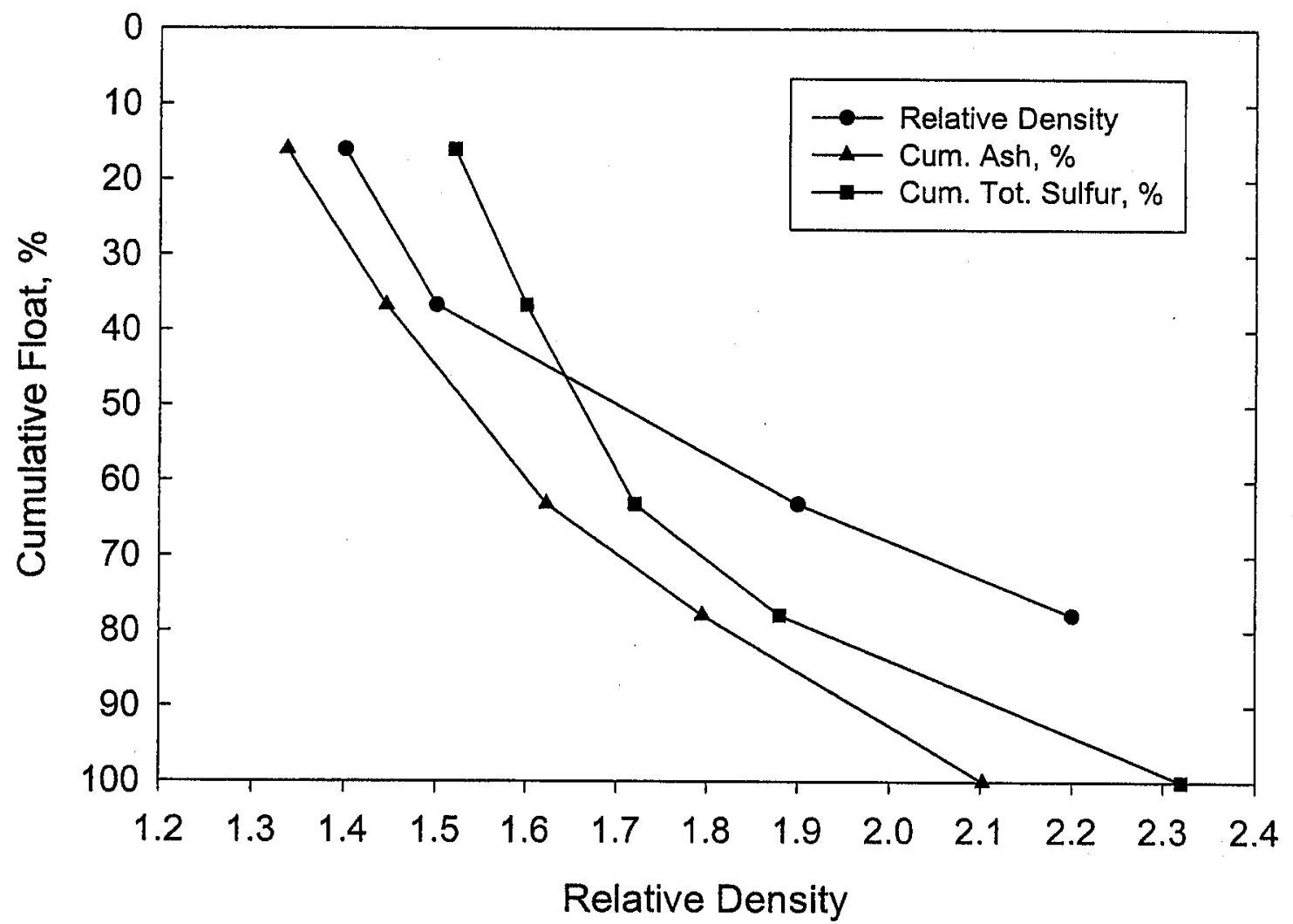

\begin{tabular}{|c|c|c|c|c|c|c|c|c|c|c|}
\hline$\Gamma$ & $T$ & $T$ & $T$ & $T$ & $T$ & 7 & $T$ & $T$ & $T$ & \\
\hline 0 & 5 & 10 & 15 & 20 & 25 & 30 & 35 & 40 & 45 & 50 \\
\hline
\end{tabular}

\begin{tabular}{cccccccc}
\hline 0.0 & 0.5 & 1.0 & 1.5 & 2.0 & 2.5 & 3.0 \\
& & & Cumulative & Total Sulfur, $\%$ & &
\end{tabular}

Figure 5. Washability analysis for 100x200 mesh size fraction of Yellow Run plant feed. 


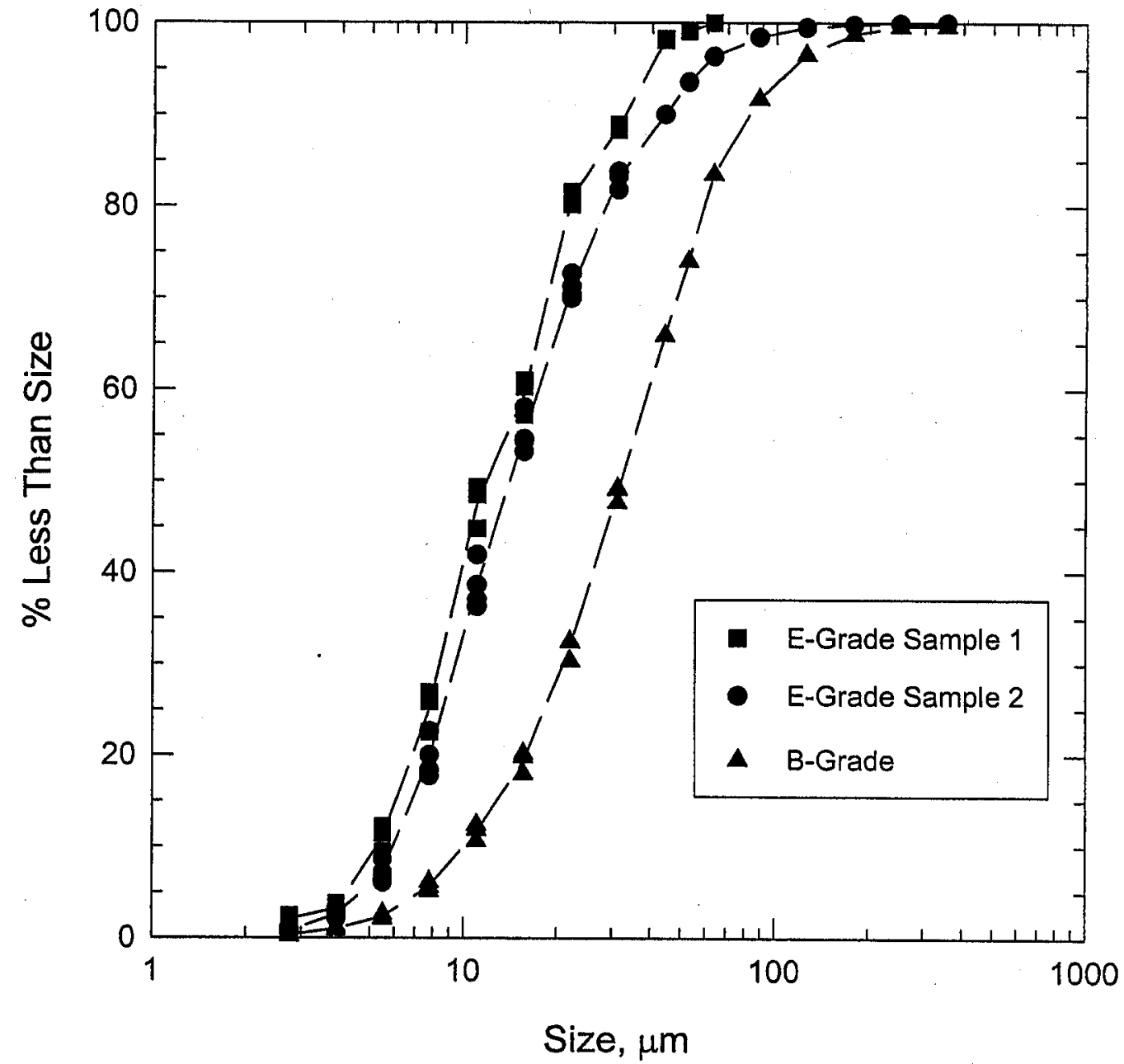

Figure 6. Size distributions for all three magnetite samples. 


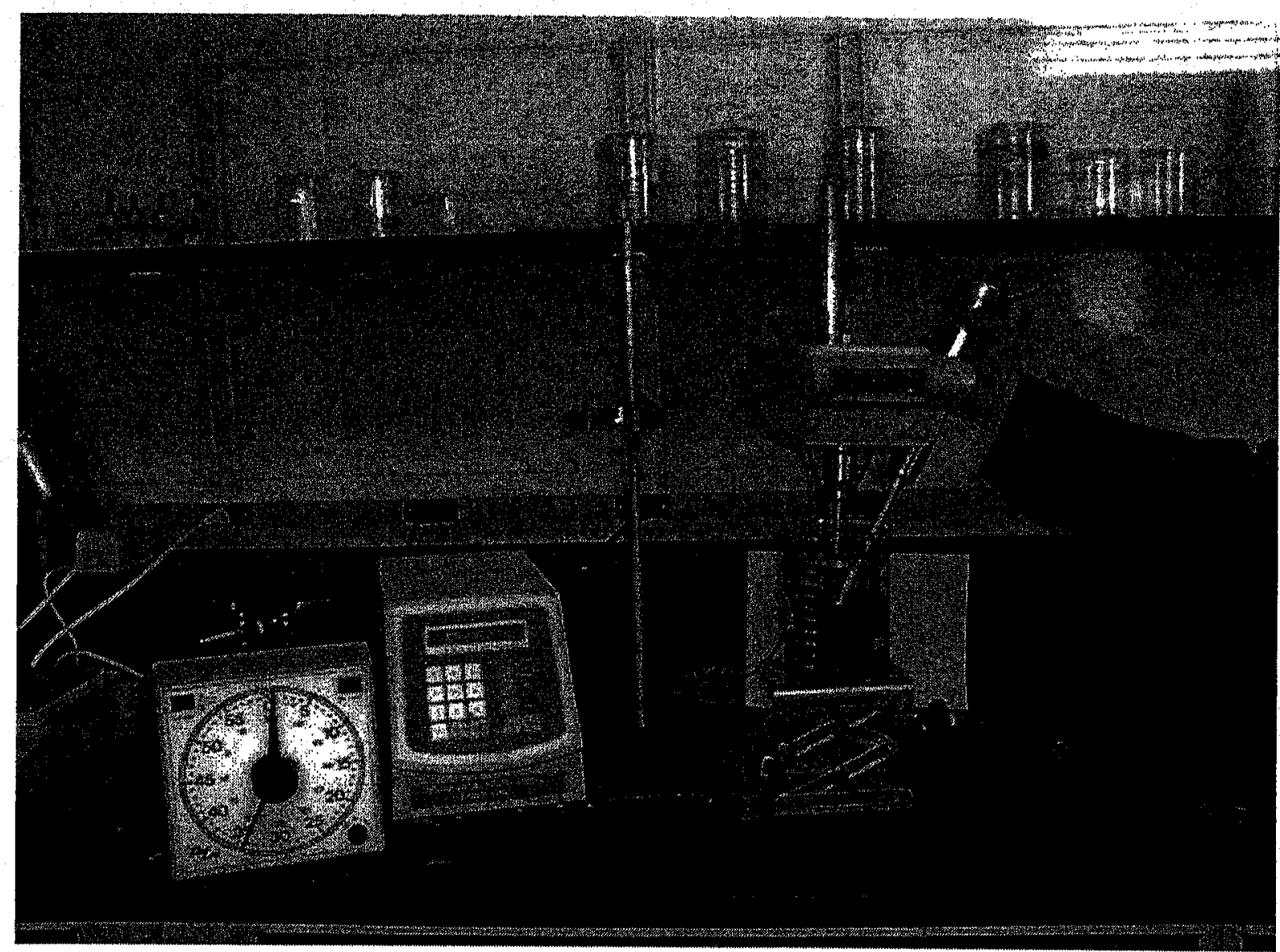

Figure 7. Ultrasonic dispersion / reagglomeration test setup. 


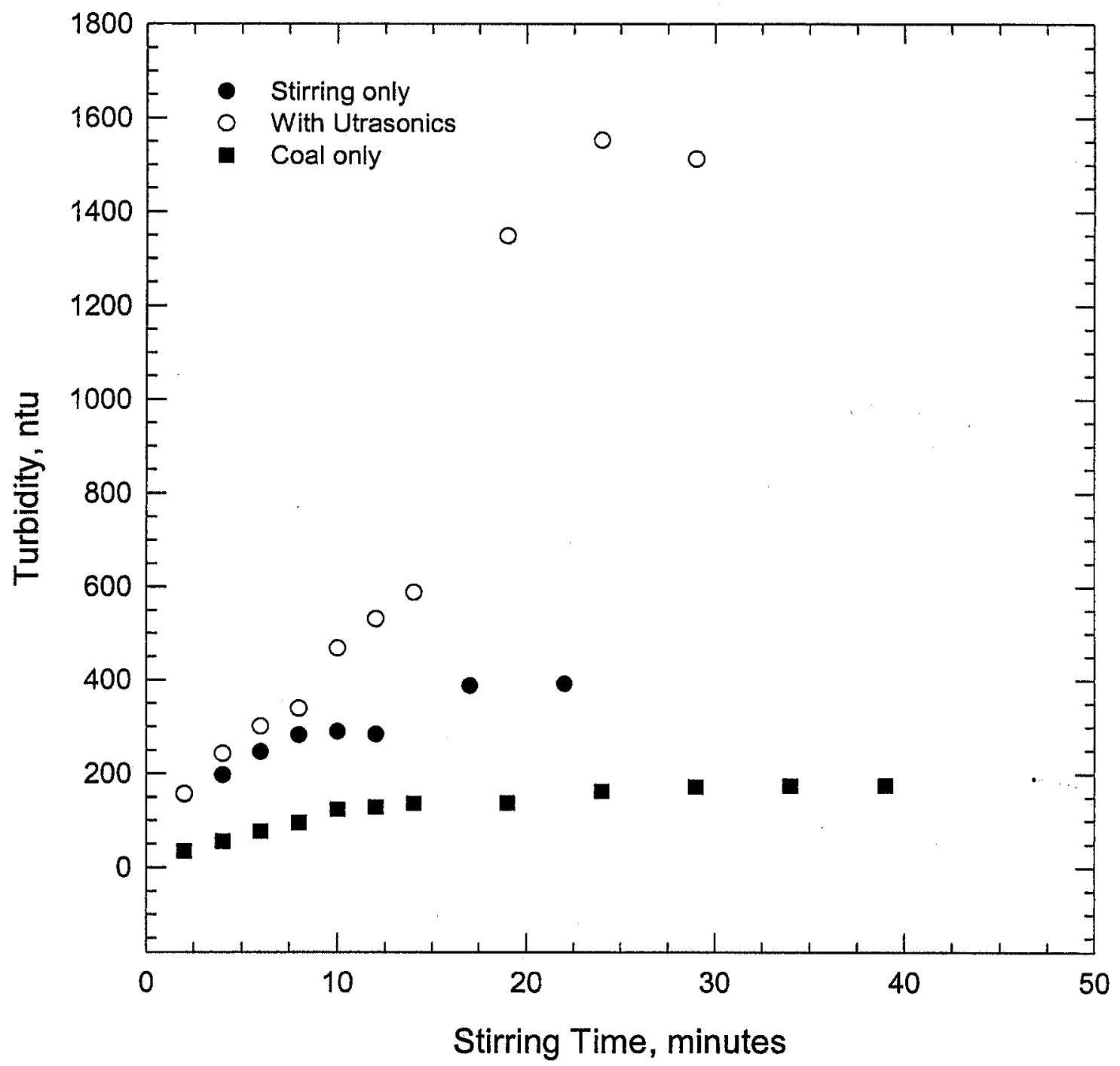

Figure 8. Effect of agitation and ultrasonic treatment on coal and coal/clay cakes. 


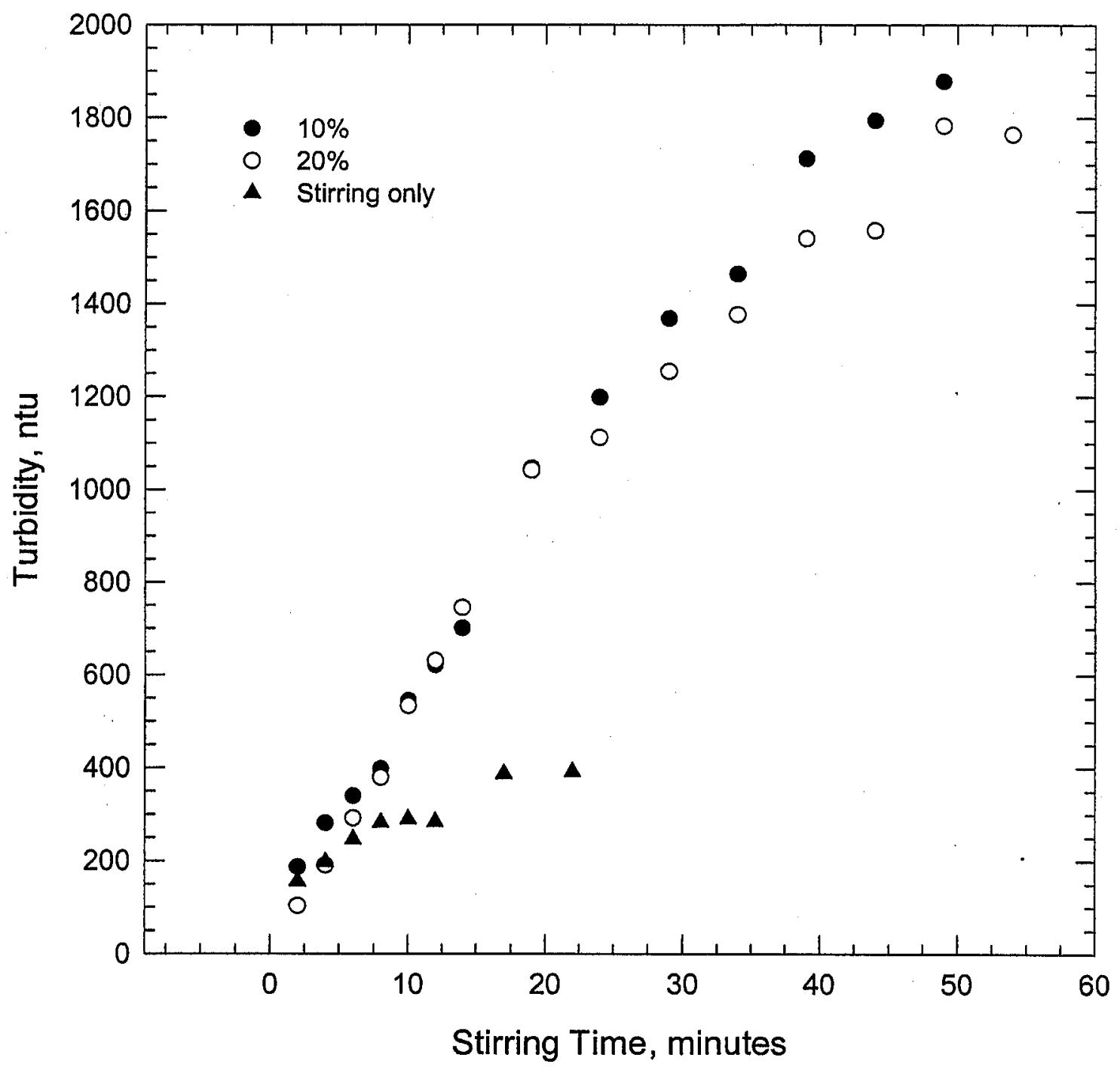

Figure 9. Effect of ultrasonic amplitude on coal/clay dispersion. 


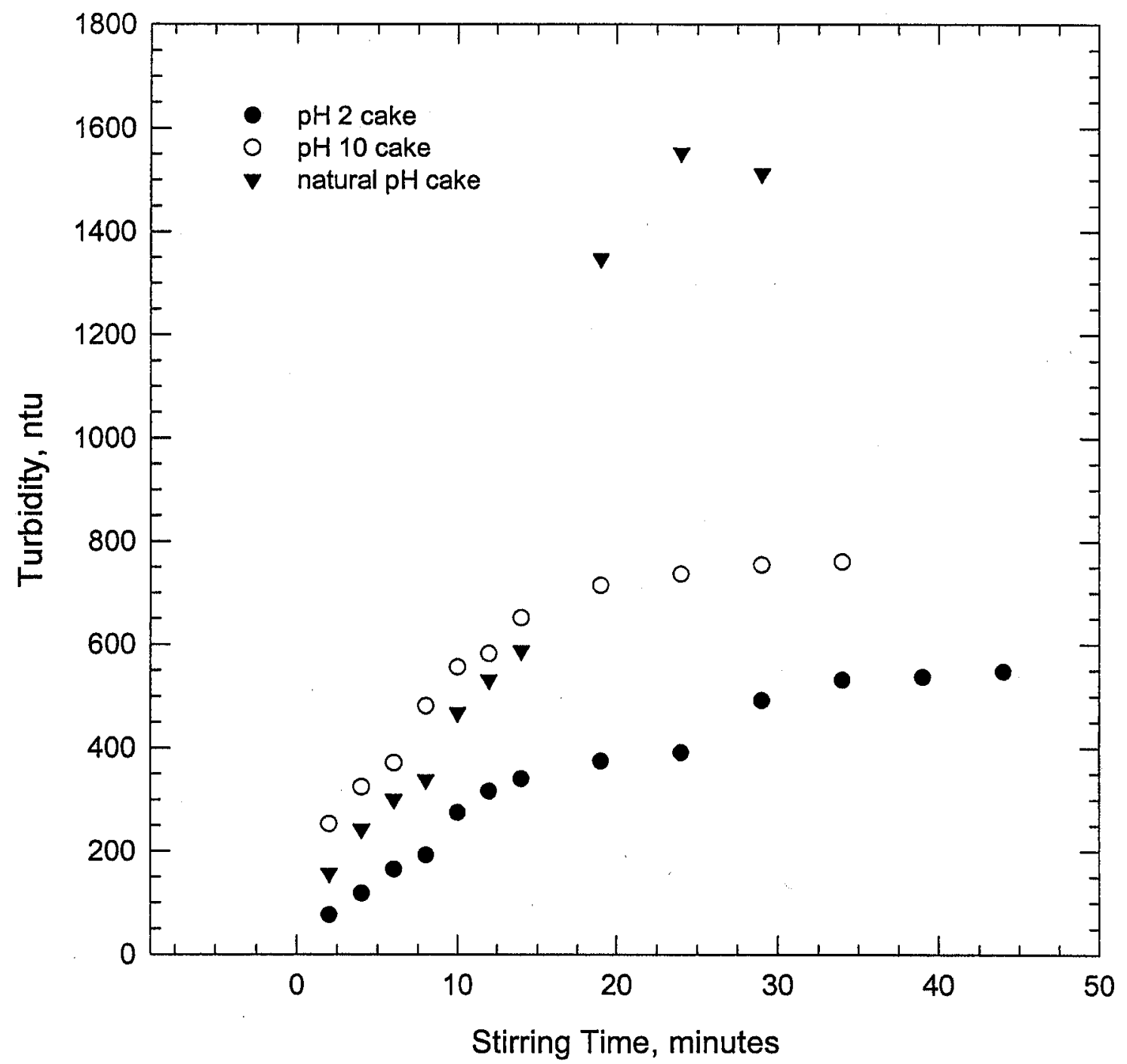

Figure 10. Effect of solution $\mathrm{pH}$ on the dispersion behavior of coal/clay cakes. 


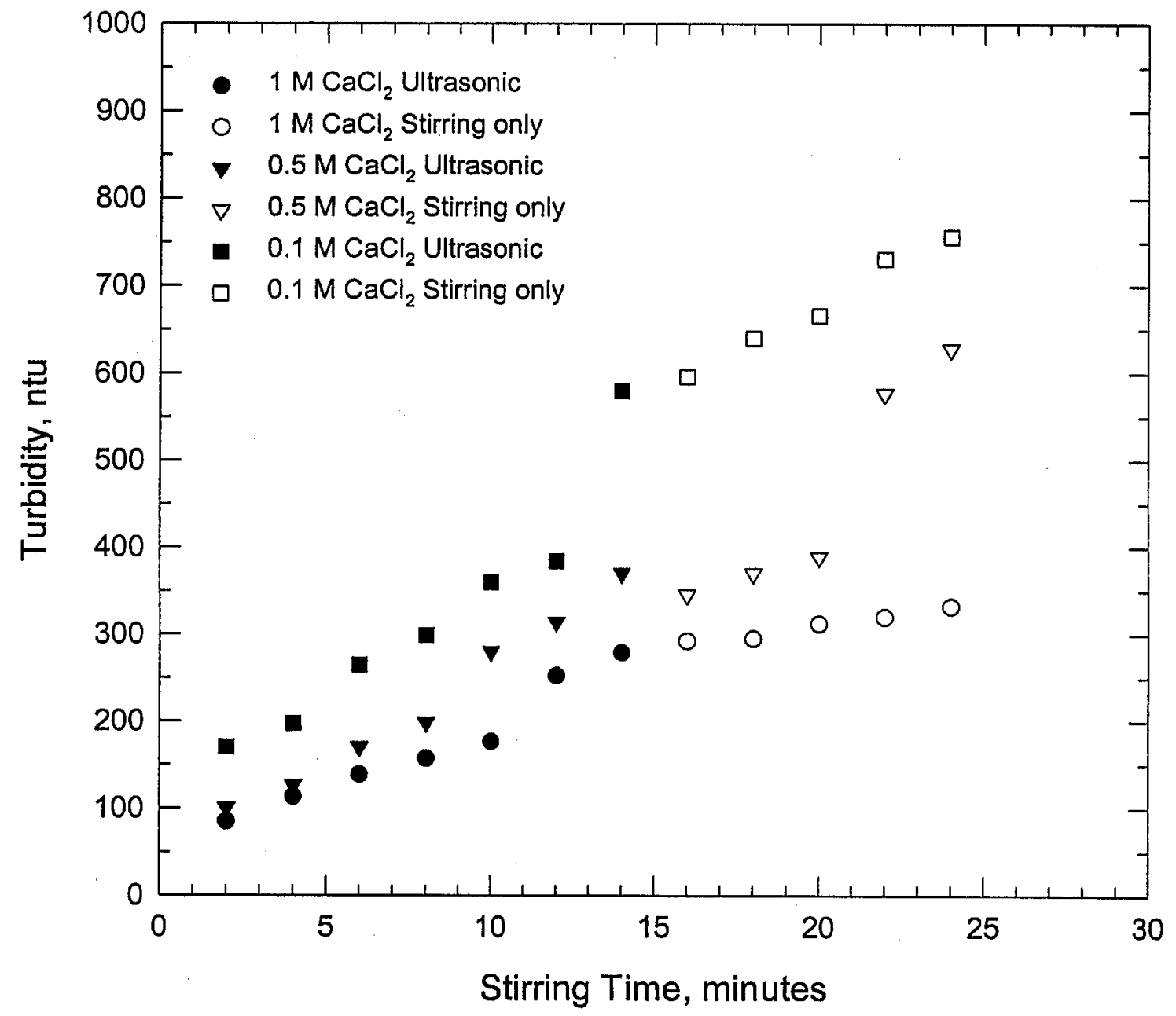

Figure 11. Effect of added salt $\left(\mathrm{CaCl}_{2}\right)$ on coal/clay dispersion by stirring and ultrasonic treatment. 


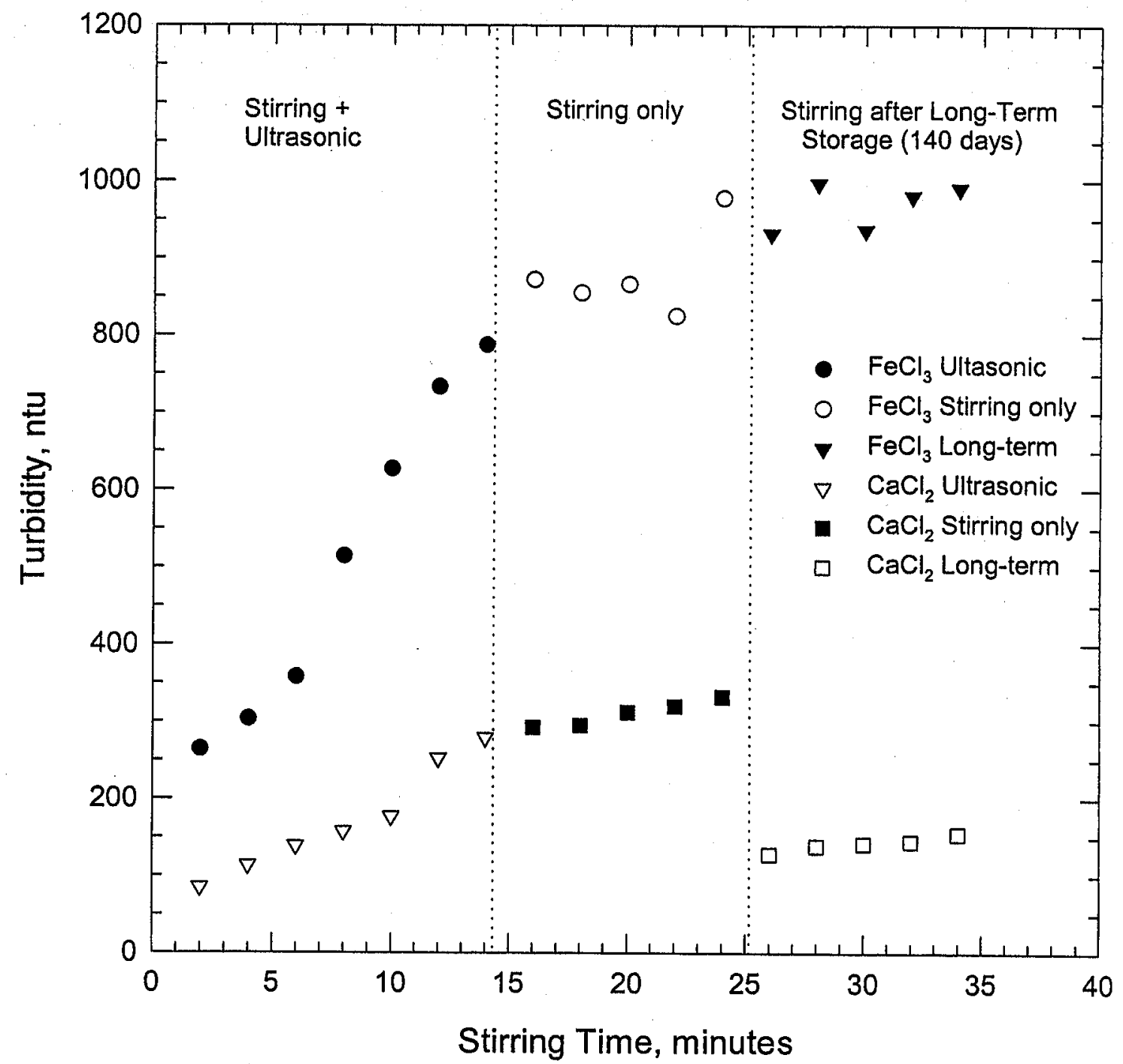

Figure 12. Ultrasonic dispersion and reagglomeration testing of coal/fine refuse mixture prepared in the presence of salts. 


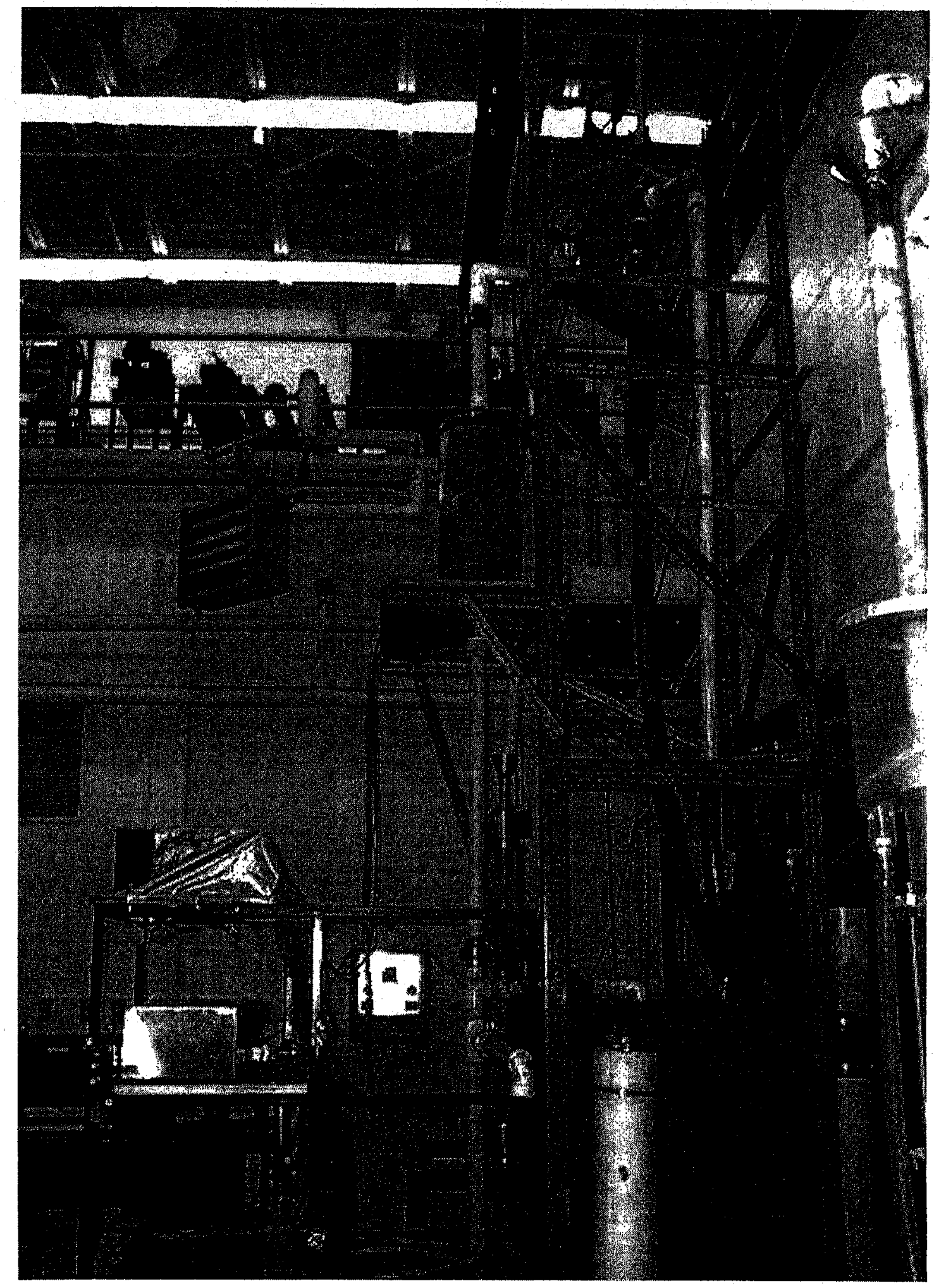

Figure 13. Krebs 3-in. cyclone circuit with ultrasonic unit. 

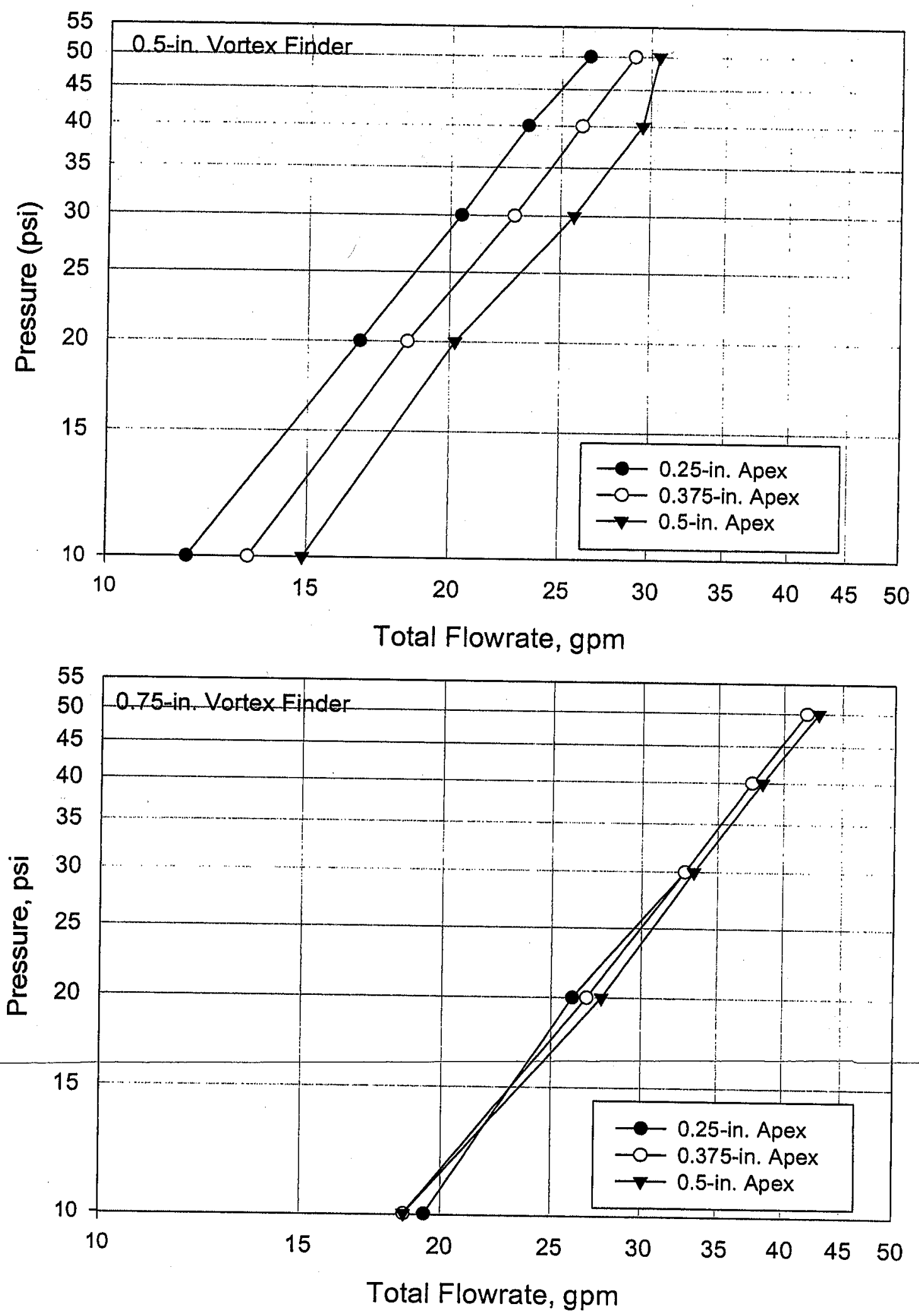

Figure 14. Water flowrates through the 3-in. Krebs cyclone. 

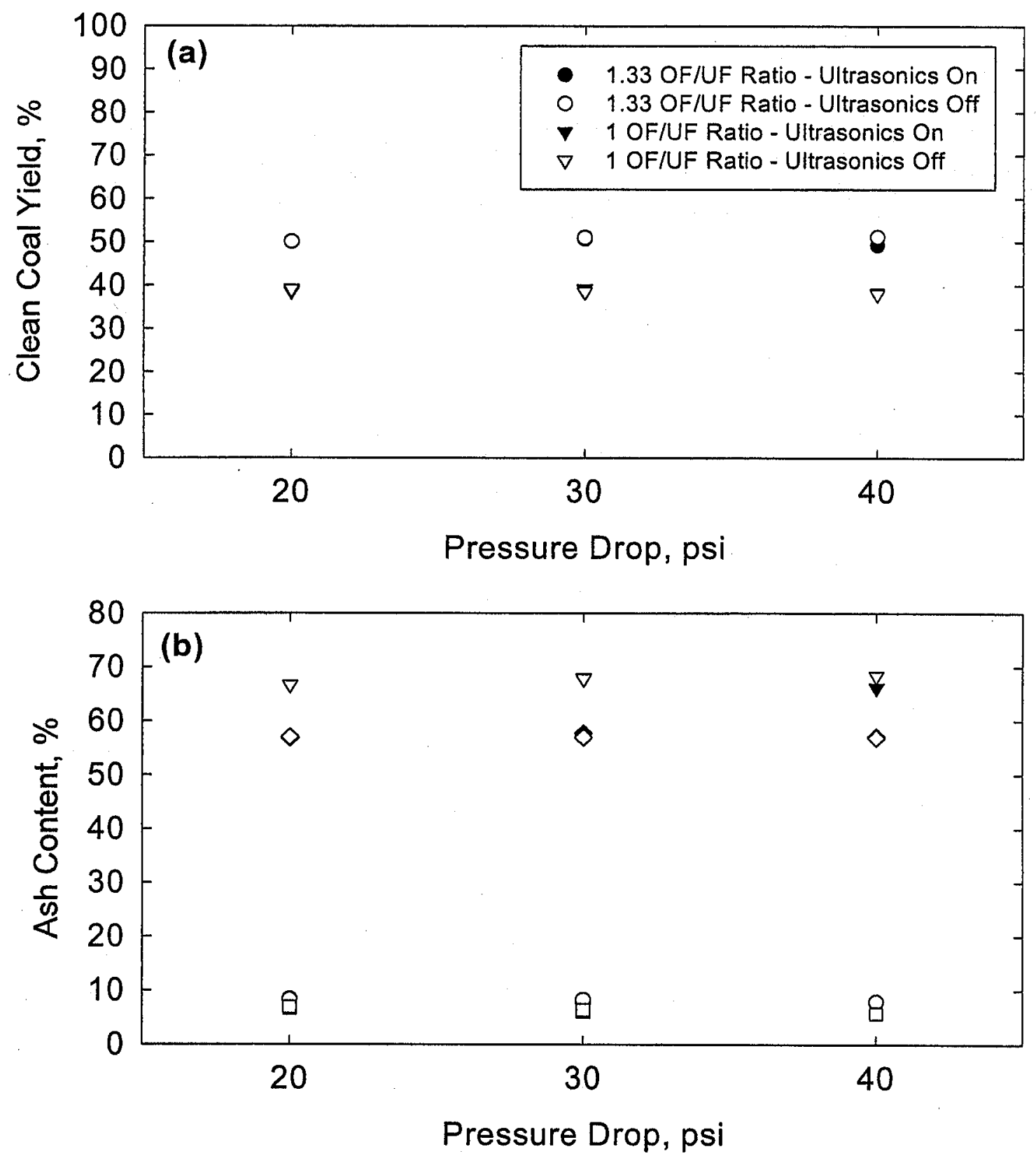

- 1.33 OF/UF Clean Coal - Ultrasonics On

- 1.33 OF/UF Clean Coal - Ultrasonics Off

$\nabla \quad 1.33$ OF/UF Refuse - Ultrasonics On

$\nabla \quad 1.33$ OF/UF Refuse - UItrasonics Off

- 1 OF/UF Clean Coal - Ultrasonics On

ㅁ 1 OF/UF Clean Coal - Ultrasonics Off

- 1 OF/UF Refuse - Ultrasonics On

$\diamond 1$ OF/UF Refuse - Ultrasonics Off

Figure 15. Cyclone results for coal 1 at 1.35 medium relative density for different test conditions: (a) clean coal yield; (b) ash content. 

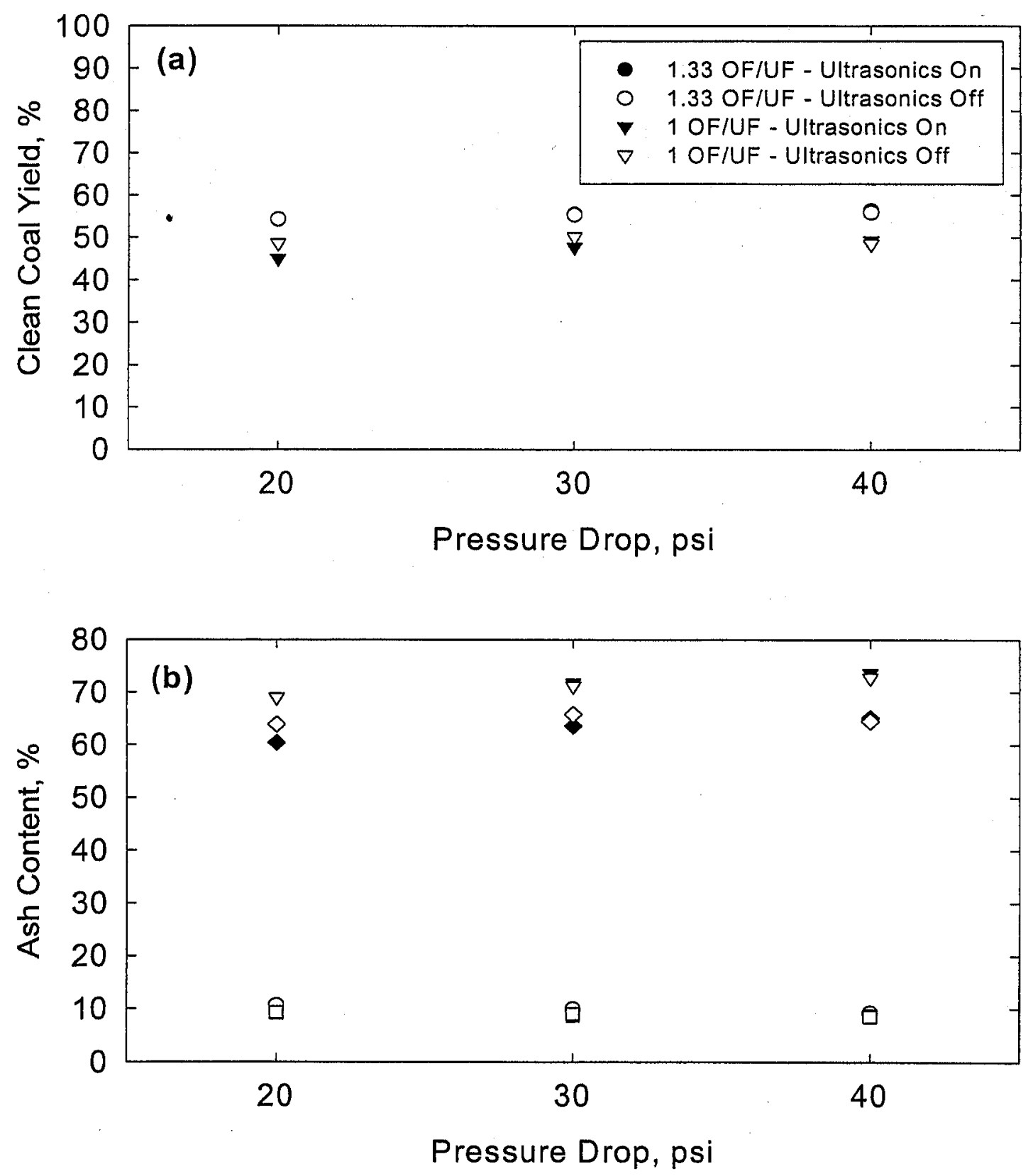

- 1.33 OF/UF Clean Coal - Ultrasonics On

- 1.33 OF/UF Clean Coal - Ultrasonics Off

$\nabla 1.33$ OF/UF Refuse - Ultrasonics On

$\nabla \quad 1.33$ UF/OF Refuse - Ultrasonics Off

- 1 OF/UF Clean Coal - Ultrasonics On

ㅁ 1 OF/UF Clean Coal - Ultrasonics Off

- 1 OFIUF Refuse - Ultrasonics On

$\diamond 1$ OFIUF Refuse - UItrasonics Off

Figure 16. Cyclone results for coal 1 at 1.45 medium relative density for different test conditions: (a) clean coal yield; (b) ash content. 

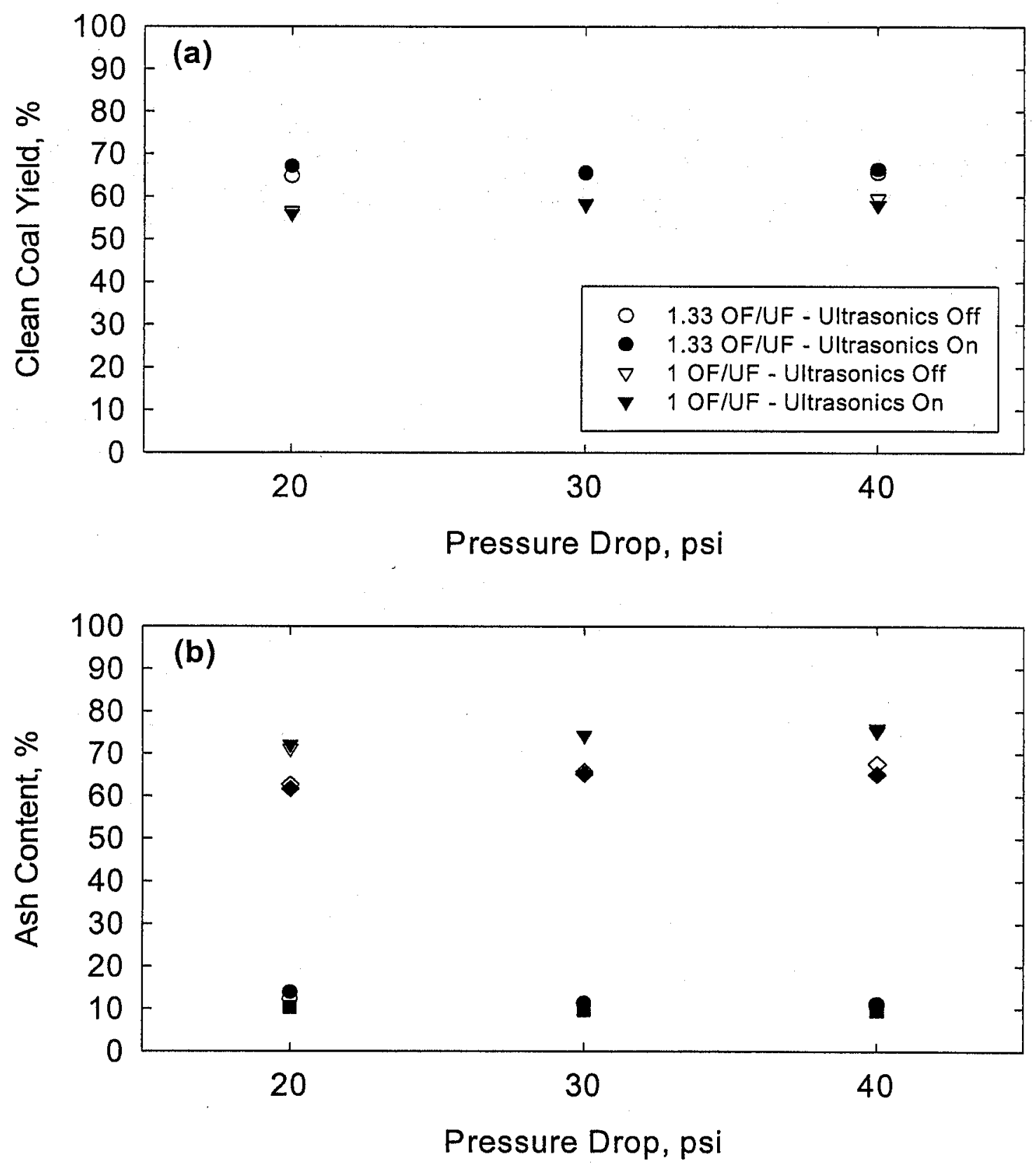

- 1.33 OF/UF Clean Coal - Ultrasonics Off

- 1.33 OF/UF Clean Coal - Ultrasonics On

- 1 OF/UF Clean Coal - Ultrasonics Off

- 1 OF/UF Clean Coal - Ultrasonics On

$\nabla \quad 1.33$ OF/UF Refuse - UItrasonics Off

$\nabla 1.33$ OF/UF Refuse - Ultrasonics On

$\diamond 1$ OF/UF Refuse - Ultrasonics Off

- 1 OF/UF Refuse - Ultrasonics On

Figure 17. Cyclone results for coal 1 at 1.55 medium relative density for different test conditions: (a) clean coal yield; (b) ash content. 

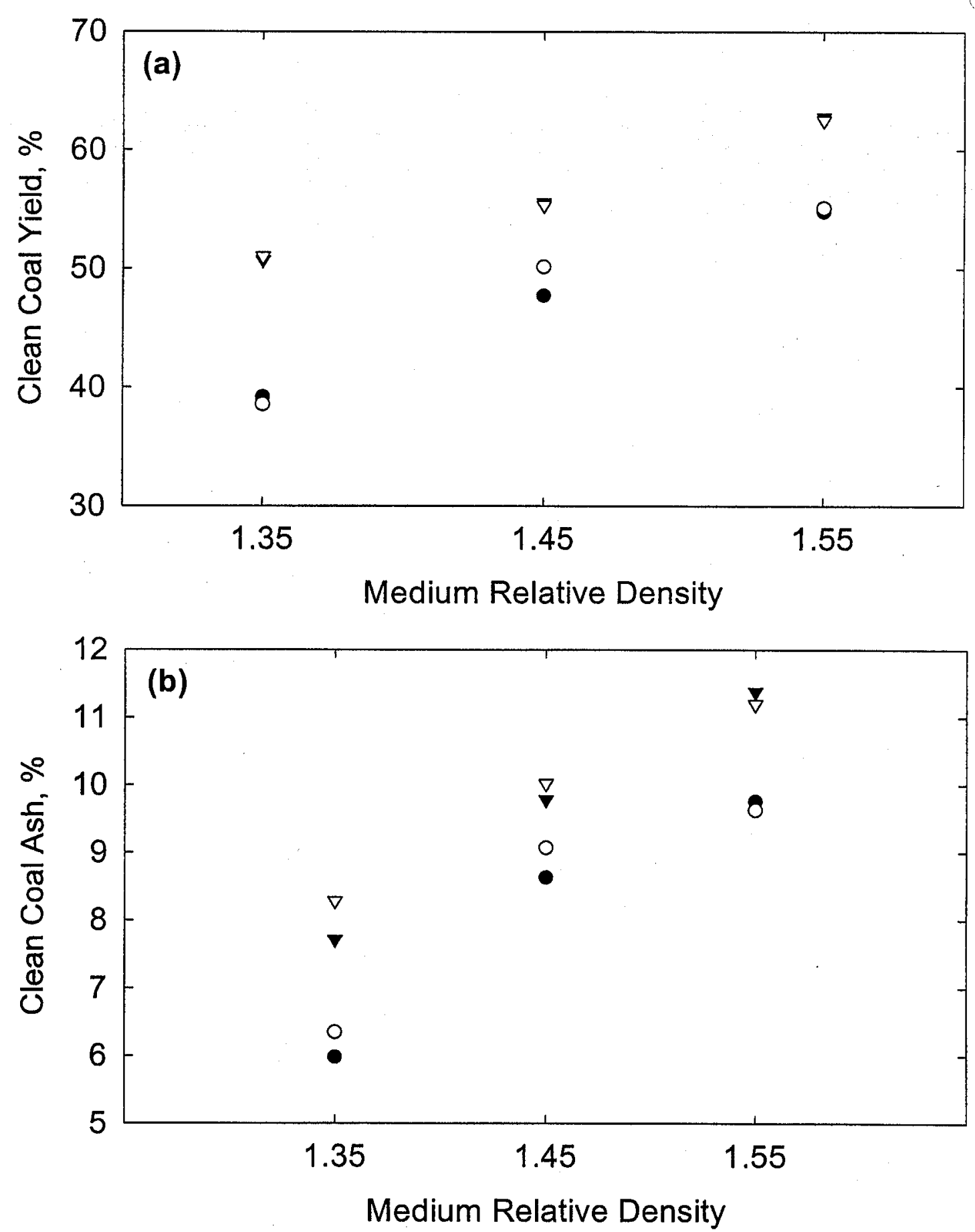

- 1:1 OF:UF Ratio, U/S On $\quad \checkmark$ 1.33:1 OF:UF Ratio, U/S On - 1:1 OF:UF Ratio, U/S Off $\quad \nabla$ 1.33:1 OF:UF Ratio, U/S Off

Figure 18. (a) Clean coal yield; (b) clean coal ash versus medium relative density at $30 \mathrm{psi}$ and varying $\mathrm{OF} / \mathrm{UF}$ ratios. 

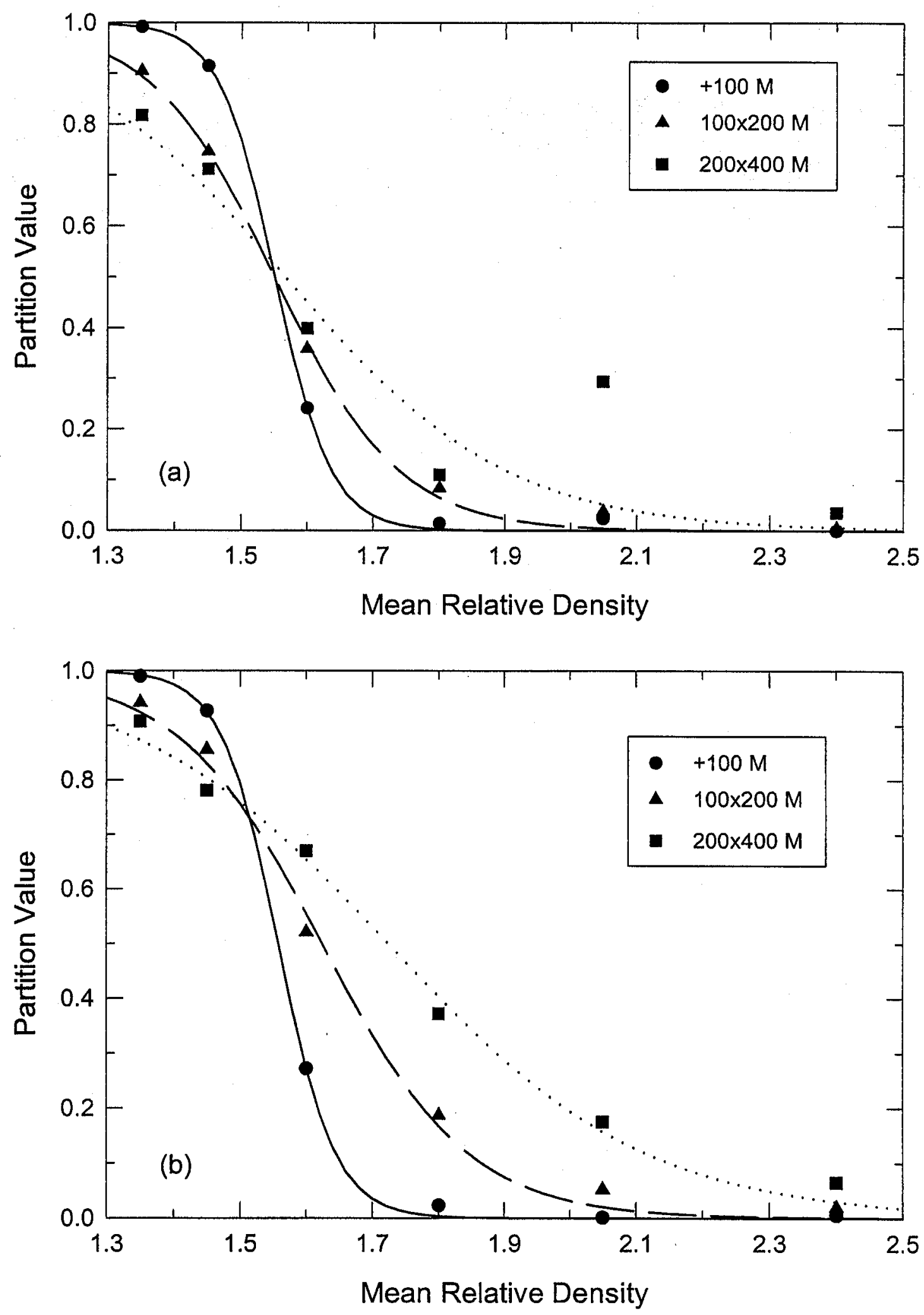

Figure 19. Actual partition values and fitted curves for coal 2 at 1.45 medium relative density: (a) without ultrasonics; (b) with ultrasonics. 


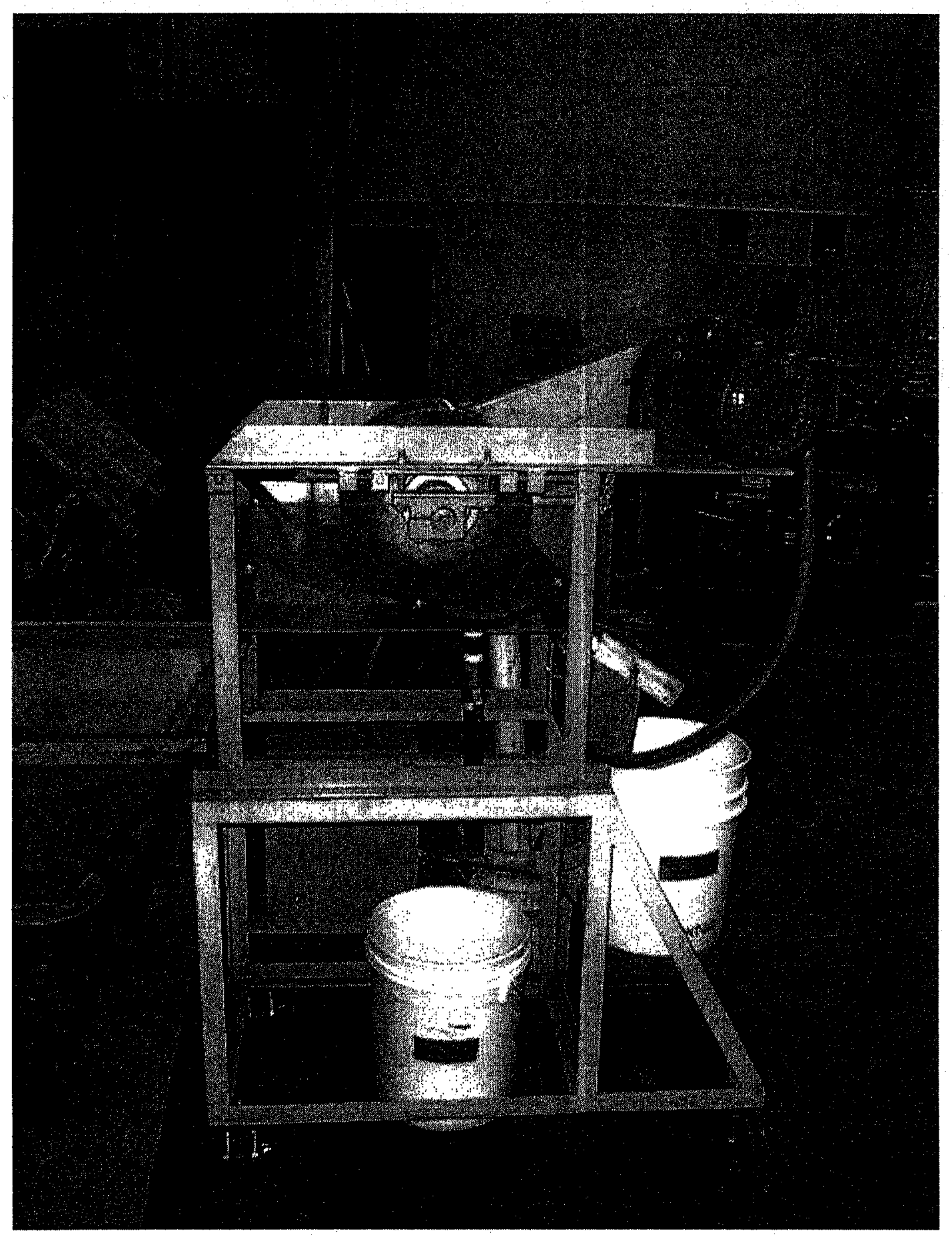

Figure 20. Eriez wet-drum magnetic separator. 


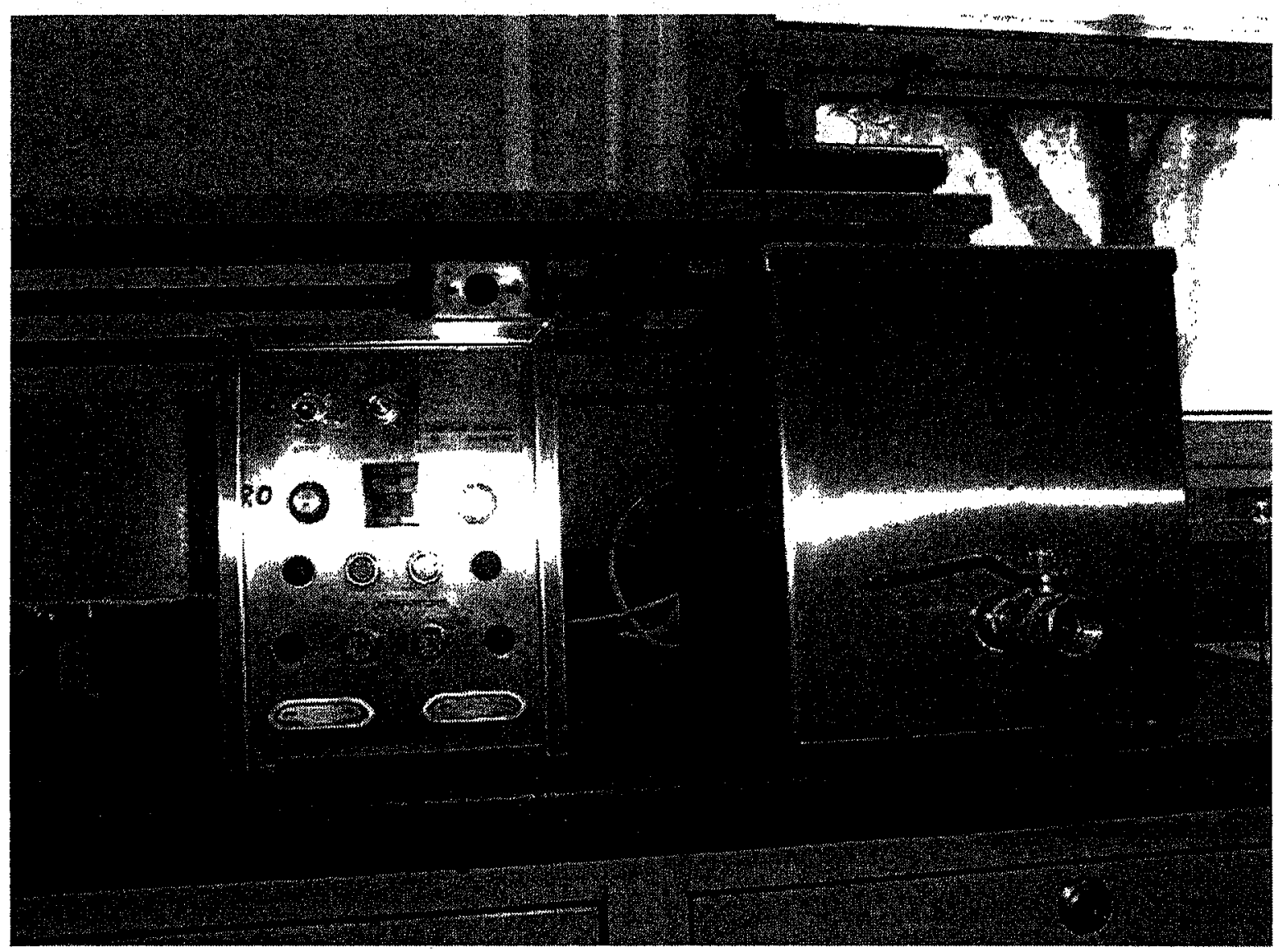

Figure 21. Zenith ultrasonic batch unit. 


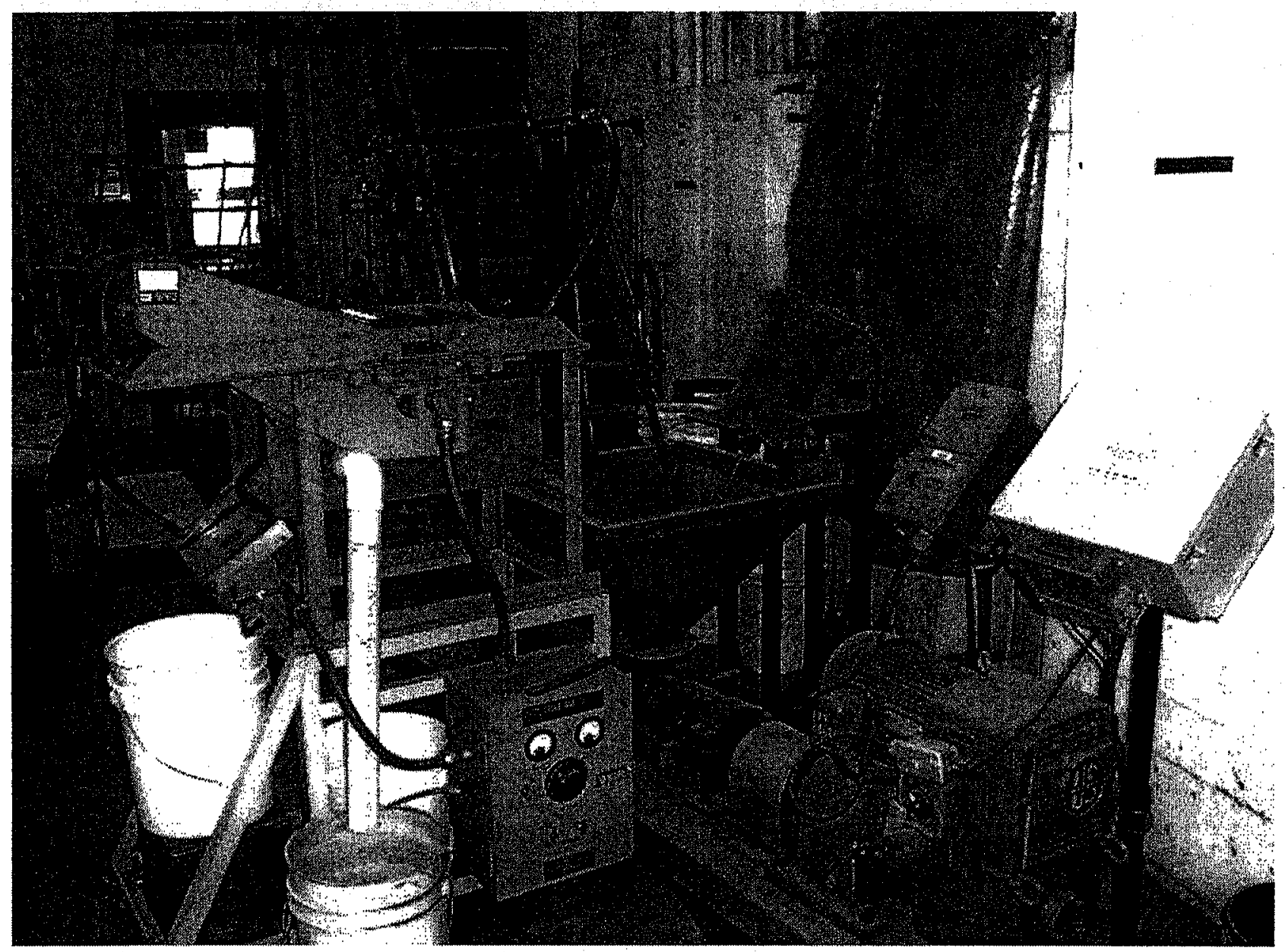

Figure 22. Baseline wet-drum magnetic separator test circuit. 


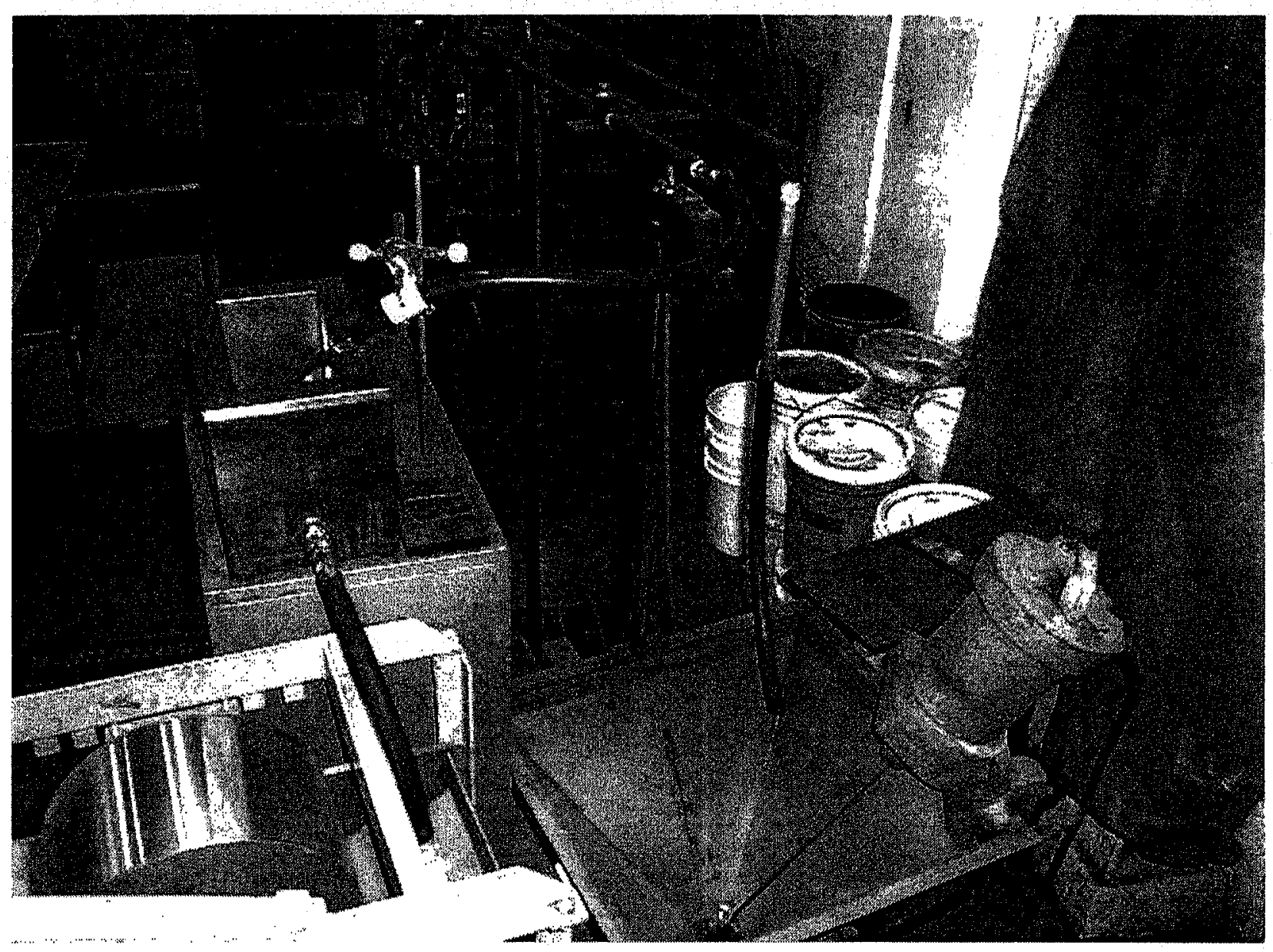

Figure 23. Wet-drum magnetic separator circuit showing in-line ultrasonic unit. 


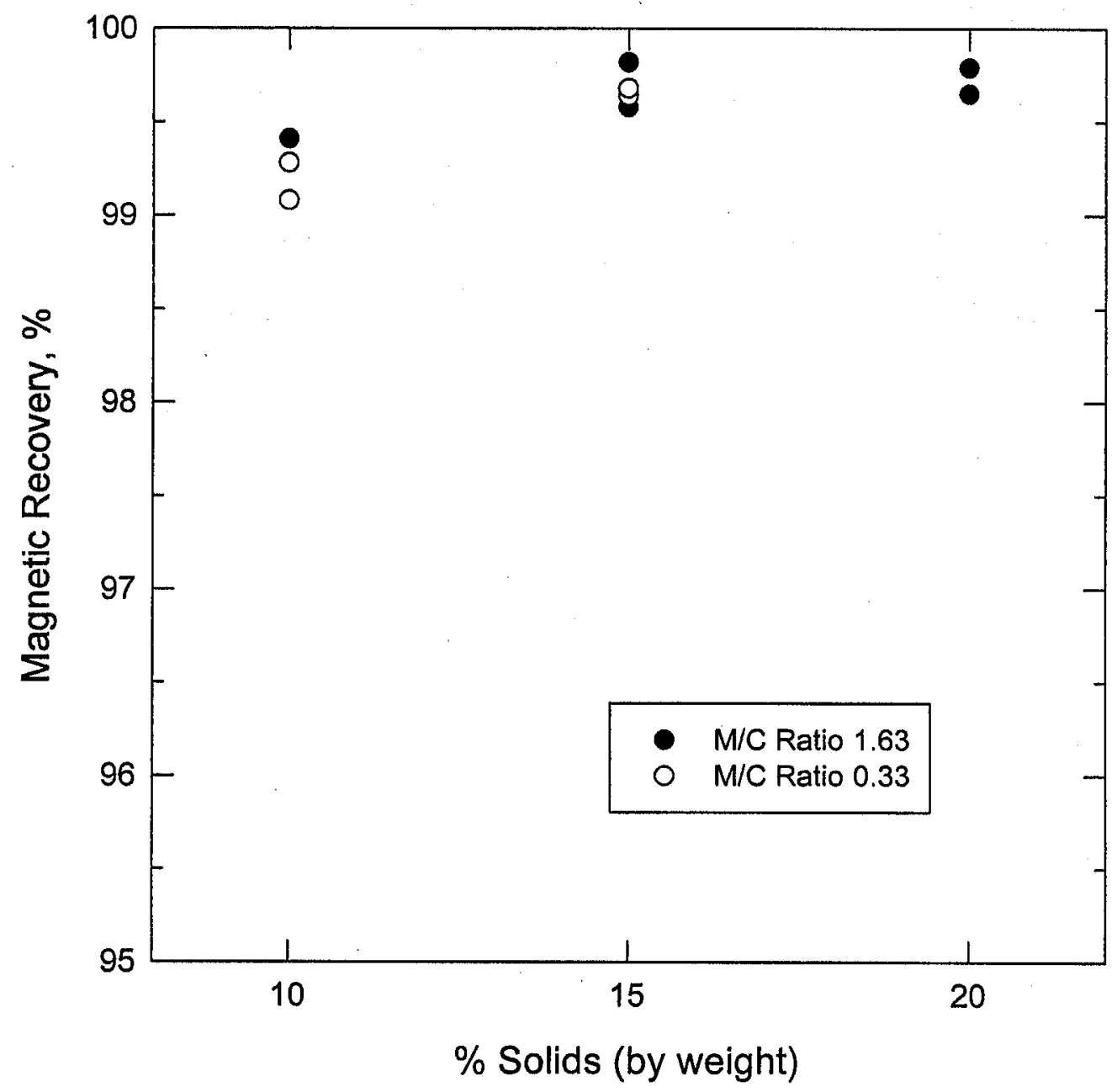

Figure 24. Average magnetic recovery for baseline testing of simulated coal and magnetite slurries. 


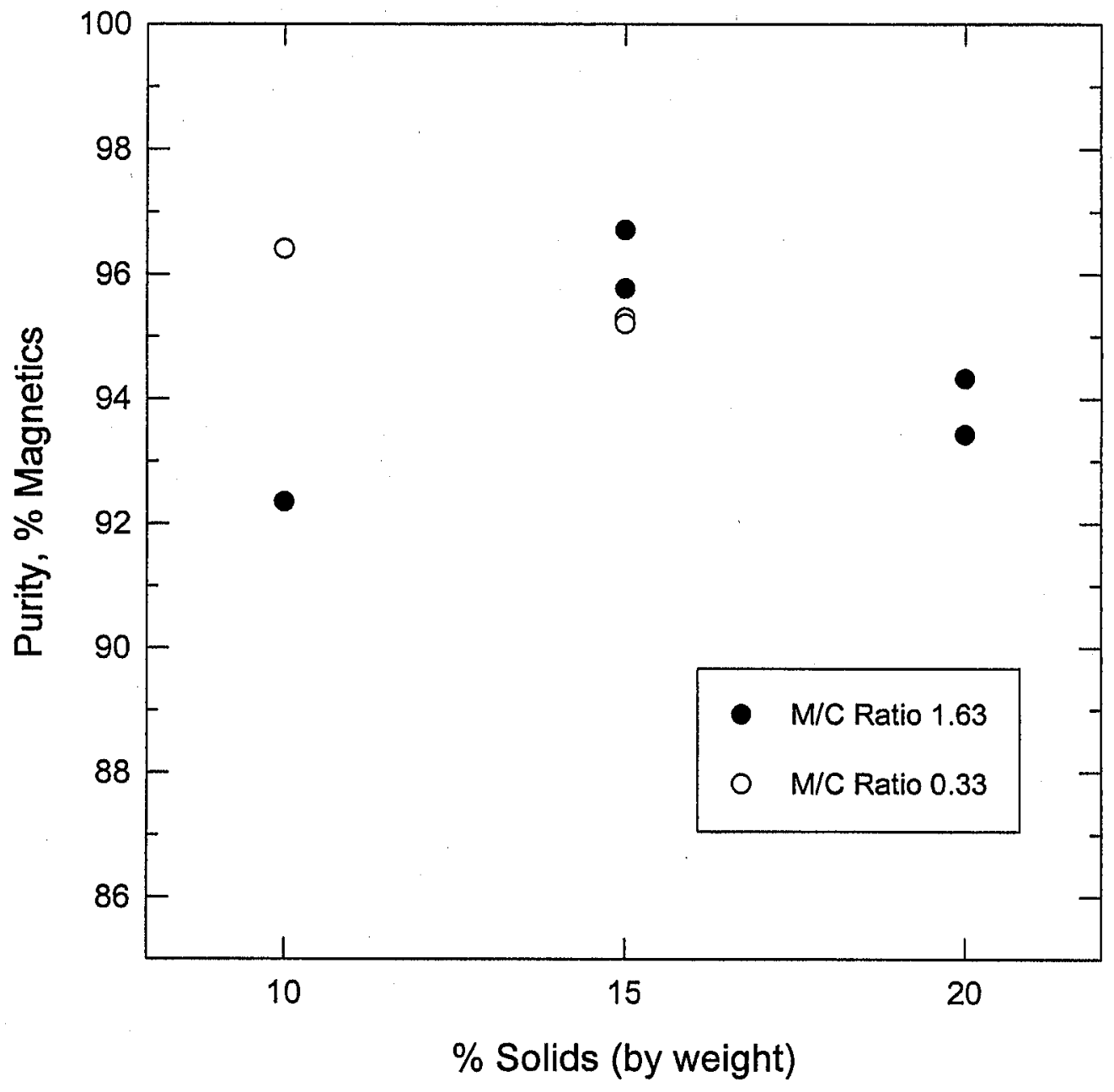

Figure 25. Average magnetic purity for baseline testing of simulated coal and magnetite slurries. 


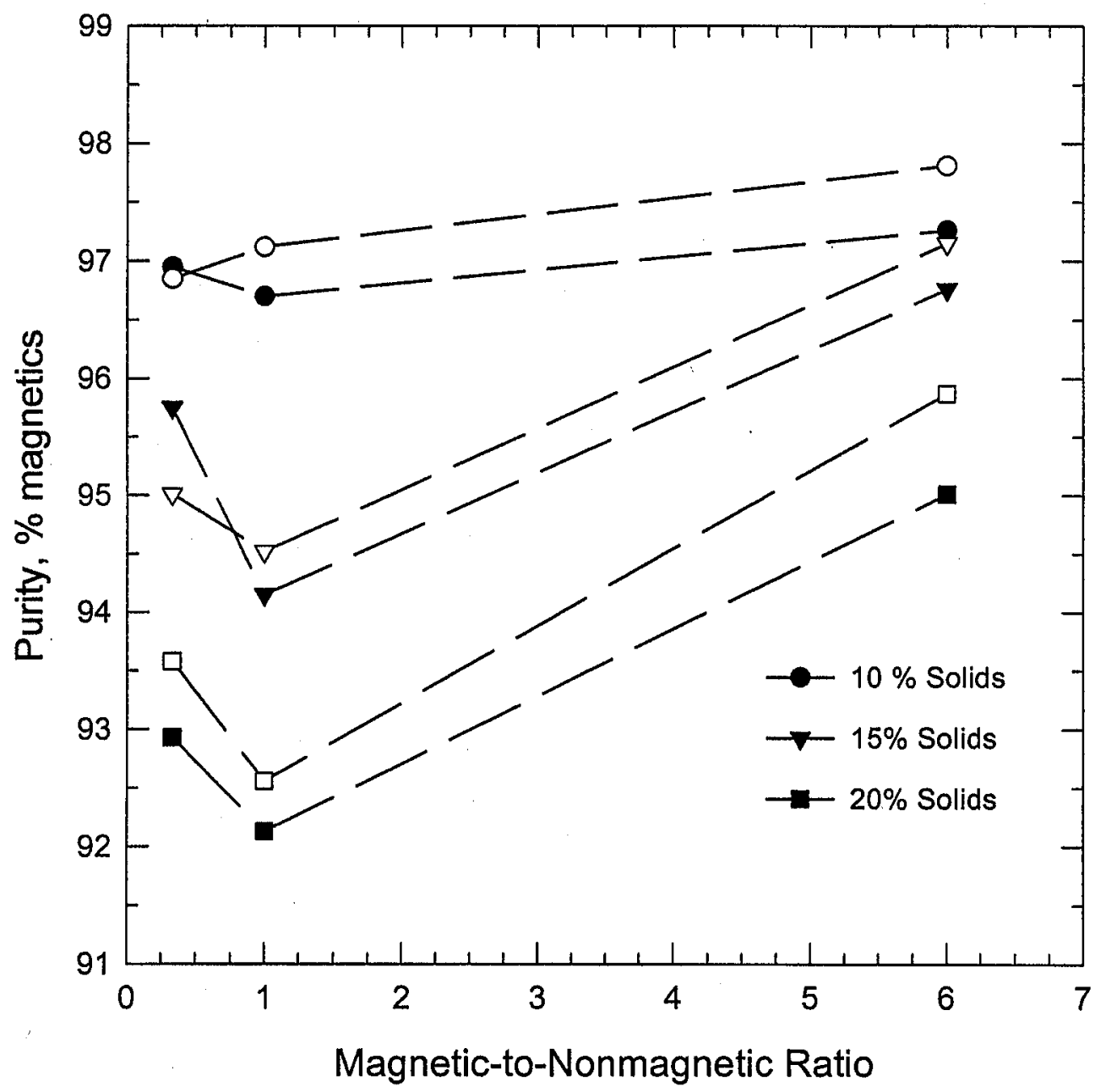

Figure 26. Magnetic purity as a function of $\mathrm{M} / \mathrm{C}$ ratio and solids concentration for the feed characteristics tests (closed symbols = no ultrasonic treatment; open symbols $=$ ultrasonic treatment). 


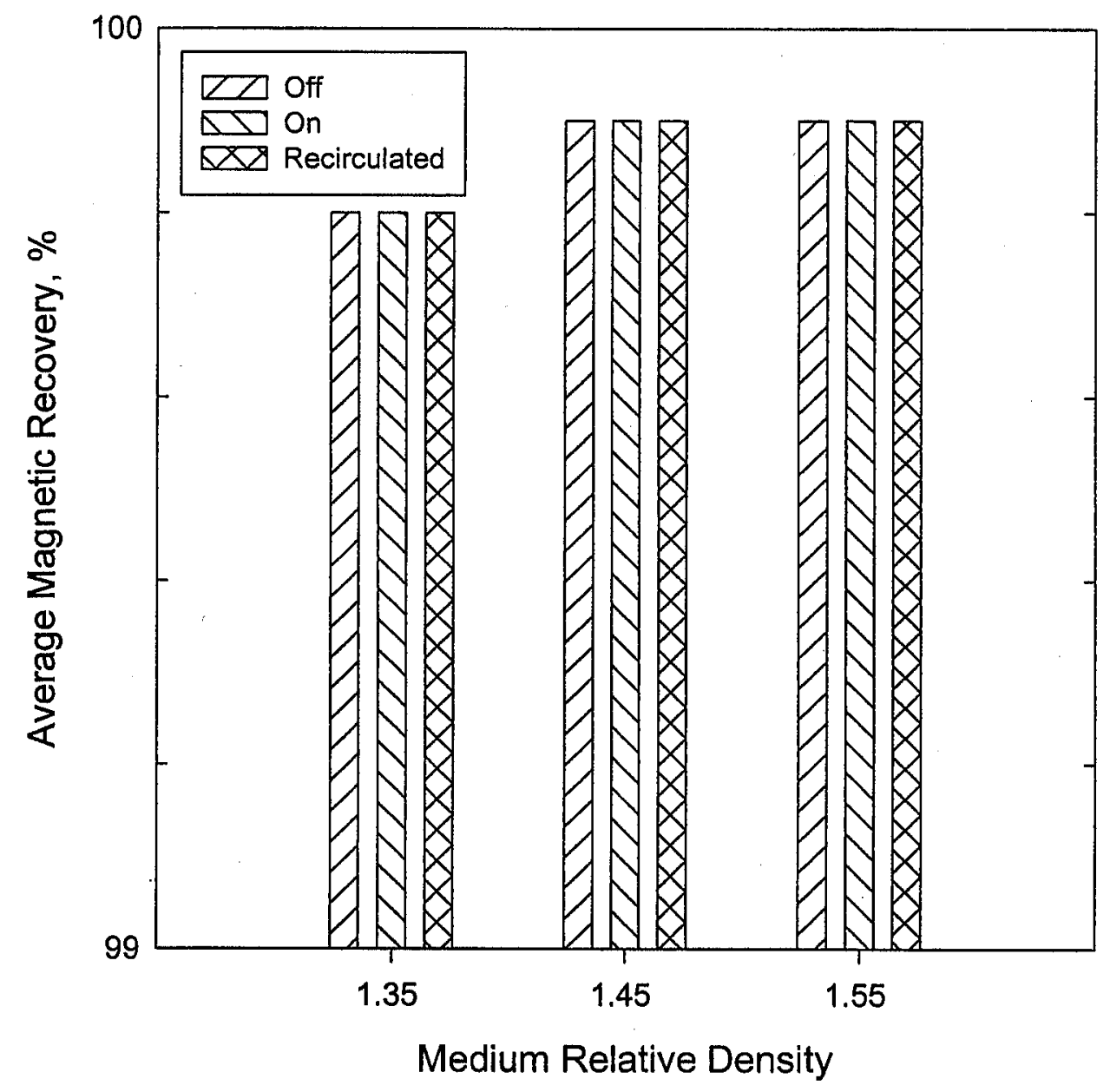

Figure 27. Average magnetic recovery for cyclone underflow using coal 1. 


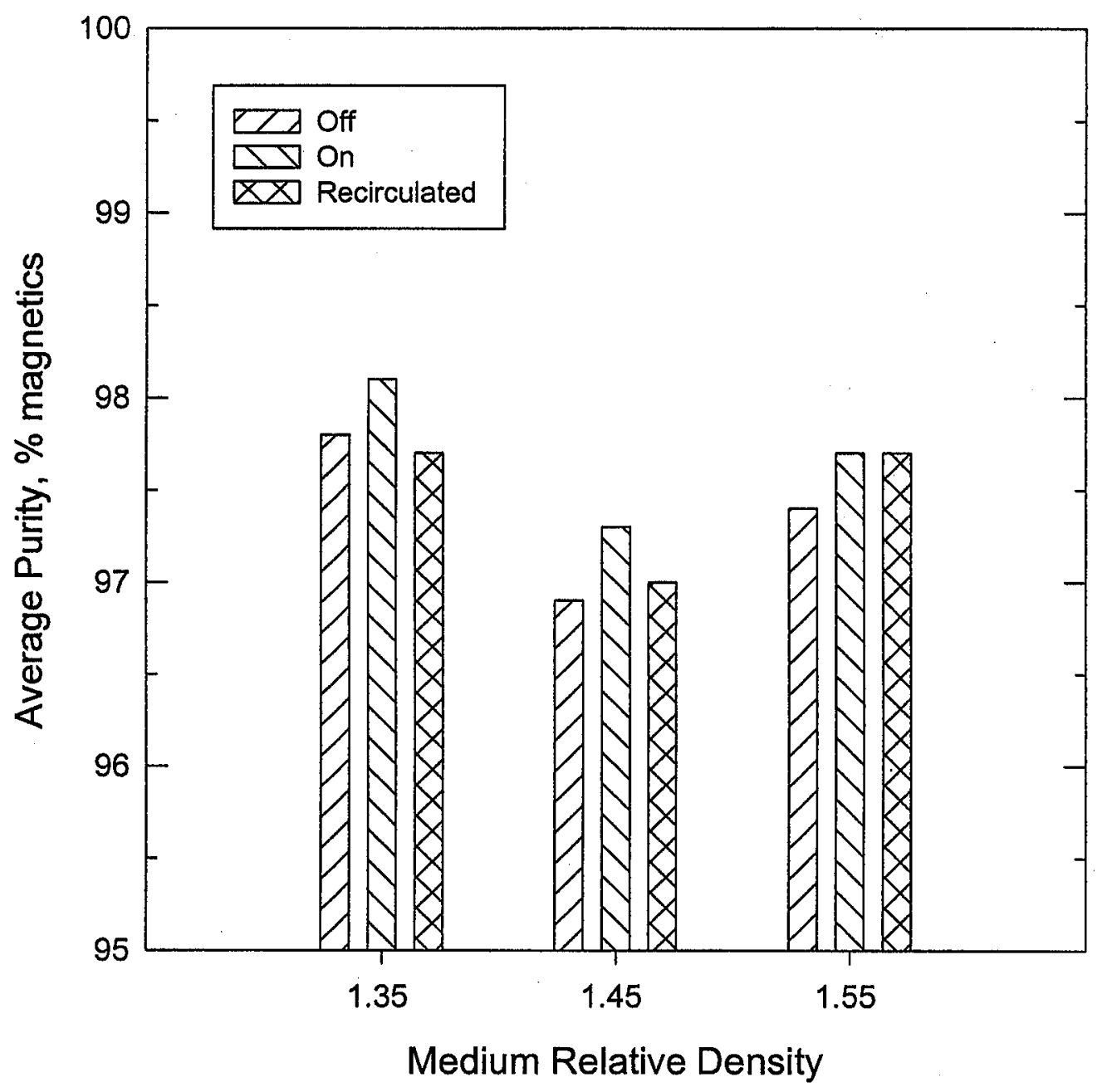

Figure 28. Average magnetic purity for the cyclone underflow using coal 1. 


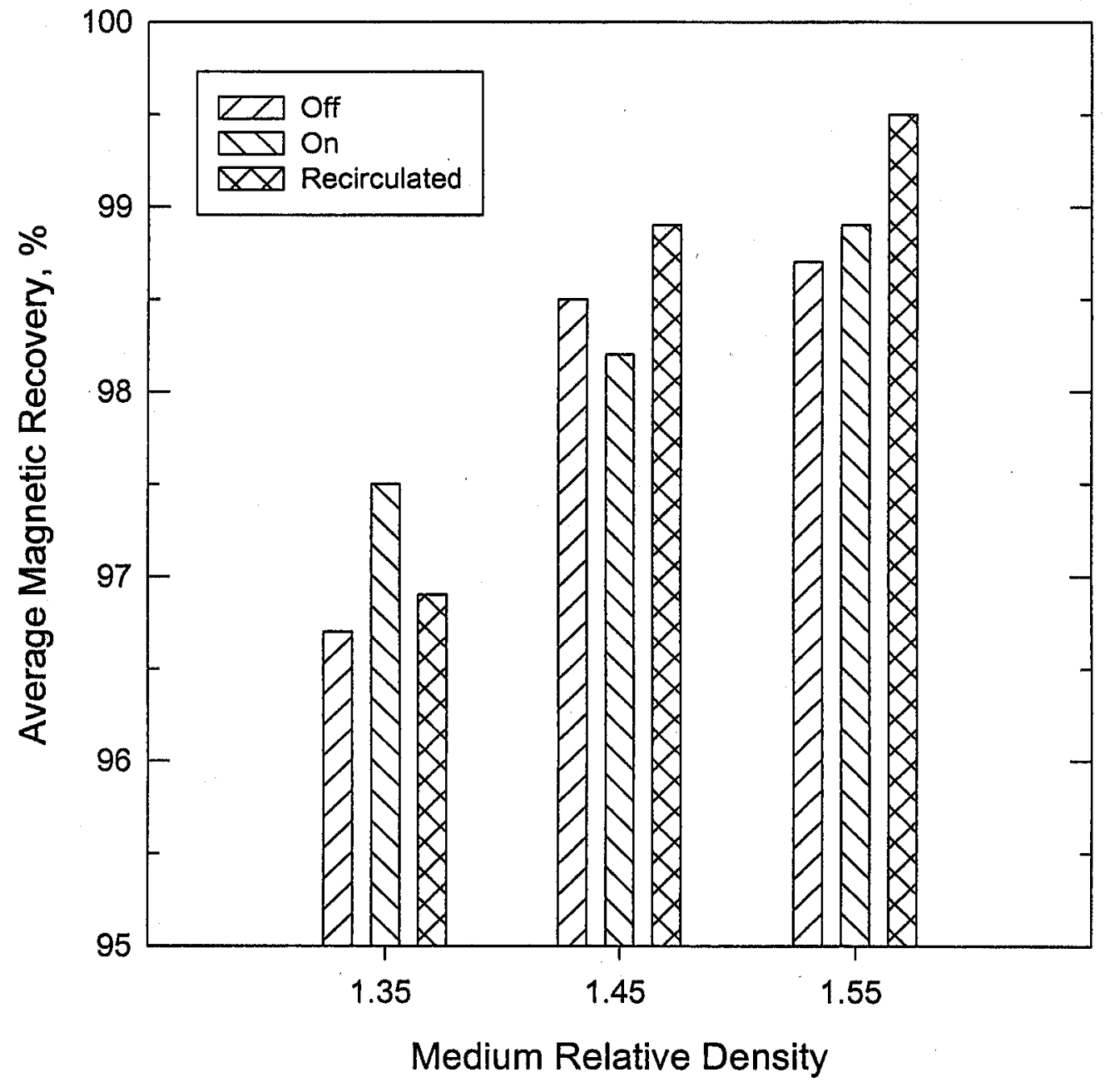

Figure 29. Average magnetic recovery for cyclone overflow using coal 1. 


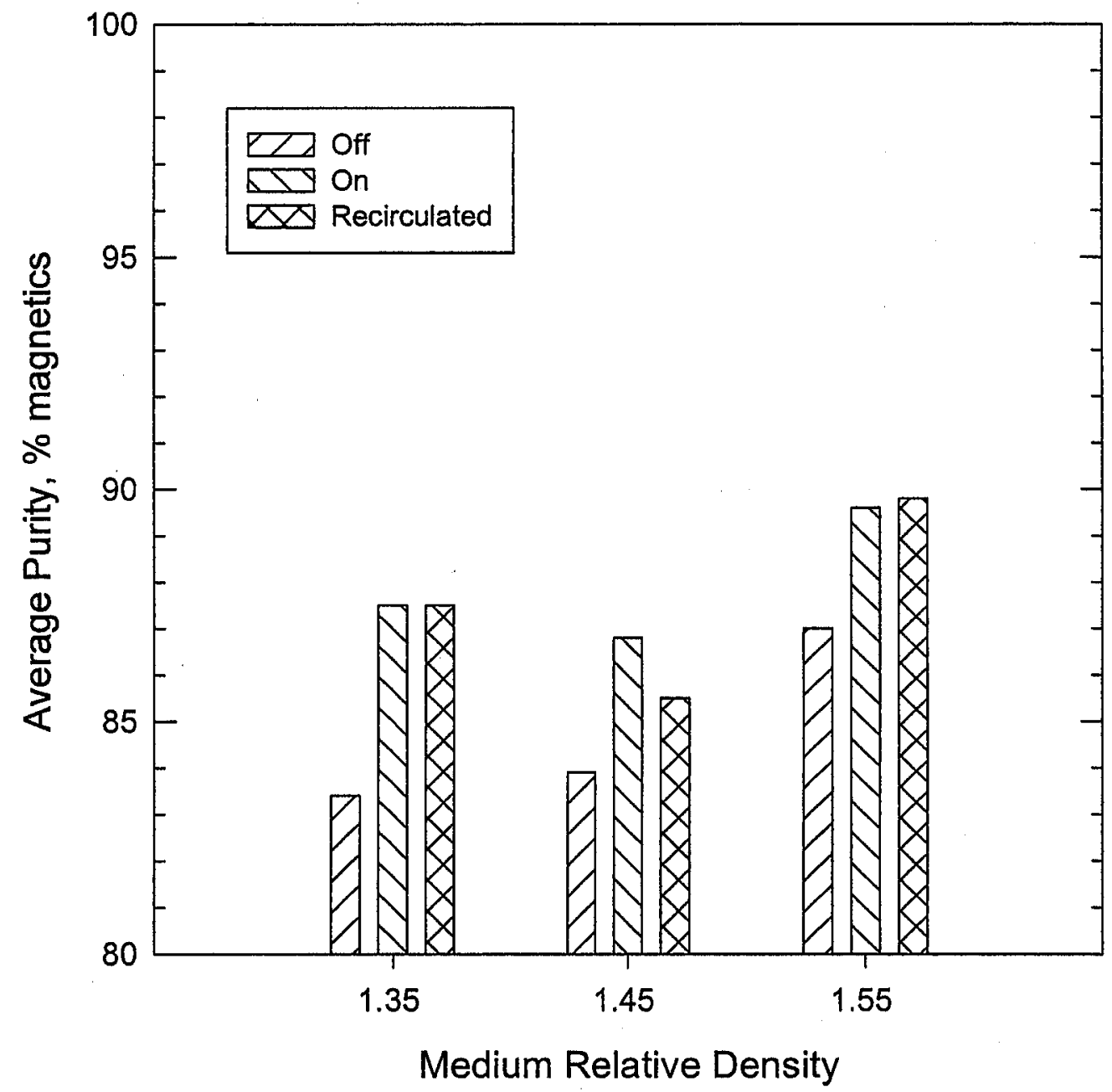

Figure 30. Average magnetic purity for cyclone overflow using coal 1. 


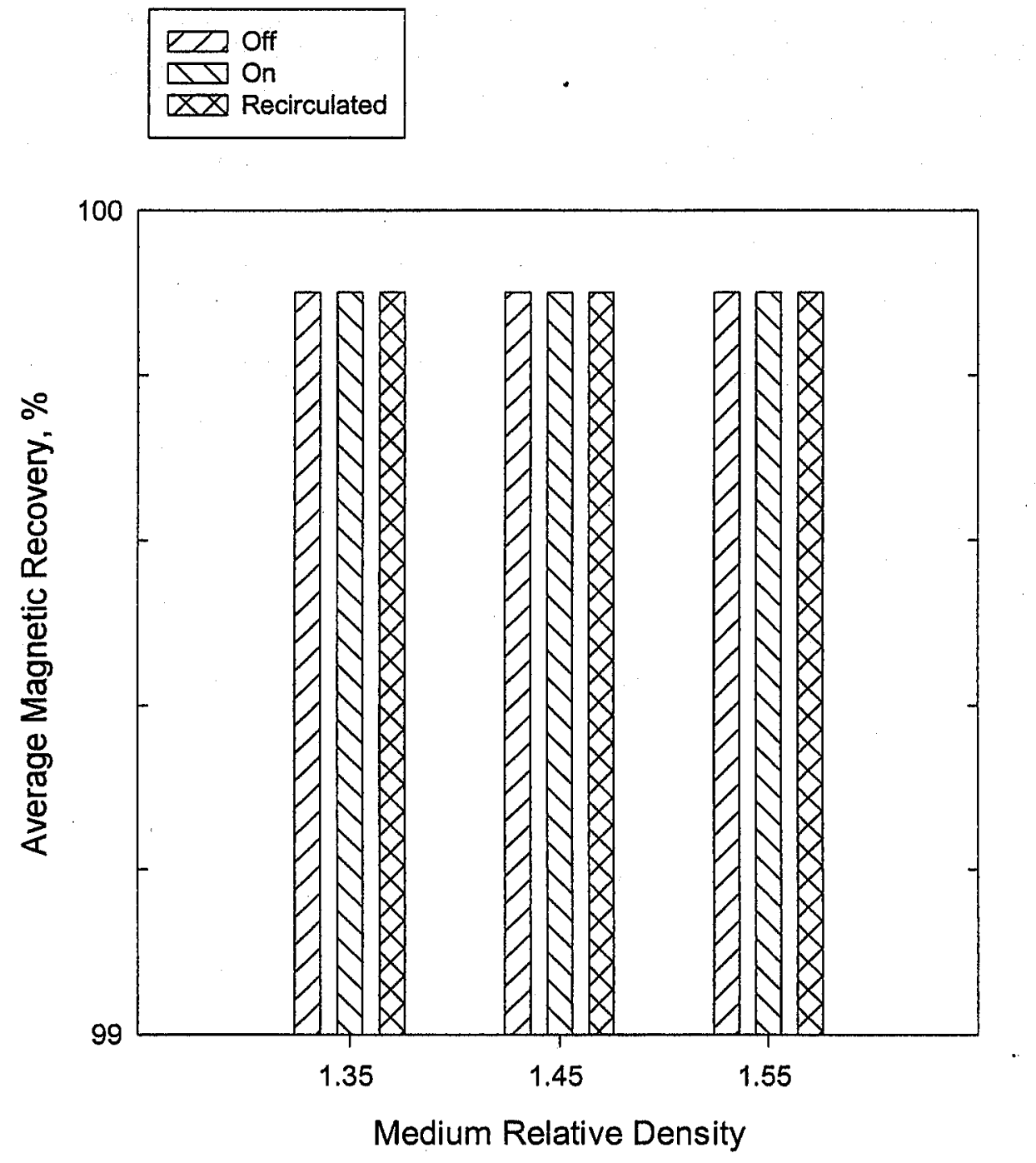

Figure 31. Average magnetic recovery for the cyclone underflow using coal 2. 


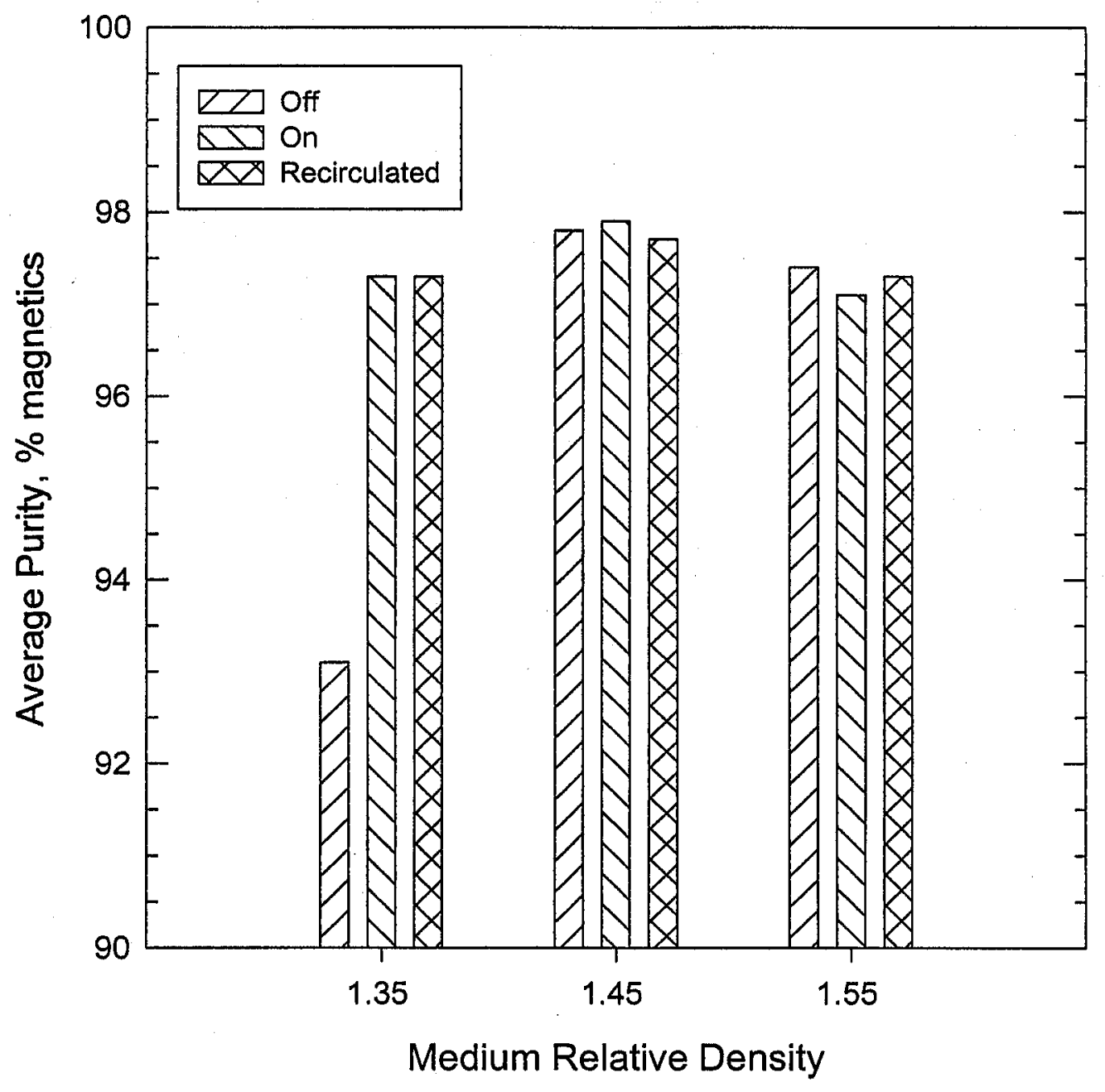

Figure 32. Average magnetic purity for the cyclone underflow using coal 2. 

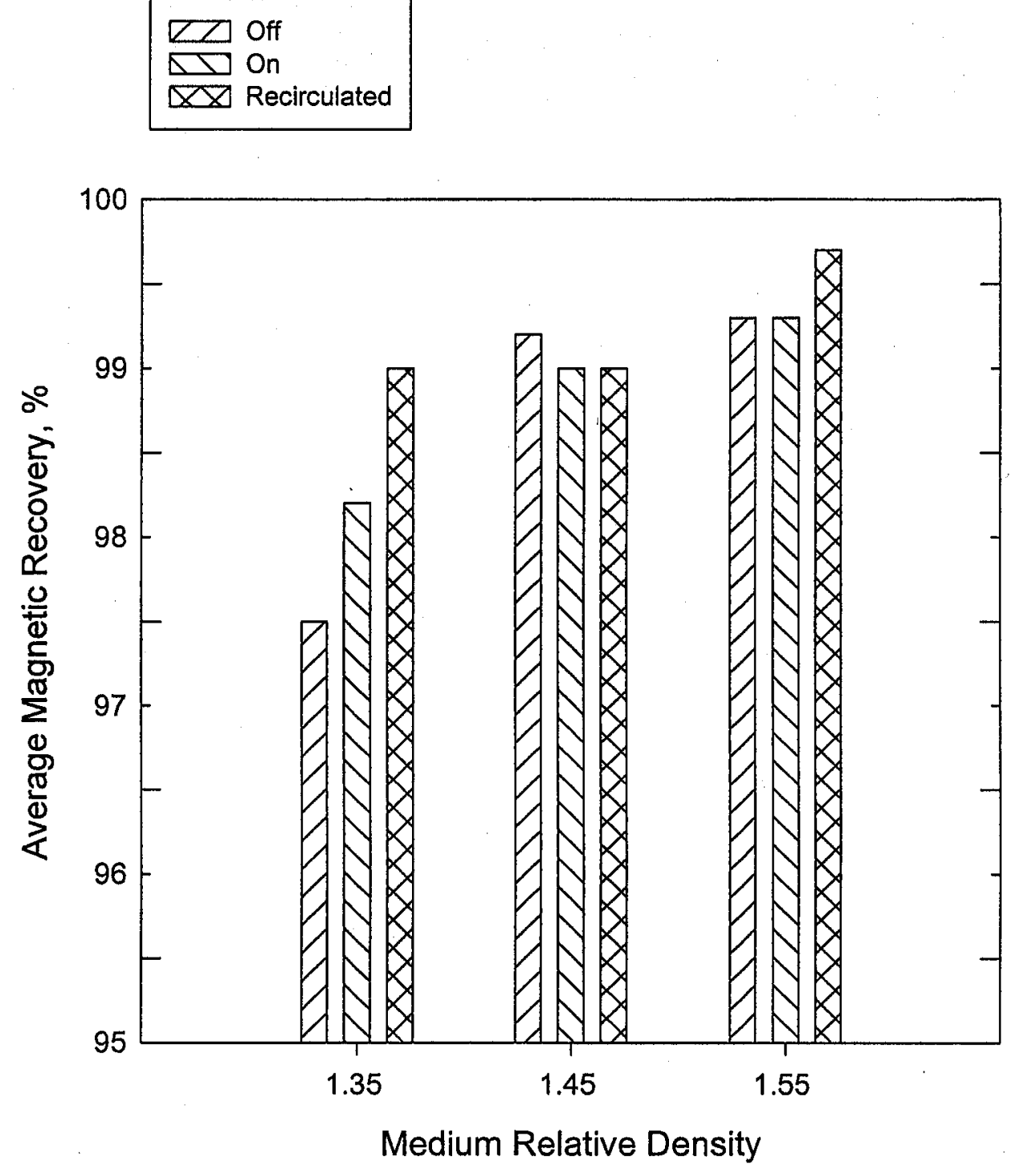

Figure 33. Average magnetic recovery for the cyclone overflow using coal 2. 


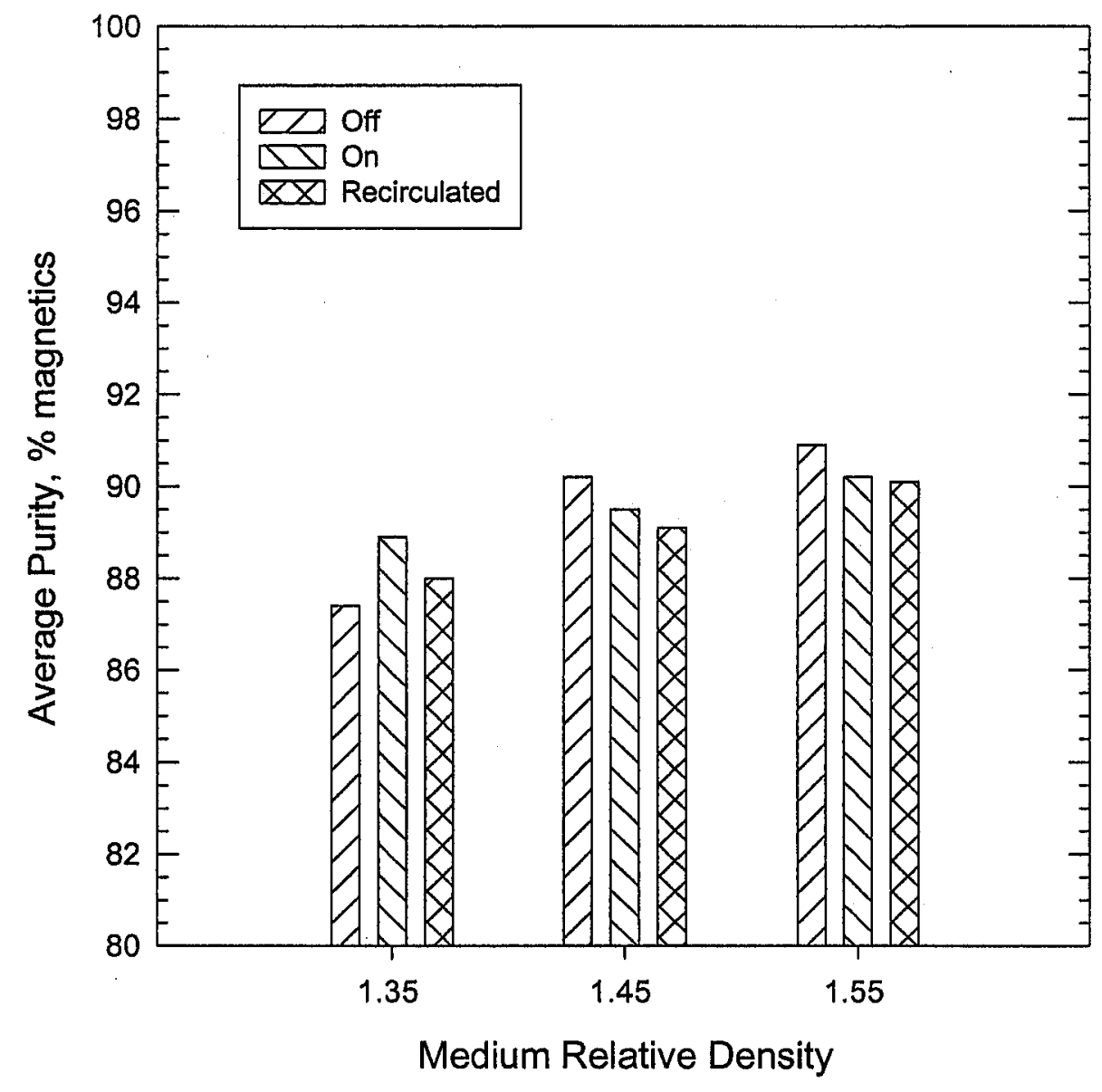

Figure 34. Average magnetic purity for the cyclone overflow using coal 2. 


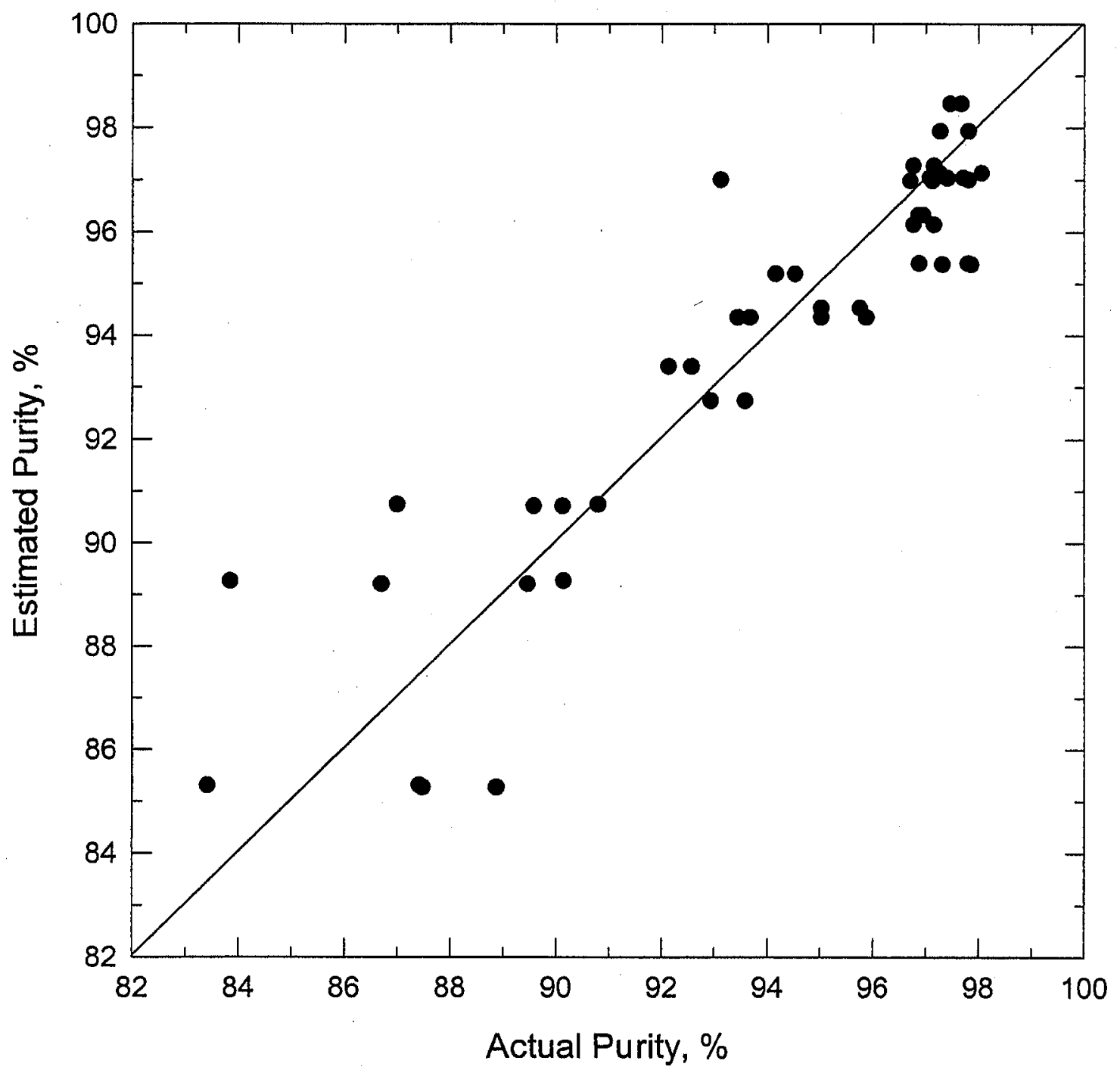

Figure 35. Estimated versus actual magnetic purity considering first and second order effects. 


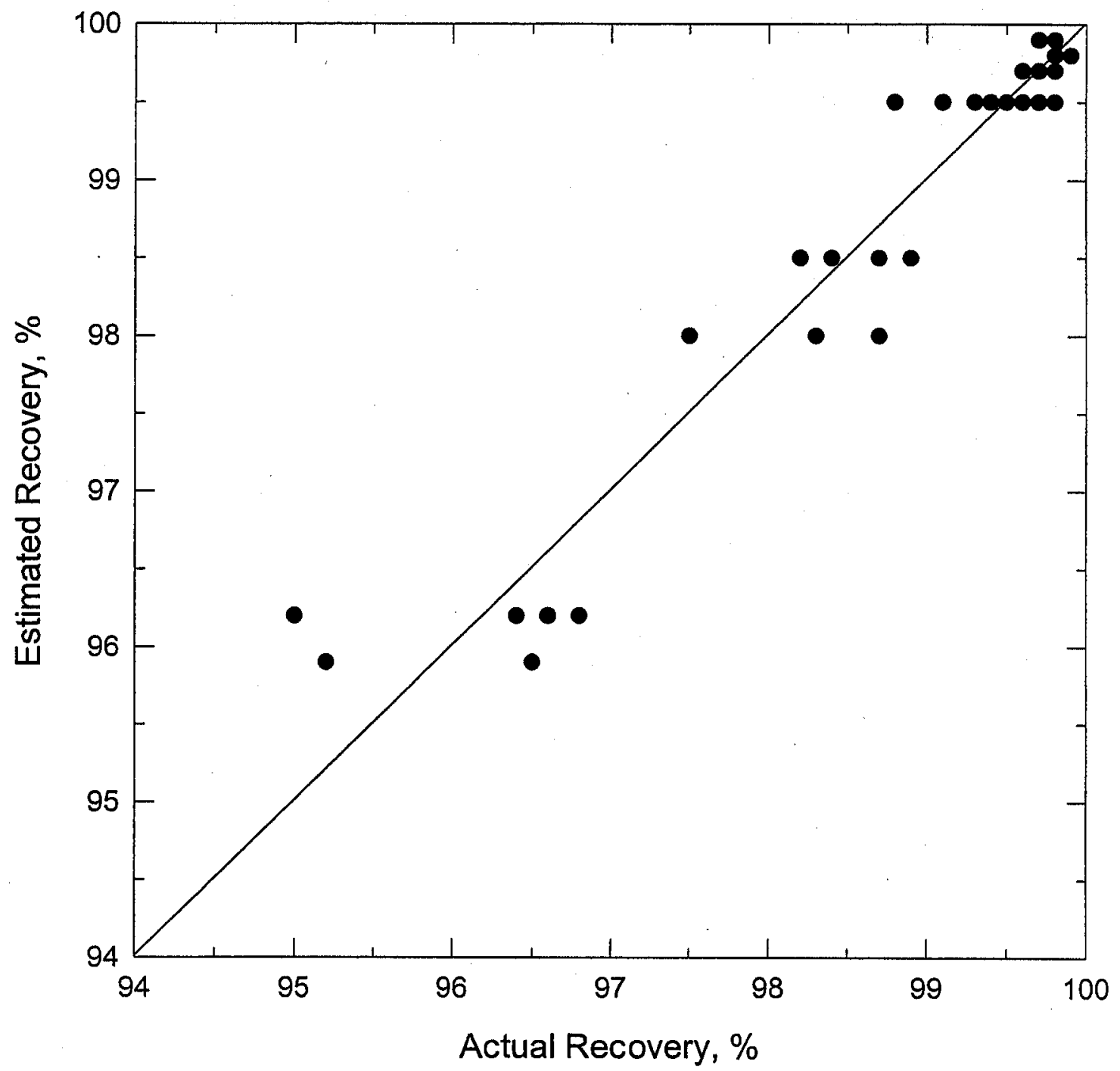

Figure 36. Estimated versus actual magnetic recovery considering first and second order effects. 

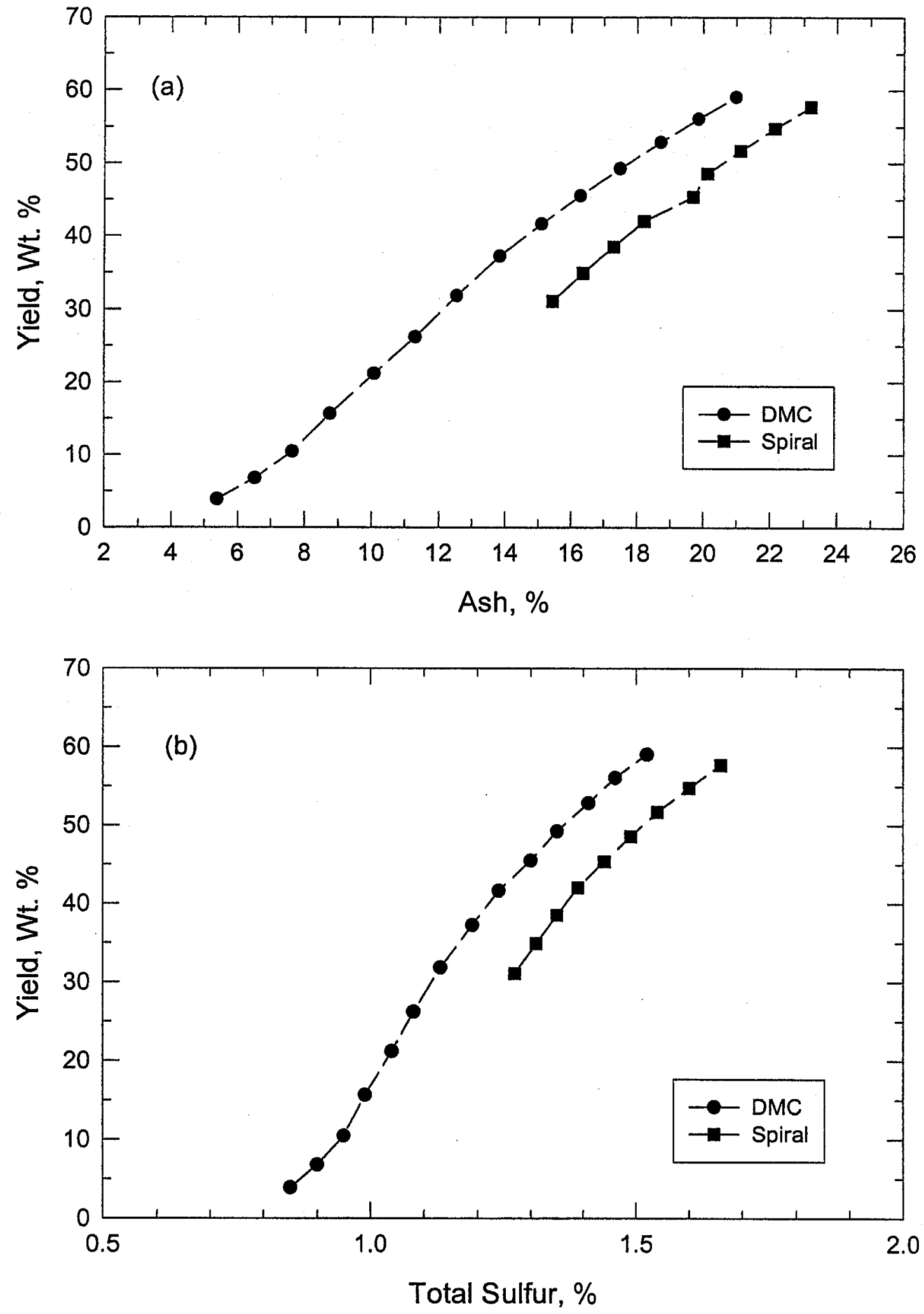

Figure 37. Simulated grade-yield curves for dense-medium and spiral separations: (a) clean coal yield vs. ash content; (b) clean coal yield vs. sulfur content. 


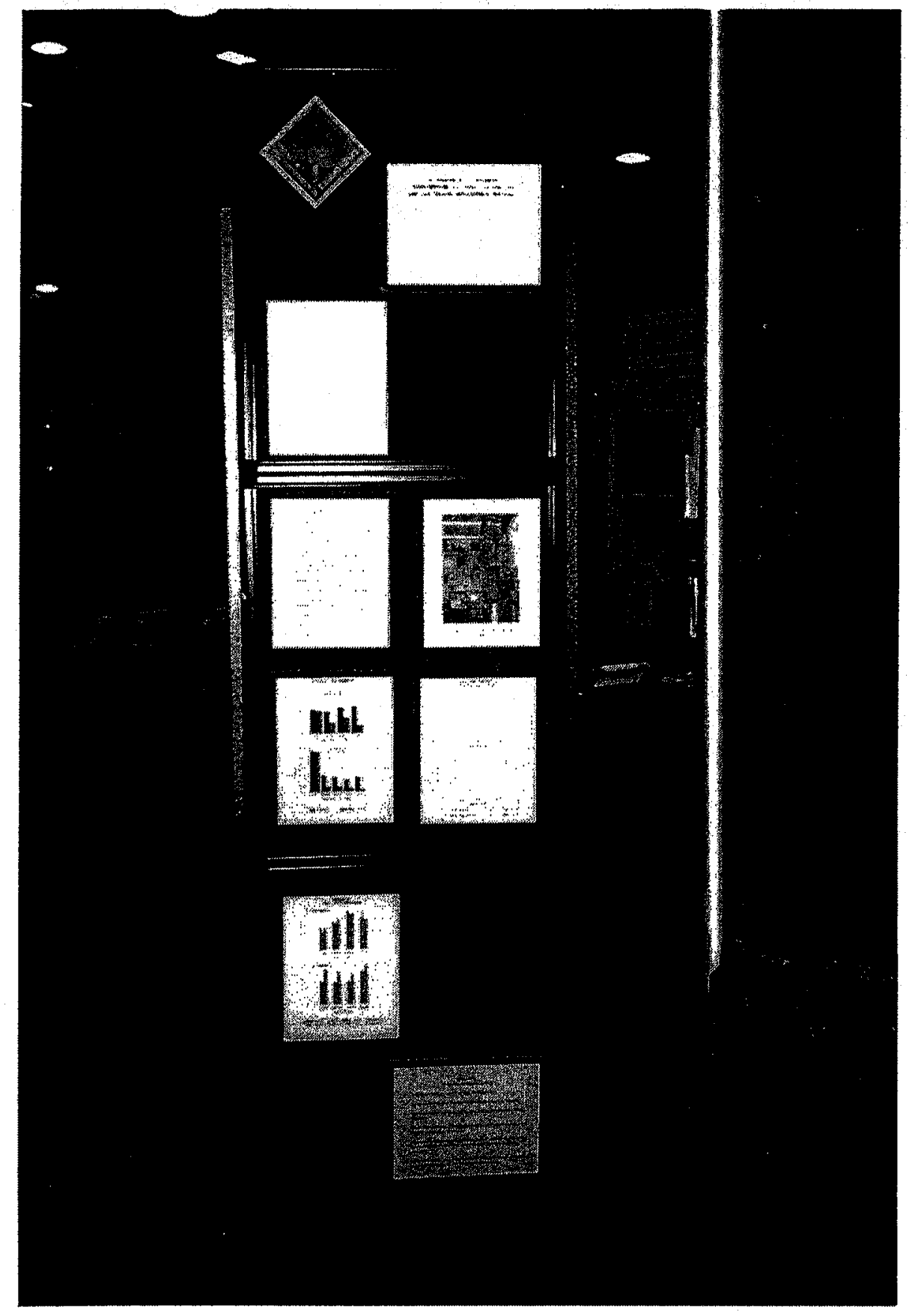

Figure 38. Poster display at Coal Prep 2000. 
Table 1. Washability prediction for coal 1 .

\begin{tabular}{cccc} 
Ash, \% & \multicolumn{3}{c}{$30 \times 200$ Mesh } \\
Yield, \% & $\frac{\text { Total Sulfur, \% }}{\text { Relative Density }}$ & $\frac{1.40^{*}}{6.1}$ \\
\cline { 2 - 3 } 10 & 15 & 1.0 & 1.47 \\
15 & 25 & 1.2 & 1.70 \\
20 & 43 & 1.5 & 1.90
\end{tabular}

\begin{tabular}{|c|c|c|c|}
\hline \multicolumn{4}{|c|}{ 30x50 Mesh } \\
\hline Ash, $\%$ & Yield, \% & Total Sulfur, \% & Relative Density \\
\hline 6.7 & 13.7 & 1.0 & $1.40^{*}$ \\
\hline 10 & 22 & 1.1 & 1.47 \\
\hline 15 & 33 & 1.3 & 1.60 \\
\hline 20 & 46 & 1.5 & 1.90 \\
\hline
\end{tabular}

\begin{tabular}{cccc}
\multicolumn{3}{c}{$\mathbf{5 0 \times 1 0 0}$ Mesh } \\
Ash, \% & $\frac{\text { Yield, \% }}{15}$ & $\frac{\text { Total Sulfur, \% }}{\text { Relative Density }}$ & $\frac{1.40^{*}}{15.0}$ \\
10 & 27 & 0.9 & 1.50 \\
15 & 41 & 1.0 & 1.68 \\
20 & 55 & 1.3 & 1.85
\end{tabular}

* Minimum density used. 
Table 2. Size selectivity results and water splits for coal 2.

\begin{tabular}{|c|c|c|c|c|c|}
\hline \multicolumn{6}{|c|}{ Ultrasonics Off } \\
\hline$\Delta \mathrm{P}, \mathrm{psi}$ & $\mathrm{d}_{50}, \mu \mathrm{m}$ & $\underline{\mathrm{SI}}$ & a-bypass & UF Yield & Water Split \\
\hline 20 & 14.1 & 0.29 & 0.51 & 0.893 & 0.55 \\
\hline 30 & 12.3 & 0.29 & 0.51 & 0.897 & 0.59 \\
\hline 40 & 12.2 & 0.30 & 0.47 & 0.888 & 0.68 \\
\hline
\end{tabular}

$\Delta \mathrm{P}, \mathrm{psi}$
20
30
40

$\underline{\mathrm{d}} \frac{50, \mu \mathrm{m}}{13.4}$
11.8
10.6

$\underline{\mathrm{SI}}$

0.27

0.27

0.23

a-bypass
0.54
0.51
0.48

UF Yield

0.899

0.903

0.891

\begin{tabular}{c} 
Water Split \\
\hline 0.52 \\
0.55 \\
0.60
\end{tabular}

\section{Recirculated at 40 psi}

Ultrasonics

$\mathrm{d}_{50}, \underline{\mu m}$

Off

On

12.2

10.6

a-bypass

$\frac{\mathrm{SI}}{0.30}$

0.23

0.47

0.48

11.3

0.22

0.51

\begin{tabular}{cc} 
UF Yield & Water Split \\
\hline 0.888 & 0.68 \\
0.891 & 0.60 \\
0.897 & 0.56
\end{tabular}


Table 3. E-grade magnetite splits, with and without ultrasonic treatment.

Without Ultrasonics

\begin{tabular}{|c|c|c|c|c|c|c|}
\hline \multirow{2}{*}{ R.D. Feed } & \multirow{2}{*}{$\begin{array}{c}\text { Delta P } \\
\text { (psi) }\end{array}$} & \multirow{2}{*}{ V.F. (in.) } & \multirow{2}{*}{ Apex (in.) } & \multicolumn{2}{|c|}{ R.D. } & \multirow{2}{*}{ Diff. } \\
\hline & & & & UF & $O F$ & \\
\hline 1.35 & 30 & 0.5 & 0.25 & 1.84 & 1.26 & 0.59 \\
\hline 1.35 & 30 & 0.5 & 0.375 & 1.61 & 1.21 & 0.40 \\
\hline 1.35 & 30 & 0.5 & 0.5 & 1.52 & 1.17 & 0.35 \\
\hline
\end{tabular}

\begin{tabular}{|c|c|c|c|c|c|c|}
\hline \multirow{2}{*}{ R.D. Feed } & \multirow{2}{*}{$\begin{array}{c}\text { Delta P } \\
\text { (psi) }\end{array}$} & \multirow{2}{*}{ V.F. (in.) } & \multirow{2}{*}{ Apex (in.) } & \multicolumn{2}{|c|}{ R.D. } & \multirow{2}{*}{ Diff. } \\
\hline & & & & $\overline{\mathrm{UF}}$ & OF & \\
\hline 1.35 & 20 & 0.5 & 0.375 & 1.58 & 1.22 & 0.36 \\
\hline 1.35 & 30 & 0.5 & 0.375 & 1.61 & 1.21 & 0.40 \\
\hline 1.35 & 40 & 0.5 & 0.375 & 1.64 & 1.21 & 0.43 \\
\hline
\end{tabular}

\begin{tabular}{|c|c|c|c|c|c|c|}
\hline \multirow{2}{*}{ R.D. Feed } & Delta P & \multirow{2}{*}{ V.F. (in.) } & \multirow{2}{*}{ Apex (in.) } & \multicolumn{2}{|c|}{ R.D. } & \multirow{2}{*}{ Diff. } \\
\cline { 5 - 6 } & (psi) & & UF & OF & \\
\hline 1.35 & 30 & 0.5 & 0.375 & 1.61 & 1.21 & 0.40 \\
1.45 & 30 & 0.5 & 0.375 & 1.69 & 1.32 & 0.37 \\
1.55 & 30 & 0.5 & 0.375 & 1.76 & 1.43 & 0.33 \\
\hline
\end{tabular}

With Ultrasonics

\begin{tabular}{|c|c|c|c|c|c|c|}
\hline \multirow{2}{*}{ R.D. Feed } & \multirow{2}{*}{$\begin{array}{c}\text { Delta P } \\
\text { (psi) }\end{array}$} & \multirow{2}{*}{ V.F. (in.) } & \multirow{2}{*}{ Apex (in.) } & \multicolumn{2}{|c|}{ R.D. } & \multirow{2}{*}{ Diff. } \\
\hline & & & & $\overline{U F}$ & $\mathrm{OF}$ & \\
\hline 1.35 & 30 & 0.5 & 0.25 & 1.87 & 1.26 & 0.61 \\
\hline 1.35 & 30 & 0.5 & 0.375 & 1.61 & 1.21 & 0.40 \\
\hline 1.35 & 30 & 0.5 & 0.5 & 1.51 & 1.17 & 0.34 \\
\hline
\end{tabular}

\begin{tabular}{|c|c|c|c|c|c|c|}
\hline \multirow{2}{*}{ R.D. Feed } & \multirow{2}{*}{$\begin{array}{c}\text { Delta P } \\
\text { (psi) }\end{array}$} & \multirow{2}{*}{ V.F. (in.) } & \multirow{2}{*}{ Apex (in.) } & \multicolumn{2}{|c|}{ R.D. } & \multirow{2}{*}{ Diff. } \\
\hline & & & & UF & OF & \\
\hline 1.35 & 20 & 0.5 & 0.375 & 1.57 & 1.22 & 0.35 \\
\hline 1.35 & 30 & 0.5 & 0.375 & 1.61 & 1.21 & 0.40 \\
\hline 1.35 & 40 & 0.5 & 0.375 & 1.64 & 1.21 & 0.43 \\
\hline
\end{tabular}

\begin{tabular}{|c|c|c|c|c|c|c|}
\hline \multirow{2}{*}{ R.D. Feed } & \multirow{2}{*}{$\begin{array}{c}\text { Delta P } \\
\text { (psi) }\end{array}$} & \multirow{2}{*}{ V.F. (in.) } & \multirow{2}{*}{ Apex (in.) } & \multicolumn{2}{|c|}{ R.D. } & \multirow{2}{*}{ Diff. } \\
\hline & & & & UF & OF & \\
\hline 1.35 & 30 & 0.5 & 0.375 & 1.61 & 1.21 & 0.40 \\
\hline 1.45 & 30 & 0.5 & 0.375 & 1.70 & 1.32 & 0.38 \\
\hline 1.55 & 30 & 0.5 & 0.375 & 1.77 & 1.43 & 0.33 \\
\hline
\end{tabular}


Table 4. B-grade magnetite splits, with and without ultrasonic treatment.

\section{Without Ultrasonics}

\begin{tabular}{|c|c|c|c|c|c|c|}
\hline \multirow{2}{*}{ R.D. Feed } & \multirow{2}{*}{$\begin{array}{c}\text { Delta } P \\
\text { (psi) }\end{array}$} & \multirow{2}{*}{ V.F. (in.) } & \multirow{2}{*}{ Apex (in.) } & \multicolumn{2}{|c|}{ R.D. } & \multirow{2}{*}{ Diff. } \\
\hline & & & & UF & OF & \\
\hline 1.35 & 30 & 0.5 & 0.25 & 2.62 & 1.13 & 1.49 \\
\hline 1.35 & 30 & 0.5 & 0.375 & 2.04 & 1.06 & 0.98 \\
\hline 1.35 & 30 & 0.5 & 0.5 & 1.71 & 1.04 & 0.67 \\
\hline
\end{tabular}

\begin{tabular}{|c|c|c|c|c|c|c|}
\hline \multirow{2}{*}{ R.D. Feed } & \multirow{2}{*}{$\begin{array}{c}\text { Delta } P \\
\text { (psi) }\end{array}$} & \multirow{2}{*}{ V.F. (in.) } & \multirow{2}{*}{ Apex (in.) } & \multicolumn{2}{|c|}{ R.D. } & \multirow{2}{*}{ Diff. } \\
\hline & & & & UF & OF & \\
\hline 1.35 & 20 & 0.5 & 0.375 & 2.04 & 1.07 & 0.97 \\
\hline 1.35 & 30 & 0.5 & 0.375 & 2.04 & 1.06 & 0.98 \\
\hline 1.35 & 40 & 0.5 & 0.375 & 1.96 & 1.06 & 0.90 \\
\hline
\end{tabular}

\begin{tabular}{|c|c|c|c|c|c|c|}
\hline \multirow{2}{*}{ R.D. Feed } & \multirow{2}{*}{$\begin{array}{l}\text { Delta P } \\
\text { (psi) }\end{array}$} & \multirow{2}{*}{ V.F. (in.) } & \multirow{2}{*}{ Apex (in.) } & \multicolumn{2}{|c|}{ R.D. } & \multirow{2}{*}{ Diff. } \\
\hline & & & & UF & OF & \\
\hline 1.35 & 30 & 0.5 & 0.375 & 2.04 & 1.06 & 0.98 \\
\hline 1.45 & 30 & 0.5 & 0.375 & 2.34 & 1.12 & 1.22 \\
\hline 1.55 & 30 & 0.5 & 0.375 & 2.53 & 1.19 & 1.34 \\
\hline
\end{tabular}

\section{With Ultrasonics}

\begin{tabular}{|c|c|c|c|c|c|c|}
\hline \multirow{2}{*}{ R.D. Feed } & \multirow{2}{*}{$\begin{array}{c}\text { Delta P } \\
\text { (psi) }\end{array}$} & \multirow{2}{*}{ V.F. (in:) } & \multirow{2}{*}{ Apex (in.) } & \multicolumn{2}{|c|}{ R.D. } & \multirow{2}{*}{ Diff. } \\
\hline & & & & UF & OF & \\
\hline 1.35 & 30 & 0.5 & 0.25 & $* * *$ & $* * *$ & $* * *$ \\
\hline 1.35 & 30 & 0.5 & 0.375 & 2.05 & 1.06 & 0.99 \\
\hline 1.35 & 30 & 0.5 & 0.5 & 1.71 & 1.04 & 0.67 \\
\hline
\end{tabular}

\begin{tabular}{|c|c|c|c|c|c|c|}
\hline \multirow{2}{*}{ R.D. Feed } & \multirow{2}{*}{$\begin{array}{c}\text { Delta P } \\
\text { (psi) }\end{array}$} & \multirow{2}{*}{ V.F. (in.) } & \multirow{2}{*}{ Apex (in.) } & \multicolumn{2}{|c|}{ R.D. } & \multirow{2}{*}{ Diff. } \\
\hline & & & & UF & OF & \\
\hline 1.35 & 20 & 0.5 & 0.375 & 2.04 & 1.07 & 0.97 \\
\hline 1.35 & 30 & 0.5 & 0.375 & 2.05 & 1.06 & 0.99 \\
\hline 1.35 & 40 & 0.5 & 0.375 & 2.03 & 1.06 & 0.97 \\
\hline
\end{tabular}

\begin{tabular}{|c|c|c|c|c|c|c|}
\hline \multirow{2}{*}{ R.D. Feed } & \multirow{2}{*}{$\begin{array}{c}\text { Delta P } \\
\text { (psi) }\end{array}$} & \multirow{2}{*}{ V.F. (in.) } & \multirow{2}{*}{ Apex (in.) } & \multicolumn{2}{|c|}{ R.D. } & \multirow{2}{*}{ Diff. } \\
\hline & & & & UF & OF & \\
\hline 1.35 & 30 & 0.5 & 0.375 & 2.05 & 1.06 & 0.99 \\
\hline 1.45 & 30 & 0.5 & 0.375 & 2.34 & 1.12 & 1.22 \\
\hline 1.55 & 30 & 0.5 & 0.375 & 2.47 & 1.19 & 1.29 \\
\hline
\end{tabular}


Table 5. Summary of dense-medium cyclone test conditions and results (medium R.D. $=1.35$, medium-to-coal ratio $=5: 1$, OF diameter $=0.5$ in.).

Test UFDia., in. OF/UF $\underline{\Delta P, p s i}$ Ultrasonic $\underline{\text { Sulfur, \% }}$ Ash, \% Yield, \%

$1 \mathrm{OF} \quad 0.375$

$1.33 \quad 20$

OFF

0.81

8.3

50.1

$1 \mathrm{UF} \quad 0.375$

$1.33 \quad 20$

OFF

3.72

66.7

49.9

$2 \mathrm{OF} \quad 0.375$

$1.33 \quad 20$

ON

0.80

8.4

50.1

2 UF $\quad 0.375$

$1.33 \quad 20$

ON

3.67

66.6

49.9

$3 \mathrm{OF} \quad 0.375$

$1.33 \quad 30$

OFF

0.77

8.3

51.0

3 UF $\quad 0.375$

$1.33 \quad 30$

OFF

4.43

67.8

49.0

$4 \mathrm{OF} \quad 0.375$

$1.33 \quad 30$

4 UF $\quad 0.375$

$1.33 \quad 30$

5 OF $\quad 0.375$

1.33

40

5 UF $\quad 0.375$

1.33

ON

0.73

7.7

50.7

6 OF $\quad 0.375$

1.33

ON

4.02

68.0

49.3

6 UF $\quad 0.375$

1.33

OFF

0.74

8.0

51.2

$7 \mathrm{OF}^{*} \quad 0.375$

1.33

40

OFF

3.60

68.4

48.8

$7 \mathrm{UF}^{*} \quad 0.375$

1.33

40

ON

0.77

7.9

49.3

$8 \mathrm{OF}^{*} \quad 0.375$

1.33

40

ON

3.83

66.2

50.8

ON

0.74

7.5

50.6

ON

3.42

68.1

49.4

$8 \mathrm{UF}^{*}, 0.375$

1.33

0.74

7.9

49.9

$\begin{array}{llll}9 \text { OF } & 0.5 & 1.0 & 20\end{array}$

9 UF $\quad 0.5$

$1.0 \quad 20$

$10 \mathrm{OF} \quad 0.5$

$1.0 \quad 20$

$10 \mathrm{UF} \quad 0.5$

1.0

20

$11 \mathrm{OF} \quad 0.5$

1.0

30

11 UF $\quad 0.5$

1.0

30

$12 \mathrm{OF} \quad 0.5$

1.0

30

12 UF $\quad 0.5$

$1.0 \quad 30$

$13 \mathrm{OF} \quad 0.5$

1.0

40

13 UF $\quad 0.5$

1.0

40

3.74

66.8

50.1

ON

0.75

6.9

39.1

OFF

2.91

57.1

60.9

ON

0.75

6.6

38.6

ON

2.87

56.8

61.4

OFF

0.74

6.4

38.6

OFF

3.20

57.0

61.5

$14 \mathrm{OF} \quad 0.5$

1.0

40

0.76

6.0

39.2

ON

3.21

57.7

60.8

OFF

0.74

5.7

38.0

OFF

3.05

56.9

62.0

$14 \mathrm{UF}$

0.5

1.0

40

ON

0.72

5.8

38.3

ON

3.00

57.1

61.7

"Denotes replicate test. 
Table 6. Summary of dense-medium cyclone test conditions and results

(medium R.D. $=1.45$, medium-to-coal ratio $=4: 1$, OF diameter $=0.5$ in.).

Test UFDia., in. OF/UF $\underline{\text { AP,psi }}$ Ultrasonic $\underline{\text { Sulfur, \% }} \underline{\text { Ash, \% }} \quad \underline{\text { Yield, \% }}$

$\begin{array}{lccccccc}1 \text { OF } & 0.375 & 1.33 & 20 & \text { OFF } & 0.75 & 10.7 & 54.3 \\ 1 \text { UF } & 0.375 & 1.33 & 20 & \text { OFF } & 3.83 & 69.0 & 45.7 \\ 2 \text { OF } & 0.375 & 1.33 & 20 & \text { ON } & 0.79 & 10.6 & 54.1 \\ 2 \text { UF } & 0.375 & 1.33 & 20 & \text { ON } & 4.17 & 69.0 & 45.9 \\ 3 \text { OF } & 0.375 & 1.33 & 30 & \text { OFF } & 0.79 & 10.0 & 55.3 \\ 3 \text { UF } & 0.375 & 1.33 & 30 & \text { OFF } & 4.09 & 71.2 & 44.7 \\ 4 \text { OF } & 0.375 & 1.33 & 30 & \text { ON } & 0.75 & 9.8 & 55.5 \\ 4 \text { UF } & 0.375 & 1.33 & 30 & \text { ON } & 4.51 & 71.8 & 44.5 \\ 5 \text { OF } & 0.375 & 1.33 & 40 & \text { OFF } & 0.76 & 9.3 & 55.8 \\ 5 \text { UF } & 0.375 & 1.33 & 40 & \text { OFF } & 4.52 & 72.8 & 44.2 \\ 6 \text { OF } & 0.375 & 1.33 & 40 & \text { ON } & 0.77 & 9.3 & 56.5 \\ 6 \text { UF } & 0.375 & 1.33 & 40 & \text { ON } & 4.42 & 73.7 & 43.6 \\ 7 \text { OF } & 0.5 & 1.0 & 20 & \text { OFF } & 0.76 & 9.3 & 48.6 \\ 7 \text { UF } & 0.5 & 1.0 & 20 & \text { OFF } & 4.10 & 63.9 & 51.4 \\ 8 \text { OF } & 0.5 & 1.0 & 20 & \text { ON } & 0.77 & 9.2 & 45.0 \\ 8 \text { UF } & 0.5 & 1.0 & 20 & \text { ON } & 3.70 & 60.4 & 55.0 \\ 9 \text { OF* } & 0.5 & 1.0 & 20 & \text { ON } & 0.77 & 8.9 & 42.7 \\ 9 \text { UF* } & 0.5 & 1.0 & 20 & \text { ON } & 4.32 & 58.6 & 57.3 \\ 10 \text { OF* } & 0.5 & 1.0 & 20 & \text { ON } & 0.78 & 9.4 & 48.2 \\ 10 \mathrm{UF} * & 0.5 & 1.0 & 20 & \text { ON } & 4.02 & 63.4 & 51.8 \\ 11 \mathrm{OF} & 0.5 & 1.0 & 30 & \text { OFF } & 0.76 & 9.1 & 50.1 \\ 11 \mathrm{UF} & 0.5 & 1.0 & 30 & \text { OFF } & 3.46 & 65.8 & 49.9 \\ 12 \mathrm{OF} & 0.5 & 1.0 & 30 & \text { ON } & 0.76 & 8.6 & 47.7 \\ 12 \mathrm{UF} & 0.5 & 1.0 & 30 & \text { ON } & 3.31 & 63.6 & 52.3 \\ 13 \mathrm{OF} & 0.5 & 1.0 & 40 & \text { OFF } & 0.75 & 8.5 & 48.5 \\ 13 \mathrm{UF} & 0.5 & 1.0 & 40 & \text { OFF } & 3.38 & 64.5 & 51.5 \\ 14 \mathrm{OF} & 0.5 & 1.0 & 40 & \text { ON } & 0.74 & 8.8 & 49.3 \\ 14 \mathrm{UF} & 0.5 & 1.0 & 40 & \text { ON } & 3.35 & 65.1 & 50.7 \\ & & & & & & & \\ 1\end{array}$

* Denotes replicate test. 
Table 7. Summary of dense-medium cyclone test conditions and results (medium R.D. $=1.55$, medium-to-coal ratio $=5: 1$, OF diameter $=0.5$ in.).

Test UF Dia., in. OF/UF $\underline{\Delta P}$, psi $\underline{\text { Ultrasonic }}$ Sulfur, \% $\underline{\text { Ash, \% }}$ Yield, \%

$\begin{array}{llllllll}1 \text { OF } & 0.375 & 1.33 & 20 & \text { OFF } & 0.79 & 12.3 & 46.1 \\ 1 \text { UF } & 0.375 & 1.33 & 20 & \text { OFF } & 3.65 & 71.1 & 53.9 \\ 2 \text { OF } & 0.375 & 1.33 & 20 & \text { ON } & 0.86 & 13.9 & 48.2 \\ 2 \mathrm{UF} & 0.375 & 1.33 & 20 & \text { ON } & 4.31 & 72.1 & 51.8 \\ 3 \mathrm{OF} & 0.375 & 1.33 & 30 & \text { OFF } & 0.76 & 11.2 & 47.9 \\ 3 \mathrm{UF} & 0.375 & 1.33 & 30 & \text { OFF } & 3.55 & 74.2 & 52.1 \\ 4 \mathrm{OF} & 0.375 & 1.33 & 30 & \text { ON } & 0.76 & 11.4 & 48.2 \\ 4 \mathrm{UF} & 0.375 & 1.33 & 30 & \text { ON } & 3.07 & 74.3 & 51.8 \\ 5 \mathrm{OF} & 0.375 & 1.33 & 40 & \text { OFF } & 0.74 & 10.8 & 48.5 \\ 5 \mathrm{UF} & 0.375 & 1.33 & 40 & \text { OFF } & 4.54 & 75.3 & 51.5 \\ 6 \mathrm{OF} & 0.375 & 1.33 & 40 & \text { ON } & 0.78 & 11.2 & 49.4 \\ 6 \mathrm{UF} & 0.375 & 1.33 & 40 & \text { ON } & 3.72 & 76.0 & 0.6 \\ 7 \mathrm{OF} & 0.5 & 1.0 & 20 & \text { OFF } & 0.78 & 10.2 & 35.6 \\ 7 \mathrm{UF} & 0.5 & 1.0 & 20 & \text { OFF } & 3.36 & 62.7 & 64.4 \\ 8 \mathrm{OF} & 0.5 & 1.0 & 20 & \text { ON } & 0.78 & 10.3 & 34.4 \\ 8 \mathrm{UF} & 0.5 & 1.0 & 20 & \text { ON } & 3.08 & 61.7 & 65.6 \\ 9 \mathrm{OF} & 0.5 & 1.0 & 30 & \text { OFF } & 0.76 & 9.6 & 38.7 \\ 9 \mathrm{UF} & 0.5 & 1.0 & 30 & \text { OFF } & 3.27 & 65.7 & 61.3 \\ 10 \mathrm{OF} & 0.5 & 1.0 & 30 & \text { ON } & 0.74 & 9.8 & 38.2 \\ 10 \mathrm{UF} & 0.5 & 1.0 & 30 & \text { ON } & 3.29 & 65.2 & 61.8 \\ 11 \mathrm{OF} & 0.5 & 1.0 & 40 & \text { OFF } & 0.75 & 9.5 & 40.7 \\ 11 \mathrm{UF} & 0.5 & 1.0 & 40 & \text { OFF } & 3.74 & 67.6 & 59.3 \\ 12 \mathrm{OF} & 0.5 & 1.0 & 40 & \text { ON } & 0.73 & 9.8 & 38.2 \\ 12 \mathrm{UF} & 0.5 & 1.0 & 40 & \text { ON } & 2.99 & 65.1 & 61.8 \\ 13 \mathrm{OF} & 0.5 & 1.0 & 40 & \text { ON } & 0.75 & 9.9 & 41.3 \\ 13 \mathrm{UF} & 0.5 & 1.0 & 40 & \text { ON } & 3.06 & 68.0 & 58.7 \\ 14 \mathrm{OF} * & 0.5 & 1.0 & 40 & \text { ON } & 0.74 & 9.4 & 39.1 \\ 14 \mathrm{UF} & 0.5 & 1.0 & 40 & \text { ON } & 3.33 & 66.2 & 60.9\end{array}$

* Denotes replicate test. 
Table 8. Size distributions and ash contents of the +400 mesh material at 1.35 medium relative density.

\begin{tabular}{|c|c|c|c|c|c|c|c|c|}
\hline & \multicolumn{2}{|c|}{ 1 OF (U/S Off) } & \multicolumn{2}{c|}{ 2 OF (U/S On) } & \multicolumn{2}{c|}{ 1 UF (U/S Off) } & \multicolumn{2}{c|}{ 2 UF (U/S On) } \\
\hline Mesh & Wt. \% & Ash \% & Wt. \% & Ash \% & Wt. \% & Ash \% & Wt. \% & Ash \% \\
\hline $30 \times 50$ & 17.45 & 7.2 & 17.28 & 7.5 & 31.25 & 75.2 & 30.79 & 76.2 \\
\hline $50 \times 100$ & 23.11 & 7.2 & 23.79 & 7.2 & 31.67 & 72.2 & 21.14 & 73.0 \\
\hline $100 \times 200$ & 32.08 & 7.6 & 30.02 & 7.2 & 21.40 & 62.0 & 20.85 & 64.9 \\
\hline $200 \times 400$ & 27.35 & 11.2 & 28.91 & 10.5 & 15.68 & 53.7 & 17.22 & 54.7 \\
\hline
\end{tabular}

\begin{tabular}{|c|c|c|c|c|c|c|c|c|}
\hline & \multicolumn{2}{|c|}{ 3 OF (U/S Off) } & \multicolumn{2}{c|}{ 4 OF (U/S On) } & \multicolumn{2}{c|}{ 3 UF (U/S Off) } & \multicolumn{2}{c|}{ 4 UF (U/S On) } \\
\hline Mesh & Wt. \% & Ash \% & Wt. \% & Ash \% & Wt. \% & Ash \% & Wt. \% & Ash \% \\
\hline $30 \times 50$ & 16.82 & 7.0 & 16.52 & 7.1 & 33.79 & 76.3 & 32.76 & 74.9 \\
\hline $50 \times 100$ & 22.92 & 6.8 & 23.33 & 6.6 & 31.15 & 73.4 & 29.94 & 72.1 \\
\hline $100 \times 200$ & 32.58 & 6.8 & 30.27 & 6.6 & 20.74 & 66.0 & 9.48 & 67.0 \\
\hline $200 \times 400$ & 27.69 & 10.0 & 29.88 & 9.6 & 14.31 & 55.8 & 27.81 & 60.0 \\
\hline
\end{tabular}

\begin{tabular}{|c|c|c|c|c|c|c|c|c|}
\hline & \multicolumn{2}{|c|}{ 5 OF (U/S Off) } & \multicolumn{2}{c|}{ 6 OF (U/S On) } & \multicolumn{2}{c|}{ 5 UF (U/S Off) } & \multicolumn{2}{c|}{6 UF (U/S On) } \\
\hline Mesh & Wt. \% & Ash \% & Wt. \% & Ash \% & Wt. \% & Ash \% & Wt. \% & Ash \% \\
\hline $30 \times 50$ & 13.28 & 7.9 & 16.41 & 7.3 & 33.20 & 73.7 & 30.77 & 72.6 \\
\hline $50 \times 100$ & 21.56 & 6.8 & 23.35 & 6.8 & 31.63 & 73.1 & 30.70 & 71.0 \\
\hline $100 \times 200$ & 34.26 & 6.4 & 30.19 & 6.8 & 21.01 & 65.4 & 22.51 & 63.1 \\
\hline $200 \times 400$ & 30.90 & 9.2 & 30.05 & 9.3 & 14.16 & 56.0 & 16.02 & 54.8 \\
\hline
\end{tabular}

\begin{tabular}{|c|c|c|c|c|c|c|c|c|}
\hline & \multicolumn{2}{|c|}{ 7 OF (U/S On) $^{*}$} & \multicolumn{2}{c|}{ 8 OF (U/S On)* } & \multicolumn{2}{c|}{ 7 UF (U/S On) } & \multicolumn{2}{c|}{8 UF (U/S On) } \\
\hline Mesh & Wt. \% & Ash \% & Wt. \% & Ash \% & Wt. \% & Ash \% & Wt. \% & Ash \% \\
\hline $30 \times 50$ & 17.10 & 6.8 & 18.54 & 7.1 & 32.54 & 74.0 & 29.87 & 74.4 \\
\hline $50 \times 100$ & 22.09 & 6.4 & 24.35 & 6.6 & 31.45 & 72.2 & 31.34 & 70.8 \\
\hline $100 \times 200$ & 31.51 & 6.4 & 31.83 & 6.2 & 20.85 & 66.6 & 21.11 & 64.9 \\
\hline $200 \times 400$ & 29.30 & 9.0 & 25.29 & 8.4 & 15.15 & 55.1 & 17.68 & 56.3 \\
\hline
\end{tabular}

* Denotes replicate test. 
Table 8. (cont.)

\begin{tabular}{|c|c|c|c|c|c|c|c|c|}
\hline & \multicolumn{2}{|c|}{ 9 OF (U/S Off) } & \multicolumn{2}{c|}{ 10 OF (U/S On) } & \multicolumn{2}{c|}{ 9 UF (U/S Off) } & \multicolumn{2}{c|}{ 10 UF (U/S On) } \\
\hline Mesh & Wt. \% & Ash \% & Wt. \% & Ash \% & Wt. \% & Ash \% & Wt. \% & Ash \% \\
\hline $30 \times 50$ & 18.53 & 6.2 & 18.47 & 6.1 & 26.79 & 71.3 & 28.86 & 72.0 \\
\hline $50 \times 100$ & 23.54 & 5.7 & 23.33 & 5.7 & 29.29 & 67.5 & 29.91 & 67.1 \\
\hline $100 \times 200$ & 31.75 & 5.8 & 31.79 & 5.9 & 22.82 & 53.0 & 23.45 & 51.7 \\
\hline $200 \times 400$ & 26.19 & 9.1 & 26.40 & 9.0 & 21.09 & 41.8 & 17.78 & 39.5 \\
\hline
\end{tabular}

\begin{tabular}{|c|c|c|c|c|c|c|c|c|}
\hline & \multicolumn{2}{|c|}{11 OF (U/S Off) } & \multicolumn{2}{c|}{ 12 OF (U/S On) } & \multicolumn{2}{c|}{ 11 UF (U/S Off) } & \multicolumn{2}{c|}{ 12 UF (U/S On) } \\
\hline Mesh & Wt. \% & Ash \% & Wt. \% & Ash \% & Wt. \% & Ash \% & Wt. \% & Ash \% \\
\hline $30 \times 50$ & 18.54 & 5.7 & 14.87 & 5.5 & 27.38 & 70.8 & 28.94 & 70.9 \\
\hline $50 \times 100$ & 23.17 & 5.4 & 22.74 & 5.4 & 30.32 & 67.0 & 30.26 & 66.3 \\
\hline $100 \times 200$ & 32.03 & 5.4 & 30.16 & 5.6 & 22.42 & 53.3 & 23.16 & 53.3 \\
\hline $200 \times 400$ & 26.26 & 8.1 & 32.23 & 7.8 & 19.88 & 44.3 & 17.63 & 41.0 \\
\hline
\end{tabular}

\begin{tabular}{|c|c|c|c|c|c|c|c|c|}
\hline & \multicolumn{2}{|c|}{13 OF (U/S Off) } & \multicolumn{2}{c|}{14 OF (U/S On) } & \multicolumn{2}{c|}{ 13 UF (U/S Off) } & \multicolumn{2}{c|}{ 14 UF (U/S On) } \\
\hline Mesh & Wt. \% & Ash \% & Wt. \% & Ash \% & Wt. \% & Ash \% & Wt. \% & Ash \% \\
\hline $30 \times 50$ & 17.30 & 5.7 & 16.80 & 5.2 & 27.86 & 69.1 & 27.19 & 70.9 \\
\hline $50 \times 100$ & 23.09 & 5.1 & 23.26 & 5.0 & 30.18 & 64.7 & 30.16 & 66.1 \\
\hline $100 \times 200$ & 32.75 & 5.1 & 32.91 & 5.2 & 23.31 & 49.6 & 23.23 & 52.7 \\
\hline $200 \times 400$ & 26.87 & 7.8 & 27.04 & 7.1 & 18.65 & 43.0 & 19.43 & 45.7 \\
\hline
\end{tabular}


Table 9. Size distributions and ash contents of the +400 mesh material at 1.45 medium relative density.

\begin{tabular}{|c|c|c|c|c|c|c|c|c|}
\hline & \multicolumn{2}{|c|}{ 1 OF (U/S Off) } & \multicolumn{2}{c|}{ 2 OF (U/S On) } & \multicolumn{2}{c|}{ 1 UF (U/S Off) } & \multicolumn{2}{c|}{ 2 UF (U/S On) } \\
\hline Mesh & Wt. \% & Ash \% & Wt. \% & Ash \% & Wt. \% & Ash \% & Wt. \% & Ash \% \\
\hline $30 \times 50$ & 17.66 & 9.3 & 17.24 & 9.3 & 26.55 & 79.5 & 26.64 & 80.0 \\
\hline $50 \times 100$ & 25.00 & 9.3 & 24.86 & 9.2 & 30.96 & 78.0 & 31.03 & 78.0 \\
\hline $100 \times 200$ & 29.71 & 9.0 & 29.80 & 9.0 & 23.17 & 67.8 & 22.99 & 67.5 \\
\hline $200 \times 400$ & 27.63 & 13.1 & 28.11 & 12.9 & 19.33 & 52.4 & 19.35 & 52.6 \\
\hline
\end{tabular}

\begin{tabular}{|c|c|c|c|c|c|c|c|c|}
\hline & \multicolumn{2}{|c|}{3 OF (U/S Off) } & \multicolumn{2}{c|}{ 4 OF (U/S On) } & \multicolumn{2}{c|}{ 3 UF (U/S Off) } & \multicolumn{2}{c|}{ 4 UF (U/S On) } \\
\hline Mesh & Wt. \% & Ash \% & Wt. \% & Ash \% & Wt. \% & Ash \% & Wt. \% & Ash \% \\
\hline $30 \times 50$ & 16.84 & 9.3 & 16.67 & 9.2 & 28.40 & 80.2 & 27.69 & 79.6 \\
\hline $50 \times 100$ & 24.01 & 9.0 & 24.05 & 8.9 & 32.73 & 79.0 & 32.71 & 79.5 \\
\hline $100 \times 200$ & 30.47 & 8.4 & 30.29 & 8.1 & 21.12 & 70.6 & 21.32 & 70.5 \\
\hline $200 \times 400$ & 28.68 & 11.6 & 28.98 & 11.4 & 17.75 & 58.3 & 18.28 & 57.9 \\
\hline
\end{tabular}

\begin{tabular}{|c|c|c|c|c|c|c|c|c|}
\hline & \multicolumn{2}{|c|}{5 OF (U/S Off) } & \multicolumn{2}{c|}{ 6 OF (U/S On) } & \multicolumn{2}{c|}{ 5 UF (U/S Off) } & \multicolumn{2}{c|}{ 6 UF (U/S On) } \\
\hline Mesh & Wt. \% & Ash \% & Wt. \% & Ash \% & Wt. \% & Ash \% & Wt. \% & Ash \% \\
\hline $30 \times 50$ & 16.93 & 9.4 & 17.10 & 9.3 & 28.48 & 79.5 & 29.37 & 79.8 \\
\hline $50 \times 100$ & 24.48 & 9.0 & 25.05 & 8.8 & 31.81 & 79.5 & 32.73 & 79.6 \\
\hline $100 \times 200$ & 30.58 & 8.0 & 30.48 & 8.0 & 21.89 & 73.0 & 23.23 & 71.5 \\
\hline $200 \times 400$ & 28.01 & 10.6 & 27.37 & 10.6 & 17.82 & 61.2 & 14.66 & 59.0 \\
\hline
\end{tabular}

\begin{tabular}{|c|c|c|c|c|c|c|c|c|}
\hline & \multicolumn{2}{|c|}{ 7 OF (U/S Off) } & \multicolumn{2}{c|}{8 OF (U/S On) } & \multicolumn{2}{c|}{ 7 UF (U/S Off) } & \multicolumn{2}{c|}{8 UF (U/S On) } \\
\hline Mesh & Wt. \% & Ash \% & Wt. \% & Ash \% & Wt. \% & Ash \% & Wt. \% & Ash \% \\
\hline $30 \times 50$ & 18.86 & 8.7 & 19.09 & 8.8 & 25.25 & 77.8 & 26.15 & 77.3 \\
\hline $50 \times 100$ & 25.42 & 8.2 & 26.10 & 8.3 & 29.29 & 73.9 & 29.46 & 72.8 \\
\hline $100 \times 200$ & 30.12 & 7.8 & 29.15 & 7.9 & 23.63 & 51.6 & 25.60 & 54.7 \\
\hline $200 \times 400$ & 25.60 & 10.6 & 25.67 & 10.6 & 21.83 & 42.1 & 18.79 & 41.3 \\
\hline
\end{tabular}


Table 9. (cont.)

\begin{tabular}{|c|c|c|c|c|c|c|c|c|}
\hline & \multicolumn{2}{|c|}{ 9 OF (U/S On)* } & \multicolumn{2}{c|}{ 10 OF (U/S On) } & \multicolumn{2}{c|}{ 9 UF (U/S On) } & \multicolumn{2}{c|}{ 10 UF (U/S On) } \\
\hline Mesh & Wt. \% & Ash \% & Wt. \% & Ash \% & Wt. \% & Ash \% & Wt. \% & Ash \% \\
\hline $30 \times 50$ & 19.42 & 8.7 & 18.08 & 8.7 & 24.66 & 76.7 & 26.25 & 76.8 \\
\hline $50 \times 100$ & 25.20 & 8.5 & 26.04 & 8.3 & 28.73 & 73.6 & 29.88 & 71.7 \\
\hline $100 \times 200$ & 29.52 & 7.6 & 29.70 & 7.8 & 23.80 & 57.4 & 25.20 & 56.3 \\
\hline $200 \times 400$ & 25.86 & 10.2 & 26.19 & 10.5 & 22.81 & 42.7 & 18.67 & 40.2 \\
\hline
\end{tabular}

\begin{tabular}{|c|c|c|c|c|c|c|c|c|}
\hline & \multicolumn{2}{|c|}{11 OF (U/S Off) } & \multicolumn{2}{c|}{ 12 OF (U/S On) } & \multicolumn{2}{c|}{ 11 UF (U/S Off) } & \multicolumn{2}{c|}{ 12 UF (U/S On) } \\
\hline Mesh & Wt. \% & Ash \% & Wt. \% & Ash \% & Wt. \% & Ash \% & Wt. \% & Ash \% \\
\hline $30 \times 50$ & 18.57 & 8.4 & 18.49 & 8.5 & 24.93 & 76.9 & 24.74 & 77.3 \\
\hline $50 \times 100$ & 26.25 & 7.9 & 25.40 & 7.9 & 29.36 & 75.0 & 30.50 & 74.1 \\
\hline $100 \times 200$ & 29.95 & 7.4 & 29.90 & 7.1 & 23.70 & 58.0 & 23.01 & 58.3 \\
\hline $200 \times 400$ & 25.23 & 9.4 & 26.21 & 9.8 & 22.01 & 46.9 & 21.75 & 45.4 \\
\hline
\end{tabular}

\begin{tabular}{|c|c|c|c|c|c|c|c|c|}
\hline & \multicolumn{2}{|c|}{13 OF (U/S Off) } & \multicolumn{2}{c|}{ 14 OF (U/S On) } & \multicolumn{2}{c|}{ 13 UF (U/S Off) } & \multicolumn{2}{c|}{ 14 UF (U/S On) } \\
\hline Mesh & Wt. \% & Ash \% & Wt. \% & Ash \% & Wt. \% & Ash \% & Wt. \% & Ash \% \\
\hline $30 \times 50$ & 18.22 & 8.8 & 18.14 & 8.8 & 24.71 & 77.7 & 26.26 & 77.7 \\
\hline $50 \times 100$ & 25.95 & 7.9 & 24.62 & 8.2 & 30.08 & 74.9 & 30.68 & 74.7 \\
\hline $100 \times 200$ & 30.25 & 6.7 & 29.98 & 7.1 & 22.76 & 60.8 & 25.79 & 59.8 \\
\hline $200 \times 400$ & 25.58 & 9.3 & 27.26 & 9.9 & 22.45 & 47.6 & 17.28 & 44.1 \\
\hline
\end{tabular}

* Denotes replicate test. 
Table 10. Size distributions and ash contents of the +400 mesh material at 1.55 medium relative density.

\begin{tabular}{|c|c|c|c|c|c|c|c|c|}
\hline & \multicolumn{2}{|c|}{ 1 OF (U/S Off) } & \multicolumn{2}{c|}{ 2 OF (U/S On) } & \multicolumn{2}{c|}{ 1 UF (U/S Off) } & \multicolumn{2}{|c|}{ 2 UF (U/S On) } \\
\hline Mesh & Wt. \% & Ash \% & Wt. \% & Ash \% & Wt. \% & Ash \% & Wt. \% & Ash \% \\
\hline $30 \times 50$ & 18.66 & 11.3 & 18.91 & 11.9 & 29.14 & 82.5 & 23.85 & 82.2 \\
\hline $50 \times 100$ & 25.43 & 11.0 & 25.88 & 11.8 & 33.58 & 81.0 & 29.94 & 80.9 \\
\hline $100 \times 200$ & 31.04 & 10.4 & 29.97 & 11.5 & 20.20 & 68.9 & 26.21 & 69.2 \\
\hline $200 \times 400$ & 24.88 & 15.5 & 25.24 & 17.4 & 17.08 & 52.4 & 20.00 & 51.2 \\
\hline
\end{tabular}

\begin{tabular}{|c|c|c|c|c|c|c|c|c|}
\hline & \multicolumn{2}{|c|}{ 3 OF (U/S Off) } & \multicolumn{2}{c|}{ 4 OF (U/S On) } & \multicolumn{2}{c|}{ 3 UF (U/S Off) } & \multicolumn{2}{c|}{ 4 UF (U/S On) } \\
\hline Mesh & Wt. \% & Ash \% & Wt. \% & Ash \% & Wt. \% & Ash \% & Wt. \% & Ash \% \\
\hline $30 \times 50$ & 16.91 & 11.2 & 17.69 & 11.4 & 26.39 & 82.7 & 27.76 & 82.1 \\
\hline $50 \times 100$ & 25.56 & 10.3 & 24.84 & 10.7 & 33.16 & 82.1 & 33.59 & 81.6 \\
\hline $100 \times 200$ & 29.87 & 9.5 & 29.82 & 9.8 & 21.35 & 73.8 & 23.99 & 73.3 \\
\hline $200 \times 400$ & 27.65 & 13.5 & 27.64 & 13.6 & 19.11 & 57.6 & 14.66 & 56.5 \\
\hline
\end{tabular}

\begin{tabular}{|c|c|c|c|c|c|c|c|c|}
\hline & \multicolumn{2}{|c|}{5 OF (U/S Off) } & \multicolumn{2}{c|}{ 6 OF (U/S On) } & \multicolumn{2}{c|}{ 5 UF (U/S Off) } & \multicolumn{2}{c|}{ 6 UF (U/S On) } \\
\hline Mesh & Wt. \% & Ash \% & Wt. \% & Ash \% & Wt. \% & Ash \% & Wt. \% & Ash \% \\
\hline $30 \times 50$ & 17.37 & 11.6 & 17.77 & 10.9 & 29.44 & 82.5 & 26.99 & 82.0 \\
\hline $50 \times 100$ & 24.76 & 10.3 & 24.80 & 11.4 & 33.60 & 82.3 & 32.88 & 81.9 \\
\hline $100 \times 200$ & 29.65 & 9.2 & 31.97 & 9.3 & 23.31 & 75.9 & 22.24 & 76.2 \\
\hline $200 \times 400$ & 28.22 & 12.7 & 25.45 & 12.8 & 13.66 & 60.9 & 17.89 & 62.8 \\
\hline
\end{tabular}

\begin{tabular}{|c|c|c|c|c|c|c|c|c|}
\hline & \multicolumn{2}{|c|}{ 7 OF (U/S Off) } & \multicolumn{2}{c|}{8 OF (U/S On) } & \multicolumn{2}{c|}{ 7 UF (U/S Off) } & \multicolumn{2}{c|}{ 8 UF (U/S On) } \\
\hline Mesh & Wt. \% & Ash \% & Wt. \% & Ash \% & Wt. \% & Ash \% & Wt. \% & Ash \% \\
\hline $30 \times 50$ & 19.09 & 10.6 & 16.78 & 10.4 & 23.17 & 79.9 & 28.46 & 79.8 \\
\hline $50 \times 100$ & 25.53 & 9.9 & 24.86 & 10.1 & 29.86 & 75.8 & 33.21 & 76.3 \\
\hline $100 \times 200$ & 29.39 & 9.0 & 29.42 & 8.9 & 23.96 & 58.4 & 23.75 & 57.8 \\
\hline $200 \times 400$ & 25.98 & 12.1 & 28.94 & 11.9 & 23.01 & 44.1 & 14.57 & 41.6 \\
\hline
\end{tabular}


Table 10. (cont.)

\begin{tabular}{|c|c|c|c|c|c|c|c|c|}
\hline & \multicolumn{2}{|c|}{9 OF (U/S Off) } & \multicolumn{2}{c|}{ 10 OF (U/S On) } & \multicolumn{2}{c|}{ 9 UF (U/S Off) } & \multicolumn{2}{c|}{ 10 UF (U/S On) } \\
\hline Mesh & Wt. \% & Ash \% & Wt. \% & Ash \% & Wt. \% & Ash \% & Wt. \% & Ash \% \\
\hline $30 \times 50$ & 19.63 & 10.2 & 18.72 & 10.2 & 23.42 & 80.5 & 21.82 & 80.6 \\
\hline $50 \times 100$ & 26.17 & 9.5 & 25.29 & 9.4 & 29.15 & 77.9 & 29.26 & 77.5 \\
\hline $100 \times 200$ & 31.81 & 8.4 & 30.11 & 8.4 & 23.74 & 63.7 & 23.17 & 61.0 \\
\hline $200 \times 400$ & 22.40 & 11.2 & 25.88 & 11.1 & 23.70 & 46.9 & 25.75 & 46.1 \\
\hline
\end{tabular}

\begin{tabular}{|c|c|c|c|c|c|c|c|c|}
\hline & \multicolumn{2}{|c|}{11 OF (U/S Off) } & \multicolumn{2}{c|}{ 12 OF (U/S On) } & \multicolumn{2}{c|}{ 11 UF (U/S Off) } & \multicolumn{2}{c|}{ 12 UF (U/S On) } \\
\hline Mesh & Wt. \% & Ash \% & Wt. \% & Ash \% & Wt. \% & Ash \% & Wt. \% & Ash \% \\
\hline $30 \times 50$ & 18.68 & 10.3 & 19.70 & 10.5 & 25.81 & 80.9 & 21.86 & 80.3 \\
\hline $50 \times 100$ & 25.17 & 9.3 & 26.59 & 9.4 & 30.49 & 77.9 & 29.88 & 78.5 \\
\hline $100 \times 200$ & 30.11 & 8.0 & 31.59 & 8.2 & 24.91 & 63.4 & 23.76 & 62.9 \\
\hline $200 \times 400$ & 26.04 & 10.4 & 22.12 & 10.6 & 18.79 & 46.9 & 24.51 & 49.2 \\
\hline
\end{tabular}

\begin{tabular}{|c|c|c|c|c|c|c|c|c|}
\hline & \multicolumn{2}{|c|}{13 OF (U/S On) } & \multicolumn{2}{c|}{ 14 OF (U/S On) } & \multicolumn{2}{c|}{ 13 UF (U/S On) } & \multicolumn{2}{c|}{ 14 UF (U/S On) } \\
\hline Mesh & Wt. \% & Ash \% & Wt. \% & Ash \% & Wt. \% & Ash \% & Wt. \% & Ash \% \\
\hline $30 \times 50$ & 18.42 & 10.3 & 17.88 & 10.5 & 21.90 & 80.2 & 23.68 & 80.4 \\
\hline $50 \times 100$ & 24.95 & 9.5 & 25.81 & 9.2 & 30.64 & 77.8 & 30.09 & 77.8 \\
\hline $100 \times 200$ & 29.68 & 8.1 & 30.50 & 8.2 & 23.45 & 64.6 & 25.59 & 62.6 \\
\hline $200 \times 400$ & 26.95 & 10.6 & 25.81 & 10.5 & 24.00 & 50.6 & 20.64 & 46.9 \\
\hline
\end{tabular}

* Denotes replicate test. 
Table 11 Example of actual versus theoretical yield for coal 1

(medium R.D. $=1.45 ;$ pressure $=30 \mathrm{psi} ; \mathrm{OF} / \mathrm{UF}=1.33$; ultrasonics off)

\begin{tabular}{cccc} 
Size, mesh & Clean Coal Ash, \% & Actual Yield, \% & Theoretical Yield, \% \\
\cline { 2 - 3 } $30 \times 50$ & 9.3 & 46.0 & 21 \\
$50 \times 100$ & 9.0 & 54.1 & 25 \\
$100 \times 200$ & 8.4 & 67.5 & 31
\end{tabular}

Table 12. Comparison of size and ash content distributions for coal 1 feed samples.

$\underline{\text { Size, } \text { mesh }}$

$+400$

$-400$

$\underline{\text { Size, mesh }}$

$30 \times 50$

$50 \times 100$

$100 \times 200$

$-200$
Feed Size Distributions

As-received, \%

78.7

21.3

Sample 1,\%

53.6

46.4

Sample 2,\%

51.1

48.9

\section{Feed Ash Distributions}

\begin{tabular}{ccc} 
As-received, \% & Sample 1,\% & Sample 2, \% \\
\hline 48.5 & 47.6 & 43.6 \\
46.6 & 41.1 & 41.8 \\
38.8 & 28.6 & 27.2 \\
43.1 & 44.2 & 44.1
\end{tabular}


Table 13 Summary of baseline test results for the wet drum magnetic separator (feed rate $=5 \mathrm{gpm})$.

\begin{tabular}{|c|c|c|c|c|c|}
\hline & & $\mathrm{M} / \mathrm{C}$ & \multicolumn{2}{|c|}{ Purity, \% Magnetics } & Average Magnetics \\
\hline Test & Feed $\%$ Solids & Ratio & Sample 1 & Sample 2 & Recovery, \% \\
\hline $1 \mathrm{~A}$ & 10 & * & 99.3 & 99.1 & 99.8 \\
\hline $1 B$ & 10 & * & 99.0 & 98.8 & 99.9 \\
\hline $2 \mathrm{~A}$ & 15 & $*$ & 98.2 & 98.2 & 99.8 \\
\hline $2 B$ & 15 & $*$ & 98.7 & 98.5 & 99.9 \\
\hline 3 & 10 & 1.63 & 92.2 & 92.5 & 99.4 \\
\hline 4 & 10 & .33 & 96.4 & 96.4 & 99.1 \\
\hline $5 \mathrm{~A}$ & 15 & 1.63 & 95.8 & 95.7 & 99.8 \\
\hline $5 B$ & 15 & 1.63 & 96.7 & 96.7 & 99.6 \\
\hline $6 \mathrm{~A}$ & 15 & 0.33 & 95.0 & 95.5 & 99.6 \\
\hline $6 \mathrm{~B}$ & 15 & 0.33 & 95.0 & 95.3 & 99.8 \\
\hline $7 \mathrm{~A}$ & 20 & 1.63 & 93.5 & 93.3 & 99.8 \\
\hline $7 \mathrm{~B}$ & 20 & 1.63 & 94.4 & 94.2 & 99.6 \\
\hline 8 & 20 & 0.3 & 93.4 & 93.3 & 99.3 \\
\hline
\end{tabular}

* Magnetite only tests. 
Table 14. Summary of test results for the wet-drum magnetic separator feed characteristics tests (feed rate $=4 \mathrm{gpm}$ ).

\begin{tabular}{|c|c|c|c|c|c|}
\hline Test & $\begin{array}{c}\text { Solids } \\
\text { Concentration, \% }\end{array}$ & $\begin{array}{l}\text { M/C } \\
\text { Ratio }\end{array}$ & Ultrasonics & Recovery, \% & $\begin{array}{c}\text { Purity, } \\
\% \text { Magnetics }\end{array}$ \\
\hline$\overline{9 \mathrm{~A}}$ & 10 & 0.33 & Off & 99.3 & 96.95 \\
\hline $9 \mathrm{~B}$ & 10 & 0.33 & On & 99.5 & 96.86 \\
\hline $10 \mathrm{~A}$ & 10 & 1.00 & Off & 99.3 & 96.95 \\
\hline $10 \mathrm{~B}$ & 10 & 1.00 & On & 99.6 & 96.85 \\
\hline $11 \mathrm{~A}$ & 10 & 6.00 & Off & 99.8 & 97.27 \\
\hline $11 \mathrm{~B}$ & 10 & 6.00 & On & 99.8 & 97.81 \\
\hline $12 \mathrm{~A}$ & 15 & 0.33 & Off & 99.1 & 95.75 \\
\hline $12 B$ & 15 & 0.33 & On & 98.8 & 95.01 \\
\hline $13 \mathrm{~A}$ & 15 & 1.00 & Off & 99.3 & 94.15 \\
\hline $13 \mathrm{~B}$ & 15 & 1.00 & On & 99.6 & 94.52 \\
\hline $14 \mathrm{~A}$ & 15 & 6.00 & Off & 99.6 & 96.76 \\
\hline $14 \mathrm{~B}$ & 15 & 6.00 & On & 99.4 & 97.15 \\
\hline $15 \mathrm{~A}$ & 20 & 0.33 & Off & 99.6 & 92.93 \\
\hline $15 \mathrm{~B}$ & 20 & 0.33 & On & 99.7 & 93.58 \\
\hline $16 \mathrm{~A}$ & 20 & 1.00 & Off & 99.8 & 92.13 \\
\hline $16 \mathrm{~B}$ & 20 & 1.00 & On & 99.8 & 92.56 \\
\hline $17 \mathrm{~A}$ & 20 & 6.00 & Off & 99.8 & 95.01 \\
\hline $17 \mathrm{~B}$ & 20 & 6.00 & On & 99.7 & 95.87 \\
\hline $18 \mathrm{~A}$ & 30 & 6.00 & Off & 99.6 & 93.43 \\
\hline $18 \mathrm{~B}$ & 30 & 6.00 & On & 99.7 & 93.66 \\
\hline
\end{tabular}


Table 15 Comparison of size distributions of the magnetic material in the wet-drum magnetic separator product streams (feed rate $=4 \mathrm{gpm}$ ).

\begin{tabular}{|c|c|c|c|c|c|c|c|c|c|}
\hline \multicolumn{10}{|c|}{ Non-Magnetic Product Stream } \\
\hline & Feed & \multicolumn{1}{|c|}{$10 \%$ Solids } & \multicolumn{2}{|c|}{$15 \%$ Solids } & \multicolumn{4}{|c|}{$20 \%$ Solids } \\
\hline Demag.* & No & Yes & Yes & Yes & Yes & No & No & Yes & Yes \\
\hline U/S** & No & On & Off & On & Off & On & Off & On & Off \\
\hline Size, $\mu \mathrm{m}$ & & & & & & & & & \\
\hline 44.0 & 90.0 & 82.8 & 89.3 & 84.6 & 86.1 & 75.7 & 70.9 & 89.4 & 87.6 \\
\hline 31.1 & 83.1 & 72.7 & 80.5 & 75.6 & 77.6 & 53.5 & 46.7 & 80.9 & 78.7 \\
\hline 22.0 & 71.0 & 60.4 & 67.9 & 63.8 & 66.1 & 28.5 & 23.4 & 68.4 & 66.9 \\
\hline 15.6 & 55.1 & 45.9 & 53.5 & 50.1 & 52.2 & 11.8 & 9.2 & 53.1 & 52.6 \\
\hline 11.0 & 38.4 & 30.8 & 38.1 & 35.3 & 36.9 & 4.8 & 3.6 & 37.1 & 37.0 \\
\hline 7.78 & 19.7 & 16.5 & 19.9 & 19.6 & 20.5 & 1.8 & 1.3 & 20.5 & 20.5 \\
\hline 5.50 & 7.1 & 7.2 & 8.2 & 8.4 & 9.0 & 0.4 & 0.4 & 8.9 & 8.6 \\
\hline 3.89 & 2.6 & 3.1 & 3.8 & 3.4 & 3.7 & 0.0 & 0.0 & 3.6 & 3.3 \\
\hline 2.75 & 0.8 & 1.1 & 1.7 & 1.2 & 1.3 & 0.0 & 0.0 & 1.2 & 1.1 \\
\hline
\end{tabular}

\begin{tabular}{|c|c|c|c|c|c|c|c|c|c|}
\hline \multicolumn{9}{|c|}{ Magnetic Product Stream } \\
\hline & Feed & \multicolumn{1}{|c|}{$10 \%$ Solids } & \multicolumn{1}{|c|}{$15 \%$ Solids } & \multicolumn{3}{|c|}{$20 \%$ Solids } \\
\hline Demag.* & No & Yes & Yes & Yes & Yes & No & No & Yes & Yes \\
\hline U/S** & No & On & Off & On & Off & On & Off & On & Off \\
\hline Size, $\mu \mathrm{m}$ & & & & & & & & & \\
\hline 44.0 & 90.0 & 92.0 & 92.8 & 89.9 & 90.6 & 79.2 & 78.6 & 91.7 & 92.2 \\
\hline 31.1 & 83.1 & 83.1 & 83.7 & 81.0 & 81.6 & 56.5 & 55.7 & 82.6 & 83.4 \\
\hline 22.0 & 71.0 & 70.1 & 69.9 & 69.1 & 69.6 & 31.1 & 29.7 & 69.9 & 70.5 \\
\hline 15.6 & 55.1 & 54.4 & 53.0 & 54.4 & 55.2 & 12.9 & 11.7 & 55.0 & 54.5 \\
\hline 11.0 & 38.4 & 36.8 & 34.6 & 37.4 & 38.5 & 4.9 & 4.2 & 37.9 & 36.5 \\
\hline 7.78 & 19.7 & 18.2 & 16.2 & 18.9 & 19.6 & 1.7 & 1.3 & 19.0 & 17.8 \\
\hline 5.50 & 7.1 & 6.4 & 5.5 & 6.7 & 6.8 & 0.3 & 0.1 & 6.8 & 6.2 \\
\hline 3.89 & 2.6 & 2.0 & 1.7 & 2.1 & 2.0 & 0.0 & 0.0 & 2.1 & 1.9 \\
\hline 2.75 & 0.8 & 0.4 & 0.3 & 0.4 & 0.4 & 0.0 & 0.0 & 0.4 & 0.4 \\
\hline
\end{tabular}

* Demagnetization prior to size analysis.

** Ultrasonic treatment prior to wet-drum magnetic separation. 
Table 16. Summary of cyclone product test results for the wet drum magnetic separator for coal 1 (feed rate $=4 \mathrm{gpm}$; solids concentration $=15 \%$ ).

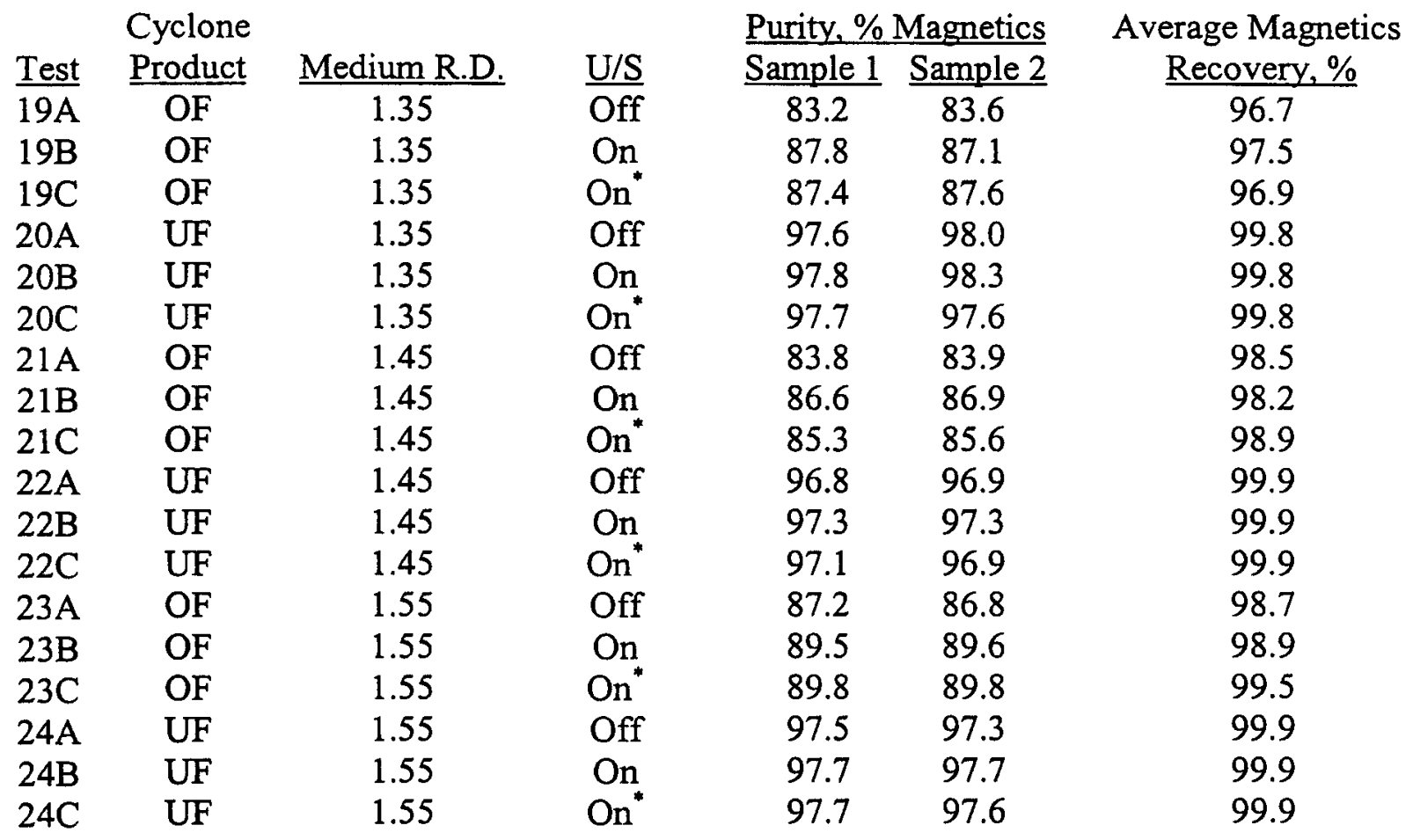

* Slurry treated with ultrasonics and then allowed to mix. 
Table 17. Summary of cyclone product test results for the wet-drum magnetic separator for coal 2 (feed rate $=4 \mathrm{gpm}$; solids concentration $=15 \%$ ).

\begin{tabular}{|c|c|c|c|c|c|c|}
\hline \multirow[b]{2}{*}{ Test } & \multirow{2}{*}{$\begin{array}{l}\text { Cyclone } \\
\text { Product }\end{array}$} & \multirow[b]{2}{*}{ Medium R.D. } & \multirow[b]{2}{*}{$\underline{U} / \mathrm{S}$} & \multicolumn{2}{|c|}{ Purity $\%$ Magnetics } & \multirow{2}{*}{$\begin{array}{c}\text { Average Magnetics } \\
\text { Recovery, \% }\end{array}$} \\
\hline & & & & Sample 1 & Sample 2 & \\
\hline $25 \mathrm{~A}$ & $\mathrm{OF}$ & 1.35 & $\overline{\text { Off }}$ & 87.5 & 87.3 & 97.5 \\
\hline $25 B$ & OF & 1.35 & On & 88.7 & 89.0 & 98.2 \\
\hline $25 \mathrm{C}$ & OF & 1.35 & $\mathrm{On}^{*}$ & 88.0 & 88.0 & 99.0 \\
\hline $26 \mathrm{~A}$ & UF & 1.35 & Off & 93.1 & 93.1 & 99.9 \\
\hline $26 \mathrm{~B}$ & UF & 1.35 & On & 97.2 & 97.3 & 99.9 \\
\hline $26 \mathrm{C}$ & UF & 1.35 & $\mathrm{On}^{*}$ & 97.3 & 97.3 & 99.9 \\
\hline $27 \mathrm{~A}$ & OF & 1.45 & Off & 90.2 & 90.1 & 99.2 \\
\hline $27 \mathrm{~B}$ & $\mathrm{OF}$ & 1.45 & On & 89.6 & 89.3 & 99.0 \\
\hline $27 \mathrm{C}$ & $\mathrm{OF}$ & 1.45 & On ${ }^{*}$ & 89.3 & 88.9 & 99.0 \\
\hline $28 \mathrm{~A}$ & UF & 1.45 & Off & 97.9 & 97.7 & 99.9 \\
\hline $28 \mathrm{~B}$ & UF & 1.45 & On & 97.9 & 97.8 & 99.9 \\
\hline $28 \mathrm{C}$ & UF & 1.45 & On ${ }^{*}$ & 97.7 & 97.7 & 99.9 \\
\hline $29 \mathrm{~A}$ & OF & 1.55 & Off & 90.9 & 90.8 & 99.3 \\
\hline $29 B$ & OF & 1.55 & On & 90.2 & 90.1 & 99.3 \\
\hline $29 \mathrm{C}$ & OF & 1.55 & $\mathrm{On}^{*}$ & 90.1 & 90.0 & 99.7 \\
\hline $30 \mathrm{~A}$ & UF & 1.55 & Off & 97.4 & 97.4 & 99.9 \\
\hline 3 & UF & 1.55 & On & 97.0 & 97.1 & 99.9 \\
\hline 8 & UF & 1.55 & $\mathrm{On}^{*}$ & 97.2 & 97.3 & 99.9 \\
\hline
\end{tabular}

Slurry treated with ultrasonics and then allowed to mix. 
Table 18. Size and ash analyses for coal 1 and coal 2 after separation at 1.35 medium relative density.

\section{Coal 1}

\begin{tabular}{|c|c|c|c|c|}
\hline \multirow[b]{2}{*}{ Size, mesh } & \multicolumn{2}{|c|}{ Clean Coal } & \multicolumn{2}{|c|}{ Refuse } \\
\hline & Weight, \% & Ash, $\%$ & Weight, \% & Ash, \% \\
\hline $30 \times 50$ & 3.9 & 6.2 & 5.8 & 54.8 \\
\hline $50 \times 100$ & 10.4 & 5.4 & 12.5 & 58.3 \\
\hline $100 \times 200$ & 16.2 & 5.1 & 15.6 & 52.8 \\
\hline $200 \times 400$ & 12.2 & 6.9 & 14.1 & 47.8 \\
\hline $400 \times 500$ & 9.8 & 11.9 & 8.0 & 51.0 \\
\hline-500 & 47.5 & 49.2 & 44.0 & 60.6 \\
\hline
\end{tabular}

\section{Coal 2}

\begin{tabular}{|c|c|c|c|c|}
\hline \multirow[b]{2}{*}{ Size, mesh } & \multicolumn{2}{|c|}{ Clean Coal } & \multicolumn{2}{|c|}{$\underline{\text { Refuse }}$} \\
\hline & Weight, \% & Ash, \% & Weight, $\%$ & Ash, \% \\
\hline+30 & 12.7 & 4.8 & 9.4 & 28.7 \\
\hline $30 \times 50$ & 10.7 & 4.3 & 12.7 & 38.9 \\
\hline $50 \times 100$ & 14.1 & 4.4 & 16.8 & 54.2 \\
\hline $100 \times 200$ & 10.8 & 4.9 & 13.4 & 59.0 \\
\hline $200 \times 400$ & 4.8 & 7.4 & 6.6 & 67.0 \\
\hline $400 \times 500$ & 3.7 & 14.6 & 3.9 & 79.4 \\
\hline-500 & 43.2 & 77.0 & 37.2 & 83.7 \\
\hline
\end{tabular}

